NBSIR 76-1155(R)

\title{
Development of Test Methods for, and the Evaluation of, Miles Transducers
}

John D. Ramboz

Engineering Mechanics Section, Mechanics Division Institute for Basic Standards

National Bureau of Standards

Washington, D. C. 20234

June 1976

Final

Prepared for

U.S. Air Force

Rome Air Develompent Center

Griffis Air Force Base

and

Electronics Surveillance Division

Hanscom Air Force Base 



\section{DEVELOPMENT OF TEST METHODS \\ FOR, AND THE EVALUATION OF, MILES TRANSDUCERS}

John D. Ramboz

Engineering Mechanics Section, Mechanics Division Institute for Basic Standards

National Bureau of Standards

Washington, D. C. 20234

June 1976

Final

Prepared for

U.S. Air Force

Rome Air Development Center

Griffis Air Force Base

and

Electronics Surveillance Division

Hanscom Air Force Base

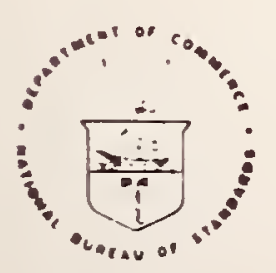

U.S. DEPARTMENT OF COMMERCE. Elliot L. Richardson, Secretary Edward O. Vetter. Under Secretary

Dr. Betsy Ancker-Johnson. Assistant Secretary for Science and Technology

NATIONAL BUREAU OF STANDARDS. Ernest Ambler. Acting Director 



\section{FOREWORD}

The work performed was done under NBS Cost Center 2130546 and was authorized by Hanscom Air Force Base Order No. Y76-901 dated December 3, 1975. 


\section{CONTENTS}

FOREWORD

ABSTRACT

1. INTRODUCTION

2. LONG-TERM RESISTANCE TO CORROSIVE MOISTURE 2

2.1 Test Specimen Description and Test Procedure 2

2.2 Test Results for Corrosive Moisture 5

2.2.1 Electrical Leakage Resistance 5

2.2.2 Corrosion of the Flat Transducers 27

2.2.3 Test for Stress Corrosion 35

2.2.4 Leaks at Ends of Flat Transducers 35

2.2.5 Changes in Polyurethane Jackets of Round Transducers 36

3. RESISTANCES TO FREEZE-THAW CYCLES 39

3.1 Description of the Freeze-Thaw Cycling Test 39

3.2 Results of Freeze-Thaw Cycling 40

3.2.1 Electrical Leakage Resistance $\quad 40$

3.2.2 Mechanical Strain Measurements $\quad 40$

4. RESISTANCE TO ROCK DAMAGE 42

4.1 Test Specimen Description and Test Procedure 42

4.2 Results of the Rock Damage Tests 44

4.2.1 Initial Tests 44

4.2.2 One Hundred-Hour Tests $\quad 46$

5. DURABILITY OF POLYURETHANE JACKETING 50

6. REELING AND UNREELING DURABILITY OF FLAT TRANSDUCERS

6.1 Mechanical Characteristics and Strengths 54

6.2 Reeling and Unreeling Laboratory Tests 56

7. COST EFFECTIVENESS ANALYSIS 60

$\begin{array}{llll}7.1 & \text { Original Cost-Estimate Comparisons } & 60\end{array}$

7.2 Life Expectancy and Cost 63 
8. SUMMARY AND RECOMMENDATIONS

8.1 Summary

8.1.1 Long-Term Resistance to Corrosive Moisture

8.1.2 Resistance to Freeze-Thaw Cycling

8.1.3 Resistance to Rock Damage

69

8.1.4 Durability of the Polyurethane Kacketing

70

8.1.5 Reeling and Unreeling Durability of the

70

Flat Transducers

71

8.1.6 Cost Effectiveness Analysis

72

8.1.7 Final Choice: Round or Flat Transducers? 72

$\begin{array}{lll}8.2 & \text { Recommendations } & 73\end{array}$

8.2.1 Flat Transducers 73

8.2.2 Round Transducers $\quad 74$

9. ACKNOWLEDGEMENTS $\quad 74$

10. REFERENCES 75

$\begin{array}{lll}\text { APPENDIX A. RELATIVE HUMIDITY AND RAINFALL DATA } & 77\end{array}$

APPENDIX B. MATERIALS WHICH OFFER GOPHER PROTECTION AND THOSE
WHICH ARE VULNERABLE

APPENDIX C. COST EFFECTIVENESS ANALYSIS EXAMPLES 80

APPENDIX D. SOIL ANALYSIS RESULTS FOR SAMPLES FROM GRIFFIS
AIR FORCE BASE SITE 2D ROME, NEW YORK 


\section{LIST OF TABLES}

Table 1 Electrical Leakage for Flat and Round Transducers Subjected to Hot Saline Solution (Corrosive Moisture Test).

Table 2 Times to Failure for the Flat Transducers (Corrosive Moisture Test).

Table 3 Leakage Resistance Values from Freeze-Thaw Cycling Test.

Table 4 Strain Measurements from Freeze-Thaw Cycle Test.

Table 5 U1timate Loads for the 25-cm Specimens (Rock Damage Tests).

Table 6 Times to Failure for Half-Ultimate Load, 20-cm Specimens (Rock Damage Tests).

Table 7 Results of Tensile Tests on Stainless Steel Sheaths from Flat Transducers.

Table 8 Results of Strain Measurements from the Reeling and Unreeling Tests of a Flat Transducer.

Table 9 Estimated Cost Comparisons for New Round and Flat Transducer Systems.

Table 10 Estimated Cost Comparisons for Replacement of Transducers On1y. 


\section{LIST OF FIGURES}

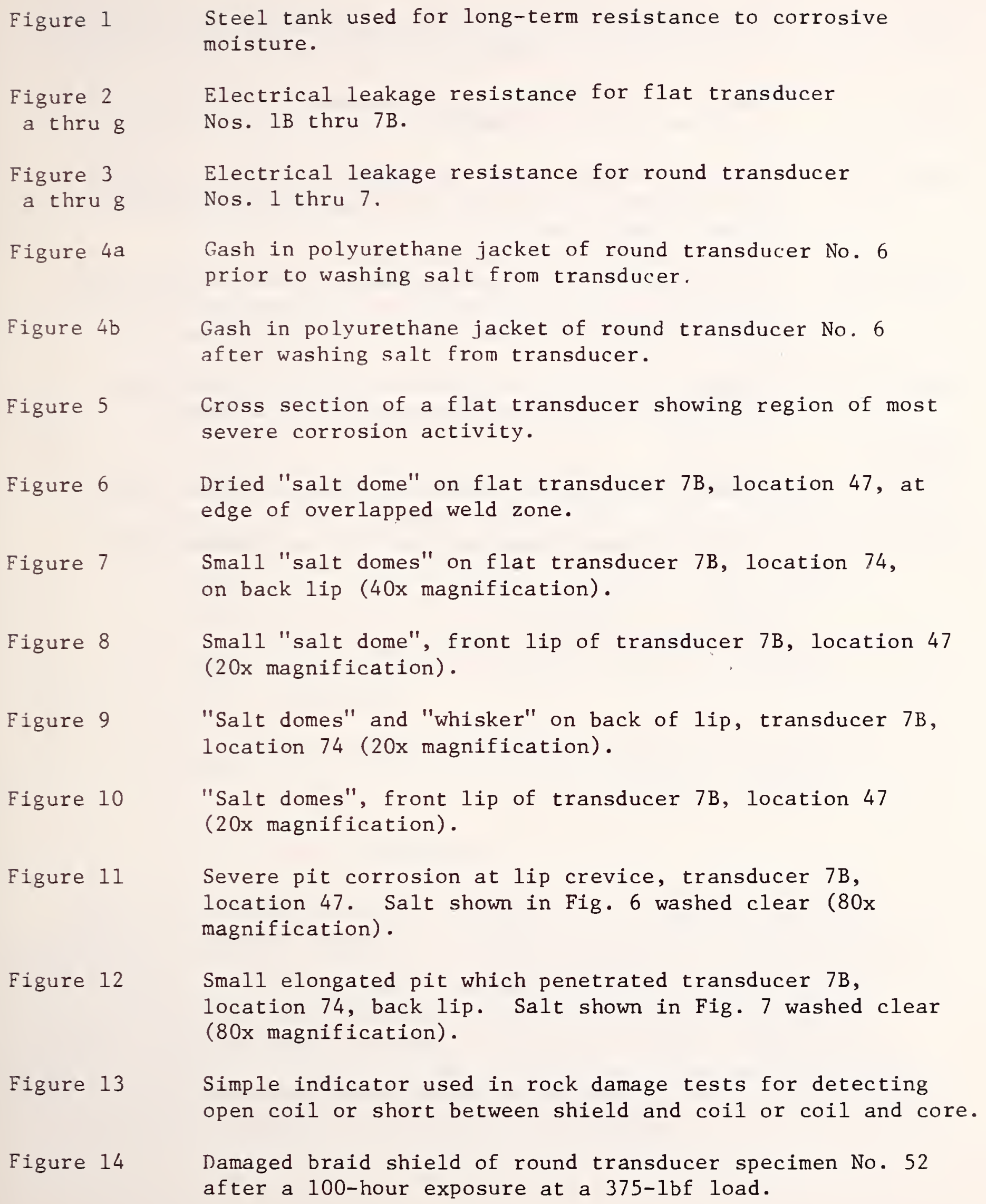


Figure 15

Figure 16

Figure 17

Figure 18

Figure 19

Figure 20

Figure 21

a thru c

Figure $A-1$
An open sense-coil winding of round transducer specimen No. 37.

The sense-coil winding of flat transducer specimen No. 71 after a 100-hour exposure at a 2043-1bf load.

Smashed sense coil for flat transducer specimen No. 71 after an exposure of 100 hours at a 2043-1bf load.

Damaged polyester tape insultation on flat transducer specimen No. 72. Note holes exposing core material beneath insulation.

A field of small pits observed on transducer MILES 96R-1 at Griffis Air Force Base. Pit diameters are approximately 0.04 to $0.09 \mathrm{~mm}$ ( 1.5 to $3.4 \times 10^{-3} \mathrm{in}$ ).

Large crack in the polyurethane jacket of transducer MILES 96R-1 located at Griffis Air Force Base.

Diagonal wrinkle in transducer stainless steel sheath. Relative humidity and rainfall during testing period. 


\title{
DEVELOPMENT OF TEST METHODS FOR, AND THE EVALUATION OF, MILES TRANSDUCERS
}

John D. Ramboz

\begin{abstract}
The development of tests is discussed and results are given for two types of Multiphenomenon Intrusion Line Sensors (MILES) transducers. The round type is fabricated as a long coaxial line having a polyurethane outer jacket. The flat type is a coaxial ribbon housing a type 304 stainless steel outer sheath. Five main tasks were completed: long-term resistance to corrosive moisture, resistance to freeze-thaw cycling, resistance to rock damage, durability of the polyurethane jacketing, and reeling and unreeling durability of the flat transducers. Comparative results between the two types of MILES transducers are given and indicate that neither type is ideally suited for all field deployment environments. Chlorides in the soil cause pit corrosion in the crevice region of the flat transducer sheaths. Rocks and rodents penetrate the polyurethane of the round transducers. Cost analyses are given with examples illustrating cost effectiveness. Design recommendations are given.
\end{abstract}

Key Words: Evaluation methods; intrusion detectors; MILES transducers; sensors; test methods; testing.

\section{INTRODUCTION}

This report describes the development of test methods and the evaluation of transducers used as intrusion detectors. Multiphenomenon Intrusion Line Sensors (MILES) are normally deployed as long buriedcable assemblies. They respond to seismic pressure changes and to near-field magnetic changes. It is desirable to have a long servicelife expectancy, perhaps ten years or more. Transducer failures can occur due to several causes. It was the purpose of the work described herein to compare the performances of two different types of line sensors and to determine comparable life-cycle cost analyses. 
The two types of transducers are referred to as "round" and "flat". A round transducer is fabricated as a round, cylindrical, coaxial line having an outer jacket material of polyurethane. A flat transducer is made as a flat ribbon coaxial line having stainless steel as the outer jacket material. Accelerated life testing was done, as well as other tests, to determine the amount of possible damage which might be incurred in handling, installations, etc.

The laboratory work was divided into the following five tasks:

Task A: Long-term resistance to corrosive moisture.

Task B: Resistance to freeze-thaw cycles.

Task C: Resistance to rock damage.

Task D: Durability of polyurethane jacketing.

Task E: Reeling and unreeling durability of transducers.

Tests for each of the above tasks will be described in terms of the work performed and the results. Comparisons between the round and the flat transducers will be made and factors influencing the tests will be discussed. The transducer sensitivity (magnetic sensitivity and seismic/ pressure sensitivity) ${ }^{l}$ was not evaluated. Only those factors 1 isted above which influence the transducer service life were investigated. Testing under combined environments was not done, e.g., rock danger tests combined with freeze-thaw testing, etc.

\section{LONG-TERM RESISTANCE TO CORROSIVE MOISTURE}

This work was performed to satisfy the requirements of Task A. Accelerated life testing was desired to determine the aging characteristics of both the round and the flat types of transducers and to obtain an estimate of life expectancy under a normal service environment. The nature of the failures are noted and suggestions for corrective action are offered in some instances.

\subsection{Test Specimen Description and Test Procedure}

Prepared specimens of both the round and the flat transducers were subjected to repeated exposures to hot saline solution followed by drying/bake cycles. The sodium chloride solution was prepared having a concentration of 5 percent by weight to simulate sea water $[1,2] . *$

The specimens were specially fabricated having an active transducer length of nominally $2.1 \mathrm{~m}$ (84 in). The special flat transducers had terminations and connectors on them which are identical to $100 \mathrm{~m}$ long transducers used in normal service and fabrication procedures were basically identical to those employed for the $100 \mathrm{~m}$ transducers. The

1 Proposed draft MIL spec, Transducer, Motional Pickup, TR-299/G( ) dated 4-10-75.

* Figures in brackets indicate the literature references in section 10. 
short round transducers used for this task were the same as those used in normal service except for length and the signal leads were made from a twisted, shielded pair with an outer insulated jacket rather than the normal armored lead. Additionally, the end of the transducer away from the connector was sealed with heat-shrink tubing and epoxy. Normally, the polyurethane jacket material is formed over the end of the transducer to provide a durable seal.

Nine round and nine flat transducers were obtained from the manufacturer under the manufacturers part numbers 28107211 and 28111425, respectively. Seven of each type were used in the testing and the remaining two of each type served as control samples.

A steel tank $0.53 \mathrm{~m}$ (21 in) in diameter and $3.5 \mathrm{~m}$ (11 ft. $4 \mathrm{in}$ ) deep was fabricated from four steel drums. Figure 1 shows the tank. Both drum heads were cut out of three of the drums. One head was removed from the fourth drum; the head remaining served as the tank bottom. The four drums were welded together at their ends to form one deep, cylindrical vertical tank. A 3/8-in thick, $4 \mathrm{ft}$ square, steel plate was welded to the bottom of the lower drum to stablize the tall column and also to strengthen the drum head against the $34.5 \mathrm{kPa}$ (5 psi) pressure when the tank was full.

A wooden rack was made to secure and support each of the fourteen transducers ( 7 round and $7 \mathrm{flat}$ ) vertically in the tank. The lower ends of the transducers were loosely secured $46 \mathrm{~cm}$ (18 in) above the bottom of the tank. The upper portion of each transducer was tightly secured about $15 \mathrm{~cm}$ ( $6 \mathrm{in}$ ) below the top level of the tank. This arrangement allowed the transducers to change their lengths freely as they were heated and cooled, without placing unnecessary strain on them, while confining them horizontally at the ends. A steel heat exchanger was attached to each of the vertical rack supports to provide a heat source during the drying/bake cycle. It had an overall folded length of approximately $14.3 \mathrm{~m}(47 \mathrm{ft})$ and provided ballast to the wooden rack to keep it from floating. The effective area of this heat exchanger was about $1.5 \mathrm{~m}^{2}$ $\left(16.2 \mathrm{ft}^{2}\right)$. Low pressure steam was passed through this exchanger and bled to the atmosphere during the drying/bake cycle.

The tank was filled about 80 percent (155 gallons) with water and salt added to make the required 5 percent (by weight) solution. Live steam was then released at the bottom of the tank and allowed to pass directly into the solution. This process added water by steam condensation. By the time the solution boiled, the liquid was at its nominal level, about $43 \mathrm{~cm}$ (17 in) below the top of the tank. The total volume of solution was then about 730 liters (192 gallons). Temperature was measured and monitored by a thermocouple located at about one-third the height of the tank. Approximately 40 minutes were required for the temperature to reach boiling. The solution was maintained at boiling for six hours, after which the tank was drained. Heat 


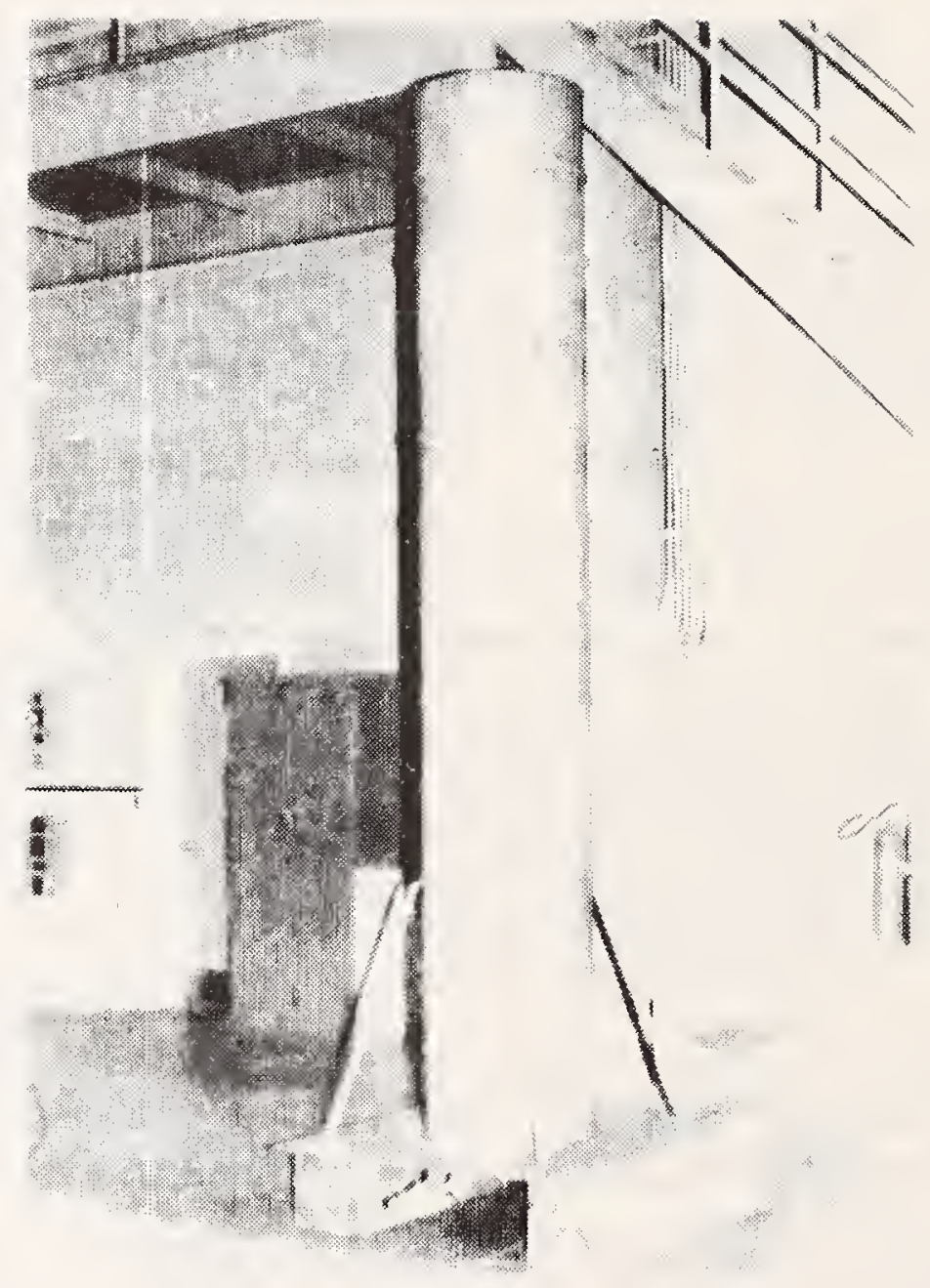

Figure 1. Steel tank used for long-term resistance to corrosive moisture. 
was then applied with the dry heat exchanger and the temperature was maintained at $38 \pm 5^{\circ} \mathrm{C}\left(100 \pm 9^{\circ} \mathrm{F}\right)$ for a period of two hours. ${ }^{2}$ Between the end of the drying/bake period and the beginning of the next boil period, the drained tank was allowed to assume the outdoor temperature. ${ }^{3}$

Twenty-one cycles of boil-drain-dry-and-bake were made during the interval from May 4, 1976 through June 4, 1976. These were done on a daily basis except for weekends, holidays and several days when personnel were not available. The transducers were exposed for an accumulative $120 \mathrm{~h}$ to hot saline solution and $39 \mathrm{~h}$ to the dry/bake environment.

\subsection{Test Results for Corrosive Moisture}

\subsubsection{Electrical Leakage Resistance}

Electrical leakage resistance was measured on each of the fourteen transducers subjected to the hot saline solution. Resistance was measured between the shield and the sense coil/core circuits. ${ }^{4}$ A megohm bridge was employed, capable of making measurements over a range from $1 \mathrm{k} \Omega\left(10^{3} \Omega\right)$ to $100 \mathrm{~T} \Omega\left(10^{14} \Omega\right)$. A test voltage of $50 \mathrm{Vdc}$ was selected for all measurements. This provided adequate sensitivity while minimizing some of the instability problems when using a higher voltage. It is common to use $500 \mathrm{Vdc}$ when making such measurements. $5,6,7$ However, once moisture has penetrated into the transducer, the resistance values were very erratic with $500 \mathrm{Vdc}$ applied. This made balancing of the megohm bridges extremely difficult. Additionally, with the higher voltages applied, slight motion of the transducer caused a great

2 The boil periods for cycles nos. 1, 2, 3, 4, 5 and 10 were $5 \mathrm{~h}$ long, all other cycles were $6 \mathrm{~h}$ long. All dry/bake periods were $2 \mathrm{~h}$ long except for cycles nos. 10 and 19; see footnotes to Table 1 for details.

3 These tests were performed during the month of llay when the climate was mild. Outdoor temperatures did not go below $4{ }^{\circ} \mathrm{C}\left(40^{\circ} \mathrm{F}\right)$ nor above $34^{\circ} \mathrm{C}\left(93^{\circ} \mathrm{F}\right)$ during this period. Light rain occurred from May 14 to 18 . See Appendix A for other climatic conditions.

4 Resistance was measured between pins $A$ and $C$ on the connectors for the flat transducers and between the white lead and shield on the round transducers.

5 Proposed draft MIL spec MIL-T-XXXXX Transducer Motional Pickup TR-299/G( ) dated 4-10-75. Paragraph 3.3.1.6, calls for $500 \pm 50 \mathrm{Vdc}$.

6 Manufacturer's drawing No. 28111425 dated 6-12-75, note 12, specifies $500 \pm 50 \mathrm{Vdc}$.

7 Manufacturer's drawing No. 28107211, sheet 1 of 2, dated 3-1-73, note 16, specifies $500 \pm 50 \mathrm{Vdc}$. 
disturbance in the bridge reading. It is believed that this was caused by an electrical charge displacement during transducer movement often referred to as triboelectric noise.

The dielectric material within the transducer absorbs a certain portion of the charge between the sense coil/core circuit and the shield. When transducer motion occurs, the capacitance between the sense coil/ core and the shield changes because of minute transducer deformations. With a constant applied voltage, when the capacitance changes, the charge must also change inversely, because the potential equals the product of the capacitance and the charge. While the charge is changing, the transducer either liberates a charge or absorbs a charge. This "charge-in-motion" is electrical current. The bridge cannot distinguish between leakage current and "motional" current. Thus, as the transducer moves, the bridge balance is unsteady, making reading difficult. This unwanted signal is in addition to the current generated by the normal operation of the transducer. When it is disturbed, however, this latter source should not be sensitive to bridge excitation voltage. It was impractical to keep the suspended transducers from undergoing some motion and, therefore, the lower voltage (50 Vdc) was selected for testing.

Leakage resistance generally decreases with increasing applied voltage. Hence, the values that were measured were somewhat greater than if they had been measured at $500 \mathrm{Vdc}$, by perhaps one-half an order of magnitude. As discussed later, whenever saline moisture penetrated into a transducer, the electrical leakage resistance decreased so dramatically that it mattered little whether it was measured at $50 \mathrm{Vdc}$ or at $500 \mathrm{Vdc}$. However, more stable readings were generally obtained at $50 \mathrm{Vdc}$.

Each of the fourteen transducers were measured for leakage resistance after they had been mounted in the support rack, prior to any exposure to the hot saline solution. Each of the round transducers had an initial leakage resistance greater than $1 \mathrm{~T} \Omega\left(10^{12} \Omega\right)$ and each of the flat transducers had a value greater than $0.1 \mathrm{~T} \Omega\left(10^{11} \Omega\right)$.

As the hot saline solution test progressed, the electrical leakage was measured just prior to the beginning of the boil portion of the cycle. The transducers had then been through a boil period, a dry/bake period, and at least an overnight period. In some cases, the interval between the end of the dry/bake period and the beginning of the next boil period was several days due to weekends, holidays, etc.

Table 1 gives the results of the measurements of the electrical leakage resistances on each of the seven flat and seven round transducers. Figures 2 (a) $-(\mathrm{g})$ and $3(\mathrm{a})-(\mathrm{g})$ show graphs of leakage resistance versus exposure time to hot saline solution. The seven round transducers 
were randomly selected from the lot of nine and arbitrarily numbered 1 through 7. The remaining two round "control sample" transducers were arbitrarily numbered as 8 and 9 . The seven flat transducers were selected in numerical sequence and had manufacturer numbers on them of $1 \mathrm{~B}, 2 \mathrm{~B}, 3 \mathrm{~B}$, etc., through 7B. Flat transducer Nos. $8 \mathrm{~B}$ and $9 \mathrm{~B}$ served as "control samples".

The initial leakage resistance for the flat transducers was approximately $200 \mathrm{G} \Omega$. Cycle-to-cycle variations of an half-an-order-of-magnitude were common. In general, the resistances remained quite high, greater than about $10 \mathrm{G} \Omega$, until moisture entered the transducer. The resistances then decreased to less than $100 \mathrm{k} \Omega$. In three instances (tranducer Nos. 3B, 4B and 7B) the resistances fell to less than $10 \mathrm{k} \Omega$. Figures $2 \mathrm{c}, 2 \mathrm{~d}$, and $2 \mathrm{~g}$ show this graphically. This suggests that significant amounts of moisture had penetrated the stainless steel jackets. Overall, five of the seven transducers "failed" when the leakage resistances became less than $20 \mathrm{M} \Omega .89$ The remaining two transducers (Nos. 5B and 6B) gave indications of impending failure, i.e., decreasing resistance. However, the resistances did not decrease to less than $20 \mathrm{M} \Omega$ and therefore, they were not considered as failures. Table 2 gives the time to failure for each of the seven flat transducers tested. Examining Figures $2 \mathrm{e}$ and $2 \mathrm{f}$, it can be seen that the resistances exhibited dramatic decreases near the end of the 120-h exposure time. It is probable that they were near failure. The mean time for the five transducers which failed is about 81 hours, as shown in Table 2. This value does not include transducer Nos. 5B and 6B. Had the latter two been tested to failure, the mean time would have increased to at least 92 hours.

Transducer No. 7B (see Fig. $2 \mathrm{~g}$ and Table 1) showed a dramatic decrease of leakage resistance after 20 hours of exposure; it then went back to a normally high value. This low resistance measurement (about $20 \mathrm{k} \Omega$ ) was verified. The low value and the "healing" are unexplained. Perhaos some insulation material shifted or broke down, temporarily, due to the temperature cycling, and repaired itself. This transducer did not exhibit indication of moisture penetration until much later (after about 108 hours of exposure).

The initial leakage resistances of the round transducers were about $2 \mathrm{~T} \Omega$. In most instances, they decreased to about $0.1 \mathrm{~T} \Omega$ towards the end of the test. Examination of the plotted data in Figures $3 a$ through $3 \mathrm{~g}$ and of the data given in Table 1 shows an unusual decrease in resistance over the exposure period from about 37 hours to 54 hours,

8 The 20-M value is specified by the manufacturer; drawing No. 28111425 dated 6-12-75, note 12 .

9 Manufacturer's report 46234, dated 9-10-75, specifies 10 M $\Omega$ or more. 
Table 1. Electrical Leakage for Flat and Round Transducers Subjected to Hot Saline Solution (Corrosive Moisture Test).

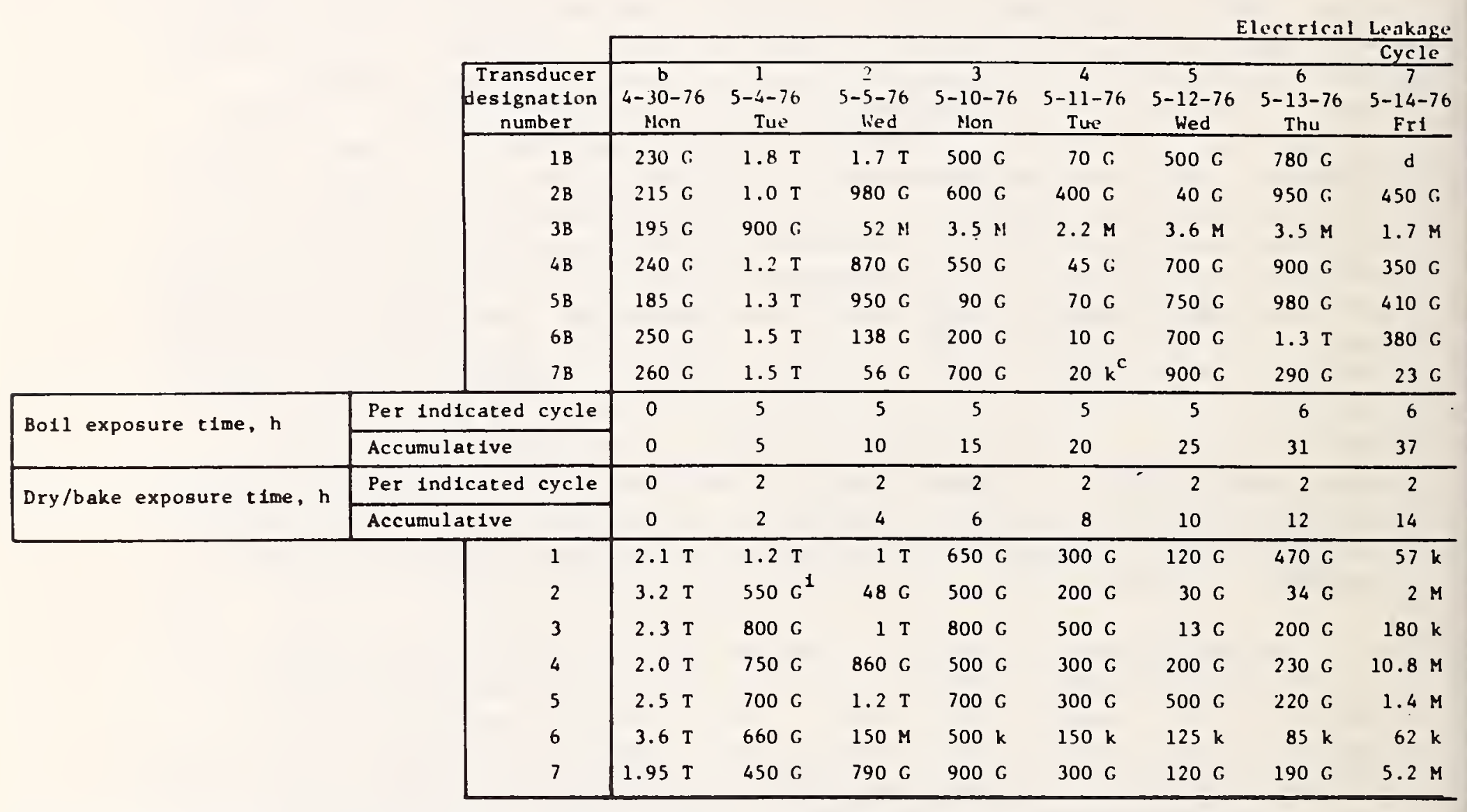

Q Value given in ohms; $k=10^{3}, M=10^{6}, G=10^{9}, T=10^{12}$. All measurements made at nominally 50 Vde. Measurements made prior to beginning of exposure to saline solution.

Measured value verifled; temporary low value which "healed", cause unexplained.

Measurement Inadvertently omitted. 
Table 1. Continued

\begin{tabular}{|c|c|c|c|c|c|c|c|c|c|c|c|c|c|}
\hline \multicolumn{14}{|c|}{ Number, Date, Dav } \\
\hline $\begin{array}{c}8 \\
5-17-7 h \\
\text { Mon }\end{array}$ & $\begin{array}{c}9 \\
5-18-76 \\
\text { Tue }\end{array}$ & $\begin{array}{c}10 \\
5-19-7 h \\
\text { Wed }\end{array}$ & $\begin{array}{c}11 \\
5-20-7 h \\
\text { Thu } \\
\end{array}$ & $\begin{array}{c}12 \\
5-21-76 \\
\mathrm{Fr} 1\end{array}$ & $\begin{array}{c}13 \\
5-24-76 \\
\text { Mon }\end{array}$ & $\begin{array}{c}14 \\
5-25-76 \\
\text { Tut }\end{array}$ & $\begin{array}{c}15 \\
5-26-76 \\
\text { Wed }\end{array}$ & $\begin{array}{c}16 \\
5-27-76 \\
\text { Thu }\end{array}$ & $\begin{array}{c}17^{6} \\
6-1-76 \\
\text { Tue } \\
\end{array}$ & $\begin{array}{c}18 \\
6-2-76 \\
\text { Wed }\end{array}$ & $\begin{array}{c}19 \\
6-3-76 \\
\text { Thu }\end{array}$ & $\begin{array}{c}20 \\
6-4-76 \\
\text { Fr1 }\end{array}$ & $\begin{array}{c}21 \\
6-7-76 \\
\text { Mon }\end{array}$ \\
\hline $8.2 \mathrm{G}$ & 5406 & $210 \mathrm{G}$ & $130 \mathrm{M}$ & $160 \mathrm{M}$ & $190 \mathrm{k}$ & $75 \mathrm{k}$ & $50 \mathrm{k}$ & $47 k$ & $55 k$ & $45 k$ & $95 k$ & $50 k$ & $50 k$ \\
\hline $5.6 \mathrm{G}$ & $120 \mathrm{G}$ & $700 \mathrm{G}$ & $500 \mathrm{G}$ & $310 \mathrm{M}$ & $90 \mathrm{G}$ & $370 \mathrm{G}$ & $270 \mathrm{G}$ & $320 \mathrm{C}$ & $800 \mathrm{M}$ & $70 \mathrm{k}$ & $1.4 \mathrm{k}$ & $2.5 \mathrm{k}$ & $5.5 \mathrm{k}$ \\
\hline $380 k$ & $750 k$ & $<1 k$ & $<1 \mathrm{k}$ & $<1 \mathrm{k}$ & $<1 k$ & $<1 \mathrm{k}$ & $<1 k$ & $<1 k$ & $<1 k$ & $<1 k$ & $<1 \mathrm{k}$ & $<1 k$ & $<1 k$ \\
\hline $420 \mathrm{G}$ & $450 \mathrm{G}$ & $740 \mathrm{G}$ & $500 \mathrm{G}$ & $240 \mathrm{G}$ & $<1 k$ & $<1 \mathrm{k}$ & $<1 \mathrm{k}$ & $<1 \mathrm{k}$ & $<1 \mathrm{k}$ & $3 k$ & $4 k$ & $3.5 \mathrm{k}$ & $5 k$ \\
\hline $520 \mathrm{G}$ & $460 \mathrm{G}$ & $770 \mathrm{G}$ & $450 \mathrm{G}$ & $250 \mathrm{G}$ & $550 \mathrm{G}$ & $350 \mathrm{G}$ & $600 \mathrm{G}$ & $420 \mathrm{G}$ & $30 \mathrm{G}$ & $70 \mathrm{G}$ & $140 \mathrm{G}$ & $650 \mathrm{M}$ & $850 \mathrm{M}$ \\
\hline $15 \mathrm{G}$ & $84 \mathrm{G}$ & $120 \mathrm{G}$ & $90 \mathrm{G}$ & $37 \mathrm{G}$ & $40 \mathrm{G}$ & $40 \mathrm{G}$ & $25 \mathrm{G}$ & $9 \mathrm{C}$ & $4.5 \mathrm{G}$ & $4.1 \mathrm{G}$ & $32 \mathrm{G}$ & $15 M$ & $600 \mathrm{M}$ \\
\hline $520 \mathrm{G}$ & $550 \mathrm{G}$ & $950 \mathrm{G}$ & $600 \mathrm{G}$ & $310 \mathrm{G}$ & $650 \mathrm{G}$ & $450 \mathrm{G}$ & $500 \mathrm{G}$ & $550 \mathrm{G}$ & $190 \mathrm{G}$ & $220 \mathrm{M}$ & $1.5 \mathrm{k}$ & $<1 k$ & $1.4 \mathrm{k}$ \\
\hline 6 & 6 & $5^{e}$ & 6 & 6 & 6 & 6 & 6 & 6 & 6 & 6 & 6 & 6 & 6 \\
\hline 43 & 49 & 54 & 60 & 66 & 72 & 78 & 84 & 90 & 96 & 102 & 108 & 114 & 120 \\
\hline 2 & 2 & $1^{e}$ & 2 & 2 & 2 & 2 & 2 & 2 & 2 & 2 & $0^{h-}$ & 2 & 2 \\
\hline 16 & 18 & 19 & 21 & 23 & 25 & 27 & 29 & 31 & 33 & 35 & 35 & 37 & 39 \\
\hline $132 k$ & $150 \mathrm{k}$ & $140 \mathrm{k}$ & $52 \mathrm{M}$ & $102 M$ & $70 \mathrm{M}$ & $410 \mathrm{M}$ & $30 \mathrm{M}$ & $5.5 \mathrm{M}$ & $400 k$ & $270 \mathrm{M}$ & $950 \mathrm{M}$ & $1.6 \mathrm{G}$ & $25 \mathrm{G}$ \\
\hline $5.6 \mathrm{M}$ & $900 \mathrm{k}$ & $104 \mathrm{C}$ & $75 \mathrm{G}$ & $70 \mathrm{G}$ & $95 \mathrm{G}$ & $75 \mathrm{G}$ & $95 \mathrm{M}$ & $160 \mathrm{M}$ & $1.4 \mathrm{M}$ & $5.5 \mathrm{M}$ & $13 \mathrm{M}$ & $12 \mathrm{M}$ & $1.3 \mathrm{M}$ \\
\hline $5.4 \mathrm{M}$ & $4 M$ & $170 \mathrm{G}$ & $150 \mathrm{G}$ & $160 \mathrm{G}$ & $120 \mathrm{C}$ & $140 \mathrm{G}$ & $300 \mathrm{M}$ & $17 \mathrm{M}$ & $2.7 \mathrm{M}$ & $950 \mathrm{H}$ & $50 \mathrm{G}$ & $230 \mathrm{G}$ & $1.8 \mathrm{M}$ \\
\hline $530 k$ & $3.7 \mathrm{M}$ & $195 \mathrm{C}$ & $160 \mathrm{G}$ & $145 \mathrm{G}$ & $160 \mathrm{C}$ & $240 \mathrm{G}$ & $130 \mathrm{M}$ & $65 \mathrm{M}$ & $40 \mathrm{M}$ & $55 \mathrm{G}$ & $190 \mathrm{M}$ & $140 \mathrm{G}$ & $170 \mathrm{G}$ \\
\hline $3 M$ & $3.9 \mathrm{M}$ & $16 \bar{E}$ & $150 \mathrm{G}$ & $130 \mathrm{G}$ & $125 \mathrm{G}$ & $160 \mathrm{G}$ & $70 \mathrm{M}$ & $12 M$ & $26 \mathrm{M}$ & $40 \mathrm{G}$ & $5.5 \mathrm{G}$ & $160 \mathrm{G}$ & $70 \mathrm{G}$ \\
\hline $68 k$ & $65 k$ & $60 k$ & $54 k$ & $45 \mathrm{k}$ & $40 k$ & $42 \cdot k$ & $41 k$ & $41 k$ & $35 \mathrm{M}$ & $35 \mathrm{k}$ & $45 k$ & $37 k$ & $36 k$ \\
\hline $1.1 \mathrm{M}$ & $4.8 \mathrm{M}$ & $120 \mathrm{G}$ & $105 \mathrm{C}$ & $120 \mathrm{G}$ & $135 \mathrm{G}$ & $150 \mathrm{G}$ & $4.7 \mathrm{M}$ & $5.7 \mathrm{M}$ & $200 \mathrm{k}$ & $750 \mathrm{k}$ & $3 \mathrm{G}$ & $70 \mathrm{G}$ & $65 \mathrm{G}$ \\
\hline
\end{tabular}

${ }_{\mathrm{f}}^{\mathrm{S}}$ Steam feed line broke loose. Temperature dropped to $63^{\circ} \mathrm{C}$ for approximately $1 \mathrm{~h}$; dry/bake pertod shortened to $1 \mathrm{~h}$.

fest leads measured for "self leakage" at end of cycle 8 , values were 5 T $\Omega$ for flat and 10 T $\Omega$ for round.

E Test leads measured for "self leakage" at end of cycle 17, values were 10 T $\Omega$ for flat and 1.7 I for round.

Tank developed leak, boll test continued full $6 \mathrm{~h}$ perlod. Water and salt added to maintain level and saline

concentration. Leak repaired and tank was filled overnight with water to check leak; no dry/bake period.

i Trinsducer lead fell into tank during cycle 1 ; washed and cleaned prior to measuring. 


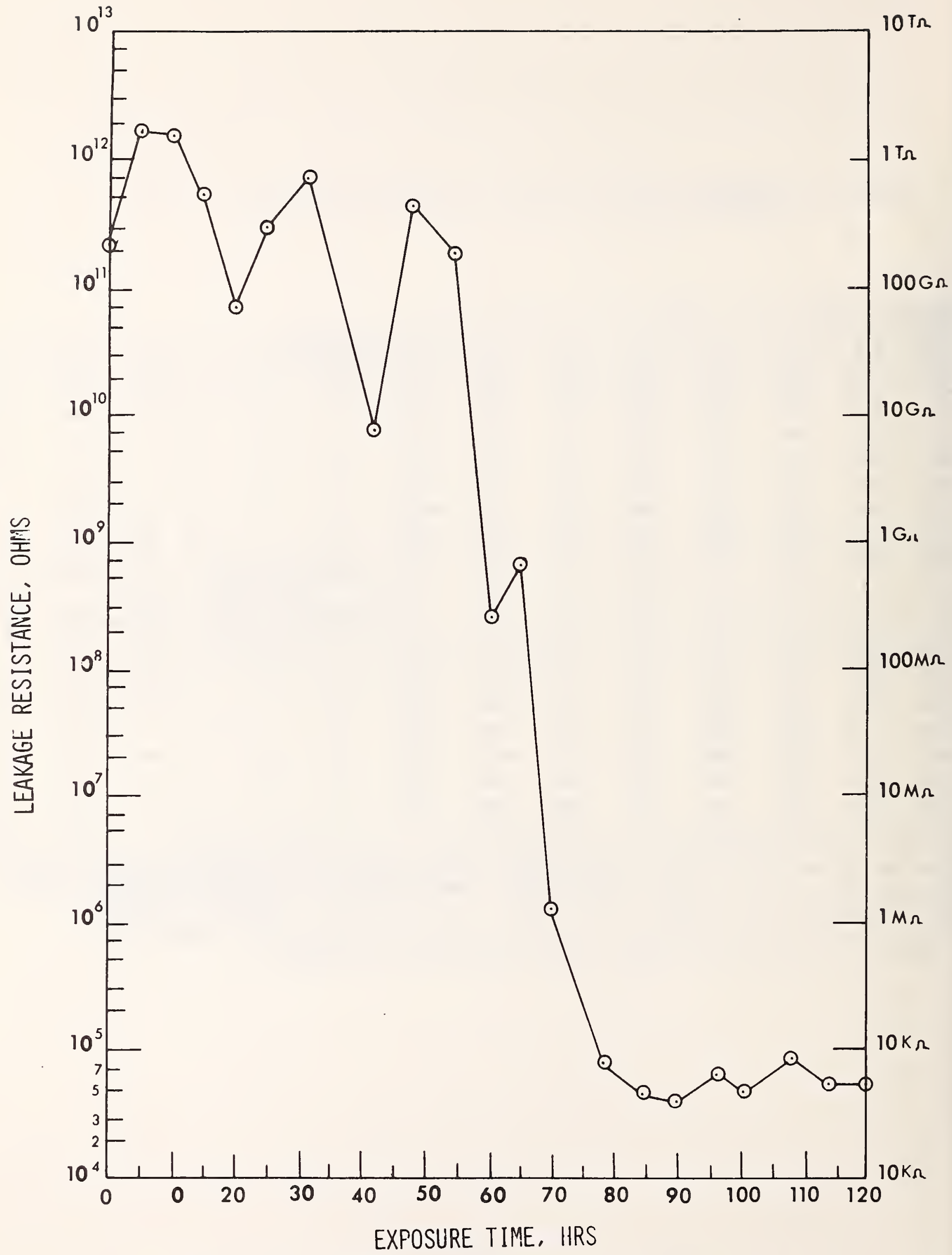

Figure 2a. Electrical leakage resistance for flat transducer No. 1B. 


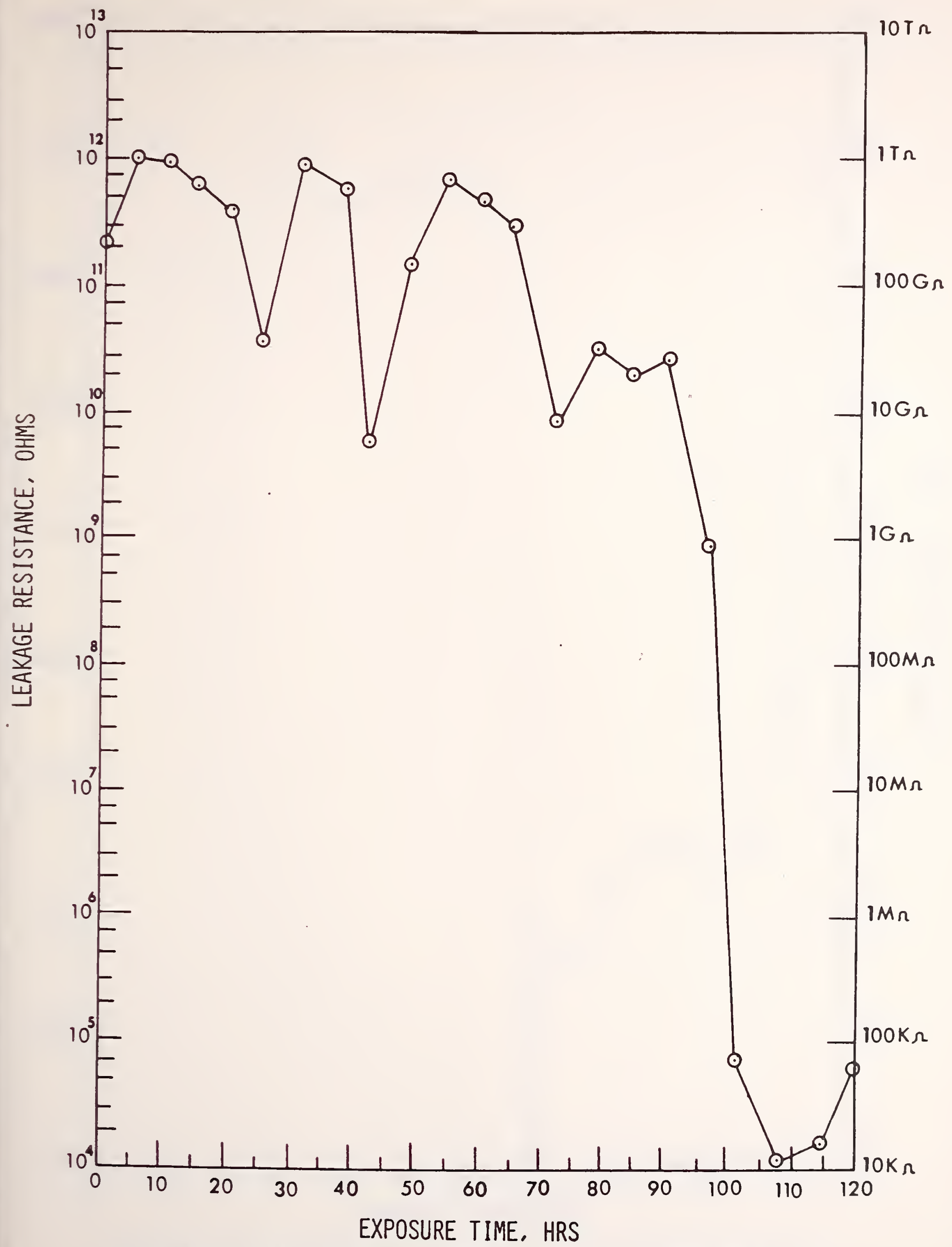

Figure 2b. Electrical leakage resistance for flat transducer No. $2 B$. 


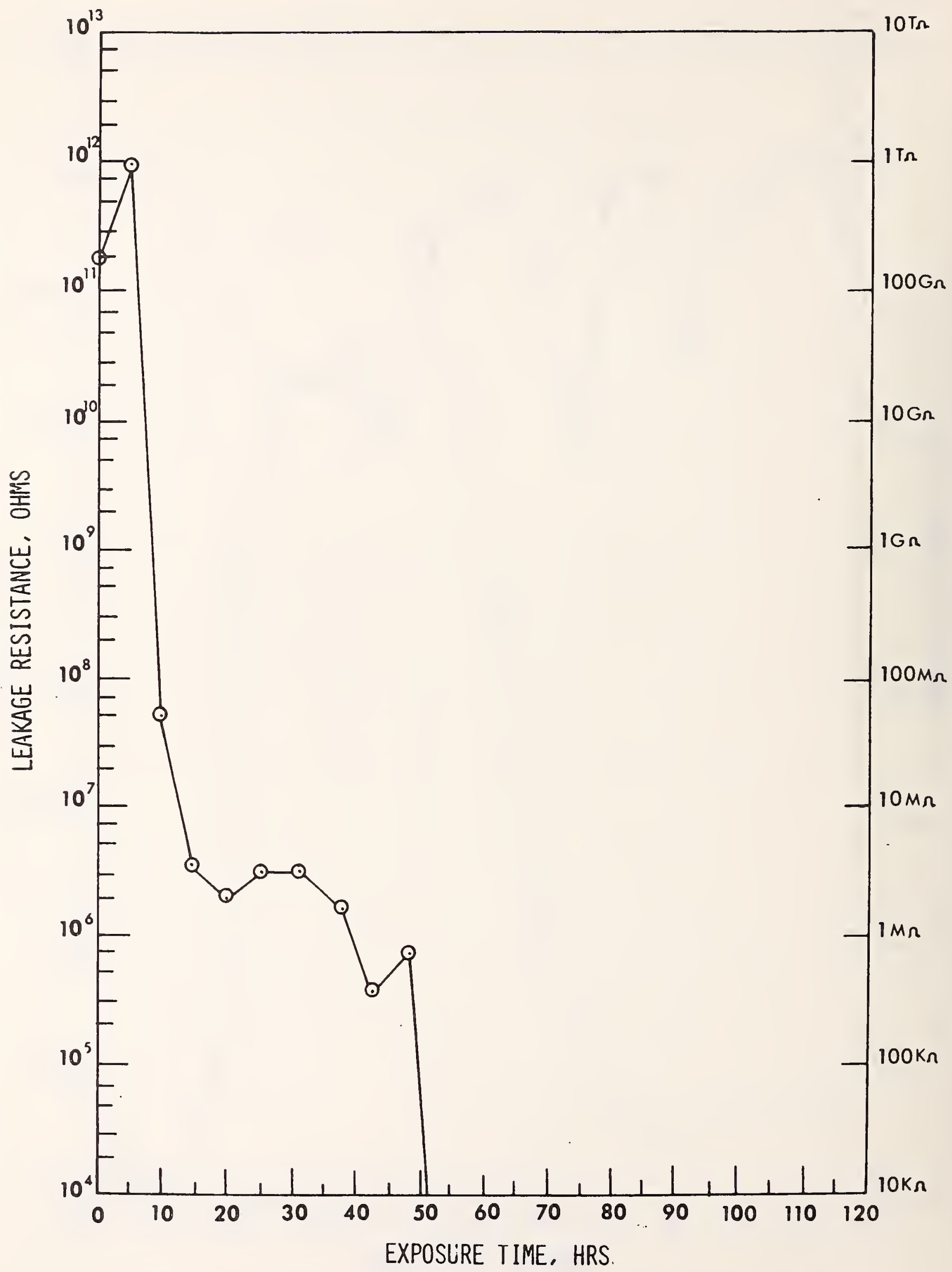

Figure 2c. Electrical leakage resistance for flat transducer No. 3B. 


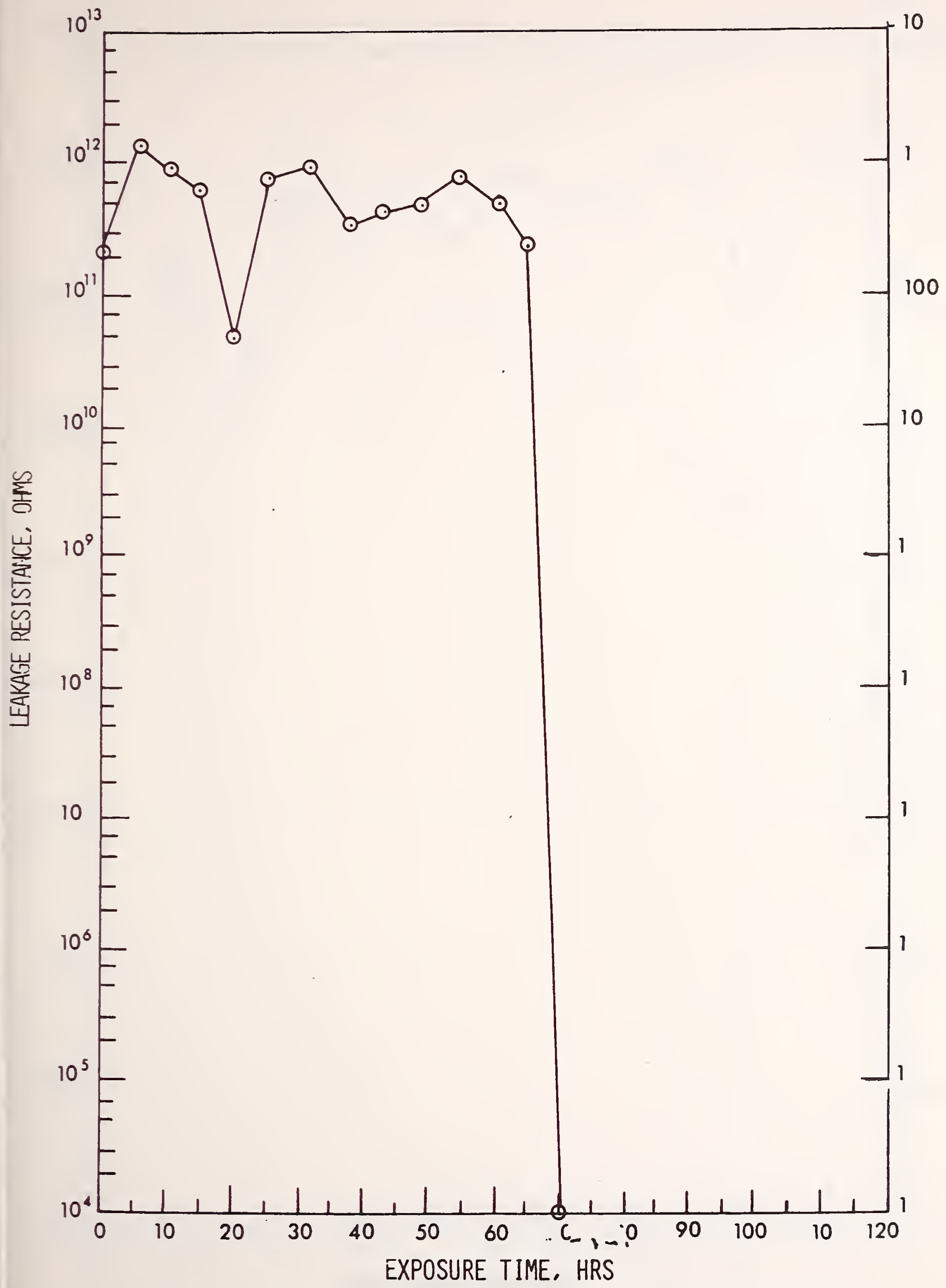

Figure 2d. Electrical leakage resistance for flat transducer No. 4B. 


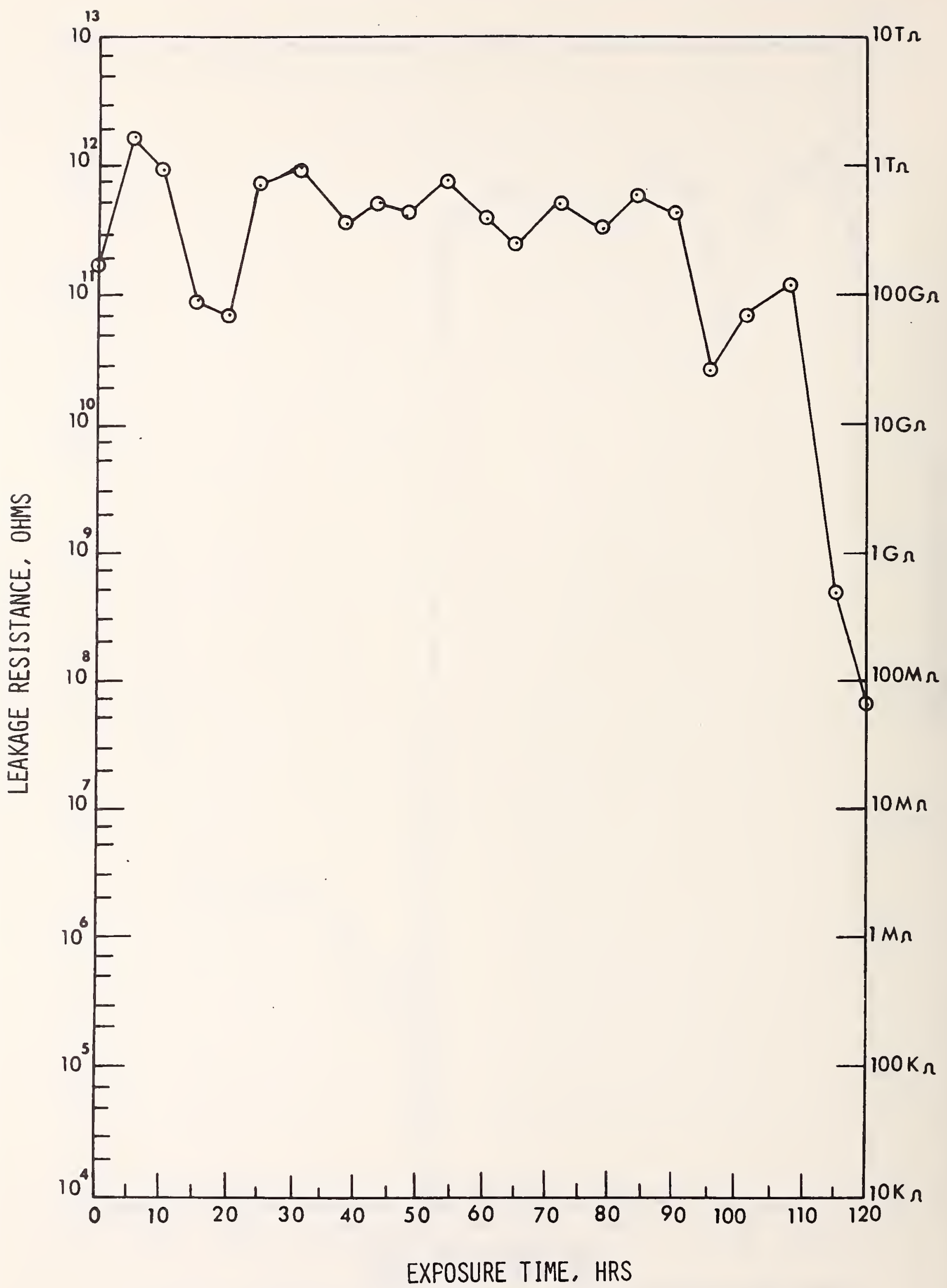

Figure 2e. Electrical leakage resistance for flat transducer No. 5B. 


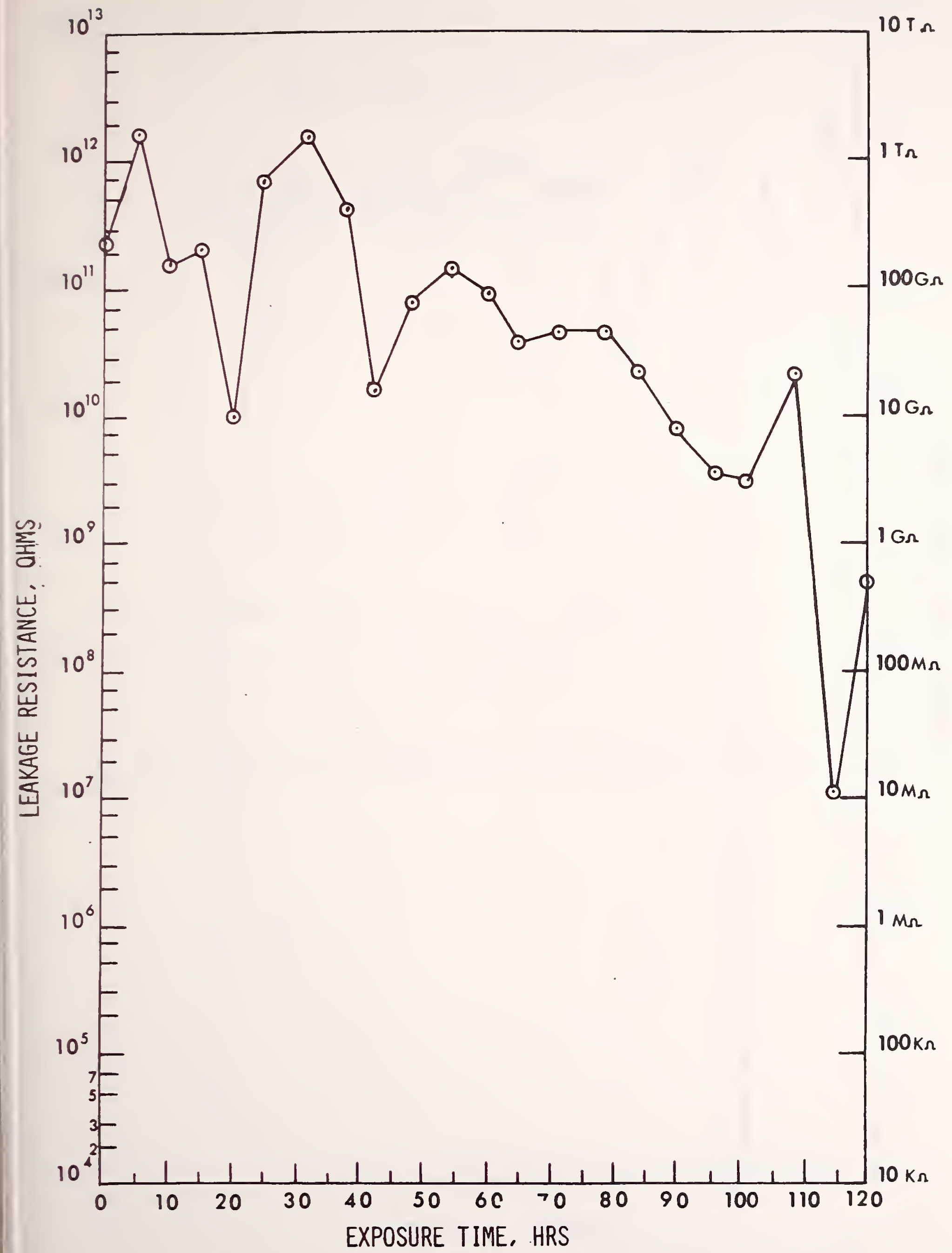

Figure 2f. Electrical leakage resistance for flat transducer No. 6B. 


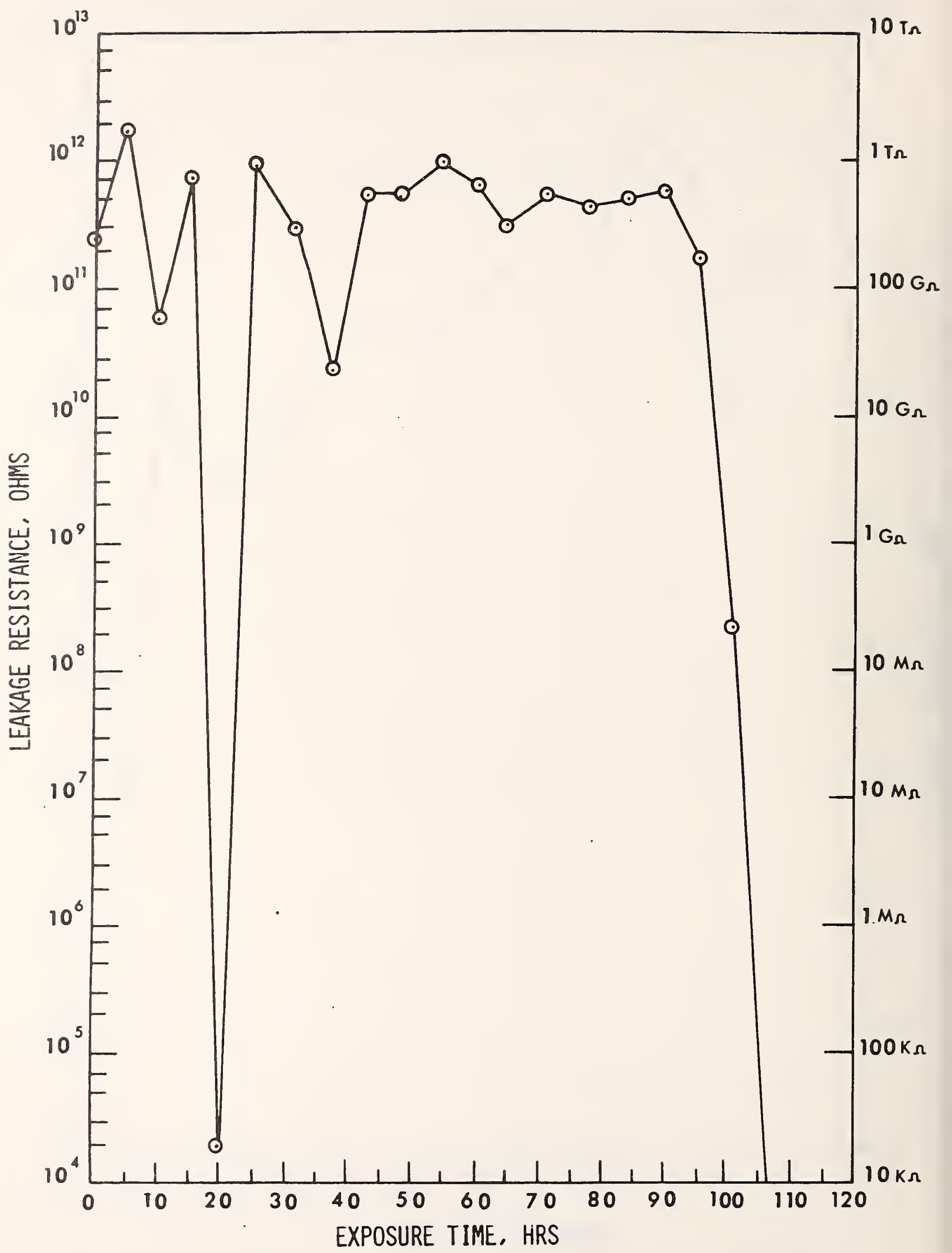

Figure $2 g$. Electrical leakage resistance for flat transducer No. 7B. 
Table 2. Time to Failure for the Flat Transducers (Corrosive Moisture Test)

\begin{tabular}{|c|c|}
\hline $\begin{array}{c}\text { Transducer } \\
\text { Designation } \\
\text { Number }\end{array}$ & $\begin{array}{c}\text { Exposure } \\
\text { Time, } \mathrm{h}\end{array}$ \\
\hline 1B & 70 \\
2B & 102 \\
3B & 54 \\
4B & 70 \\
5B & $\mathrm{b}$ \\
6B & $\mathrm{c}$ \\
7B & $108^{\mathrm{d}}$ \\
\hline Mean & $81+23$ \\
\hline
\end{tabular}

a

Time when leakage resistance became less than $10 \mathrm{M} \Omega$.

b

Resistance of $120 \mathrm{~h}$ was $850 \mathrm{M} \Omega$; no failure.

c

Resistance of 120 , h was $600 \mathrm{M} \Omega$ no failure.

d

Resistance measured $20 \mathrm{k} \Omega$ at $20 \mathrm{~h}$, "increased to greater than

$10 \mathrm{G} \Omega$, until $108 \mathrm{~h}$; cause unexplained. See footnote $\mathrm{c}$ of Table 1 and discussion in text. 


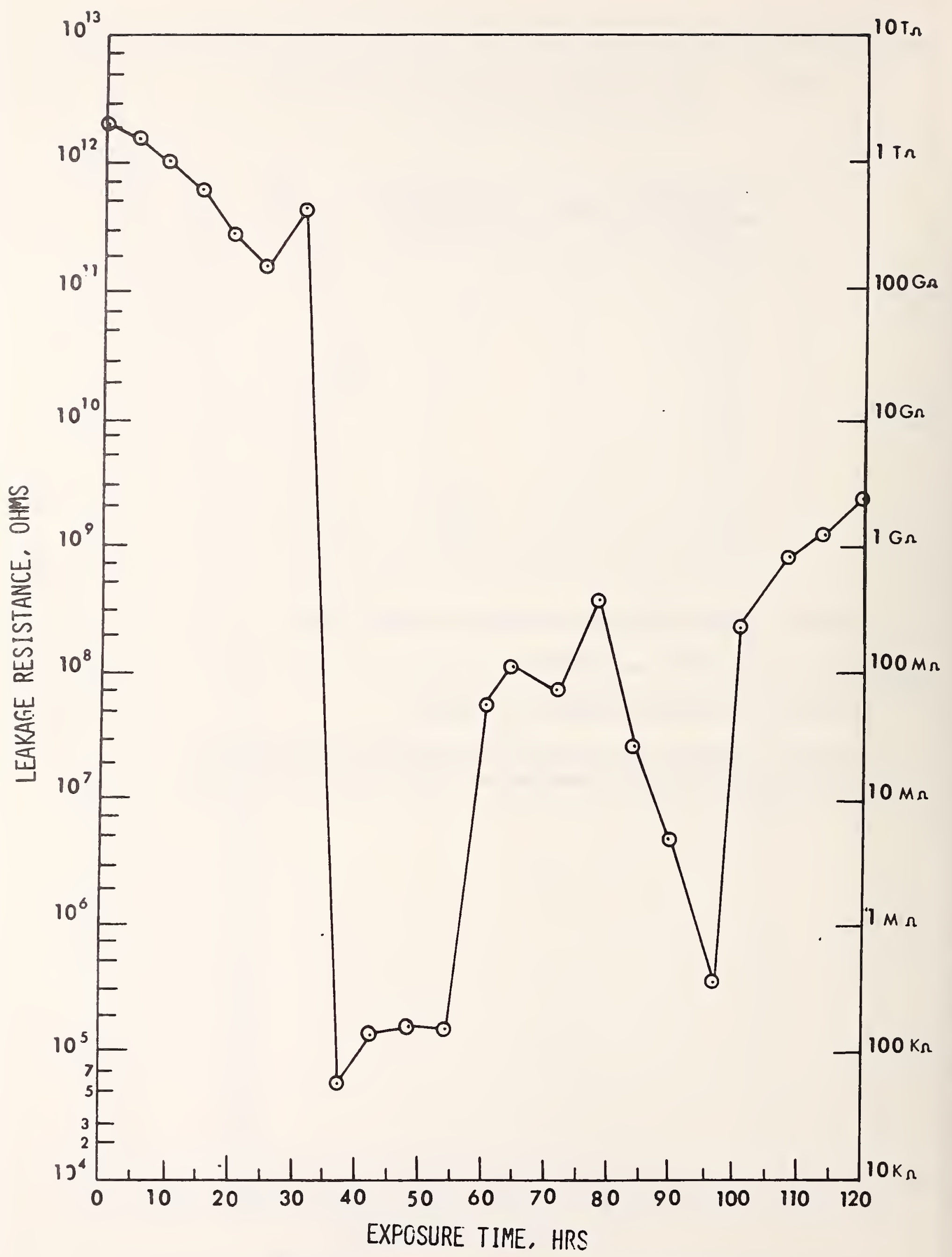

Figure 3a. Electrical leakage resistance for round transducer No. 1. 


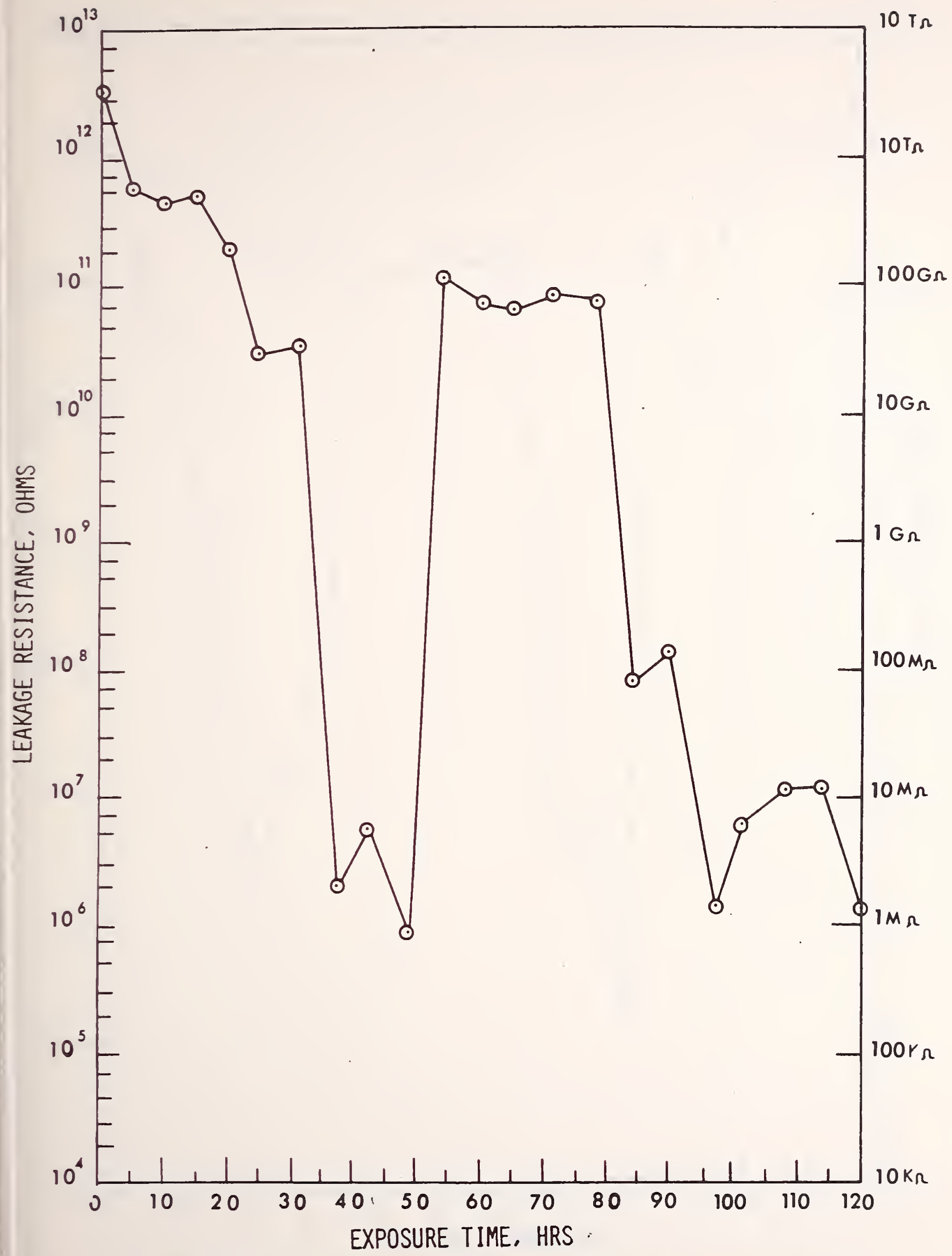

Figure 3b. Electrical leakage resistance for round transducer No. 2. 


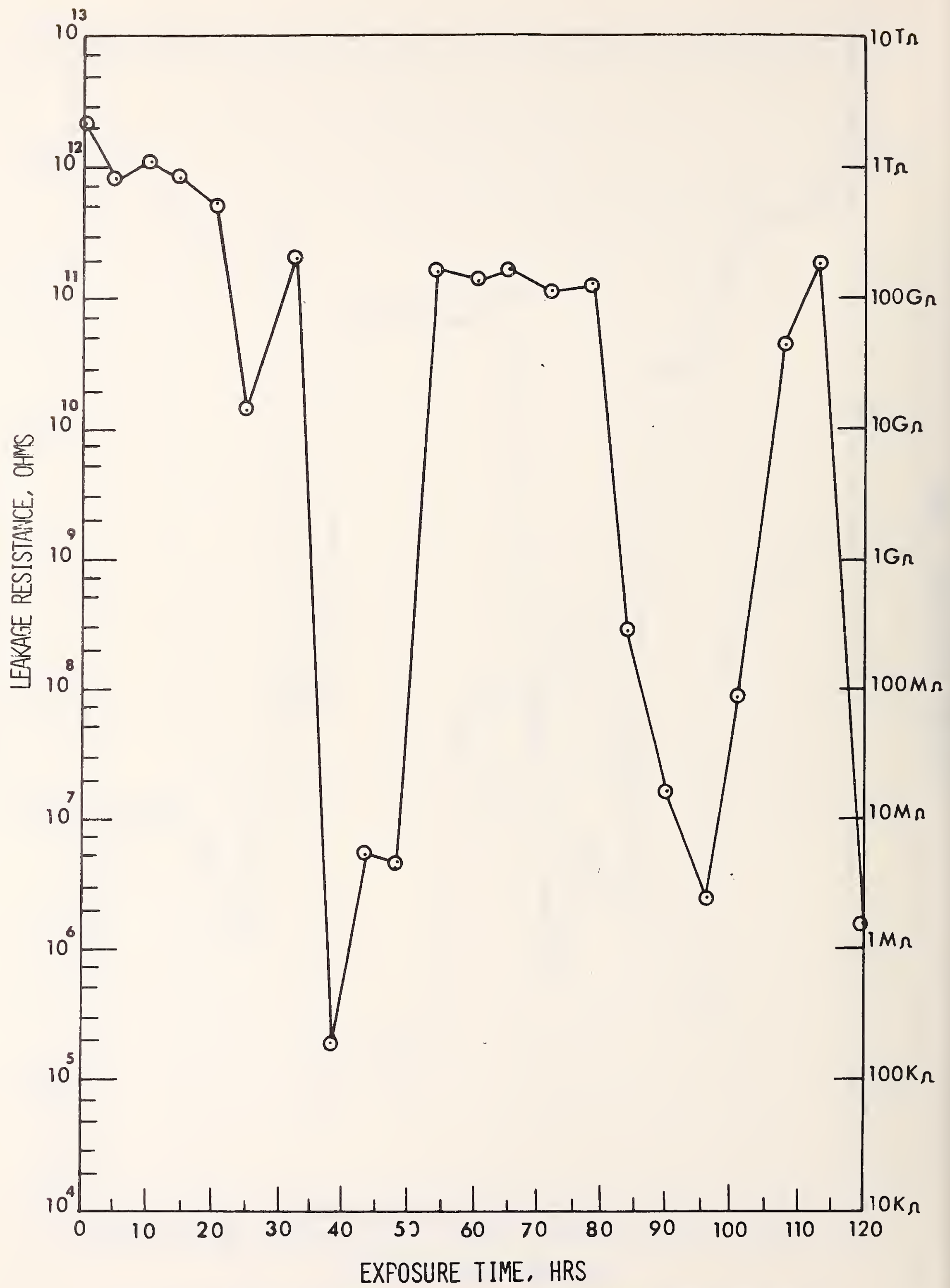

Figure 3c. Electrical leakage resistance for round transducer No. 3. 


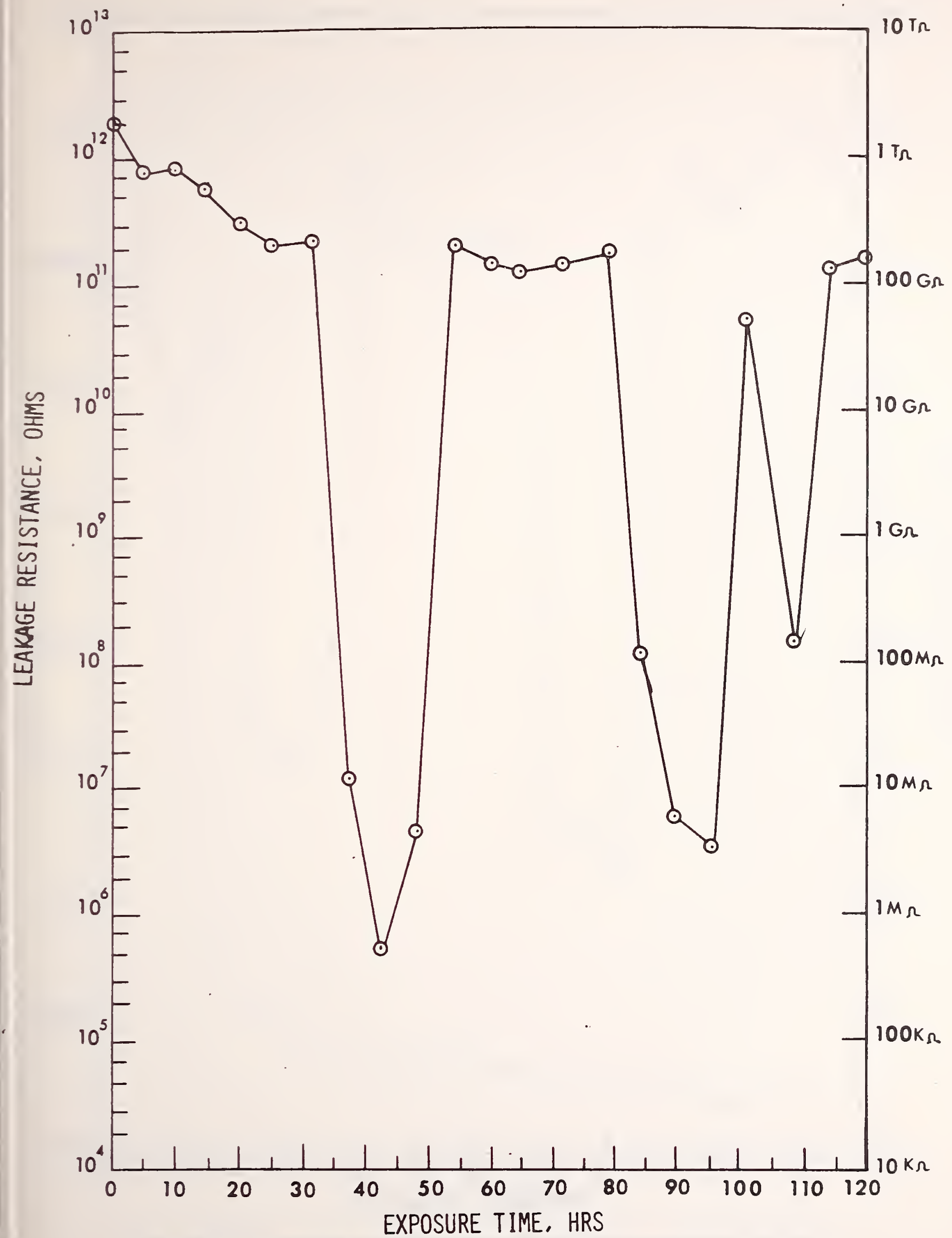

Figure 3d. Electrical leakage resistance for round transducer No. 4. 


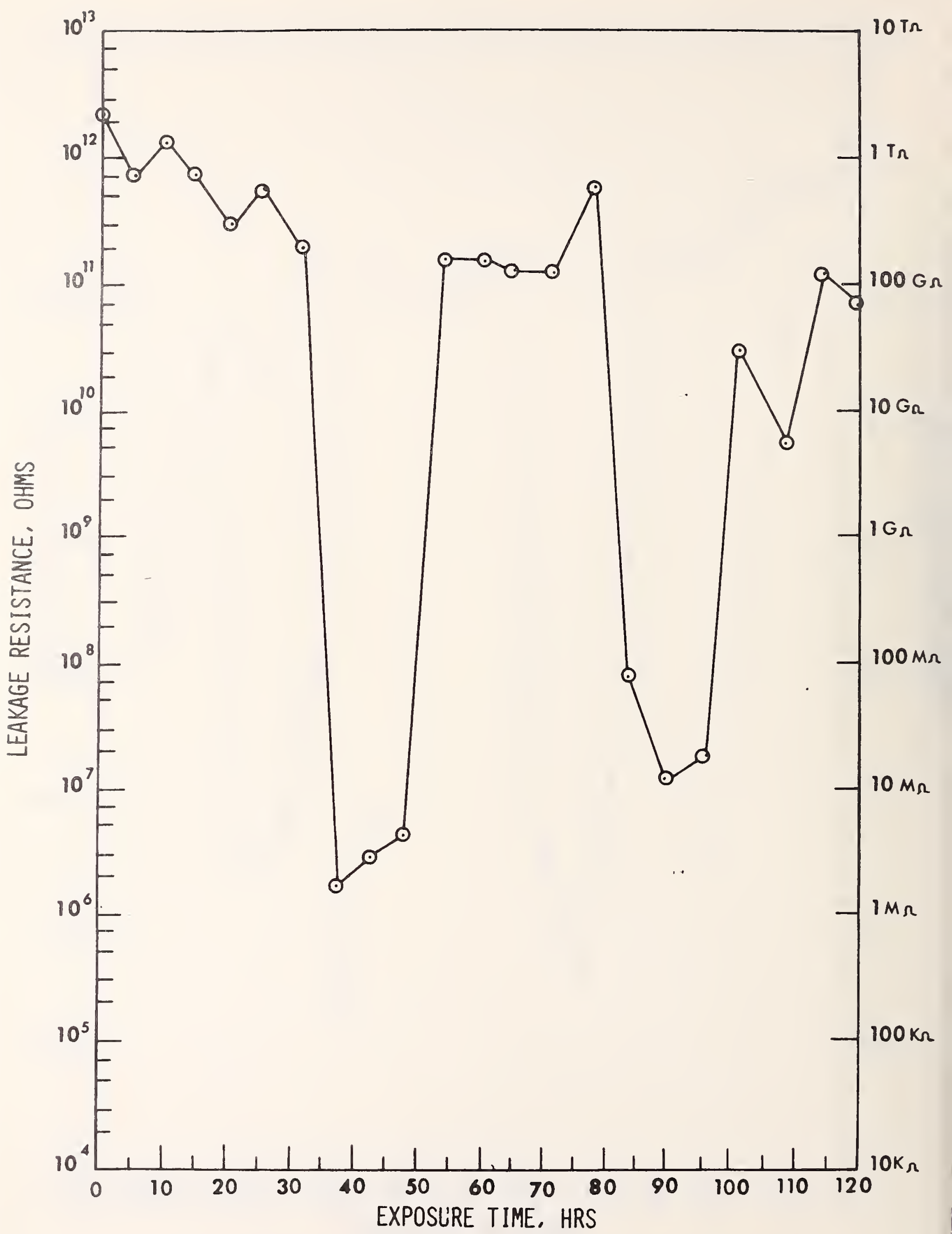

Figure 3e. Electrical leakage resistance for round transducer No. 5. 


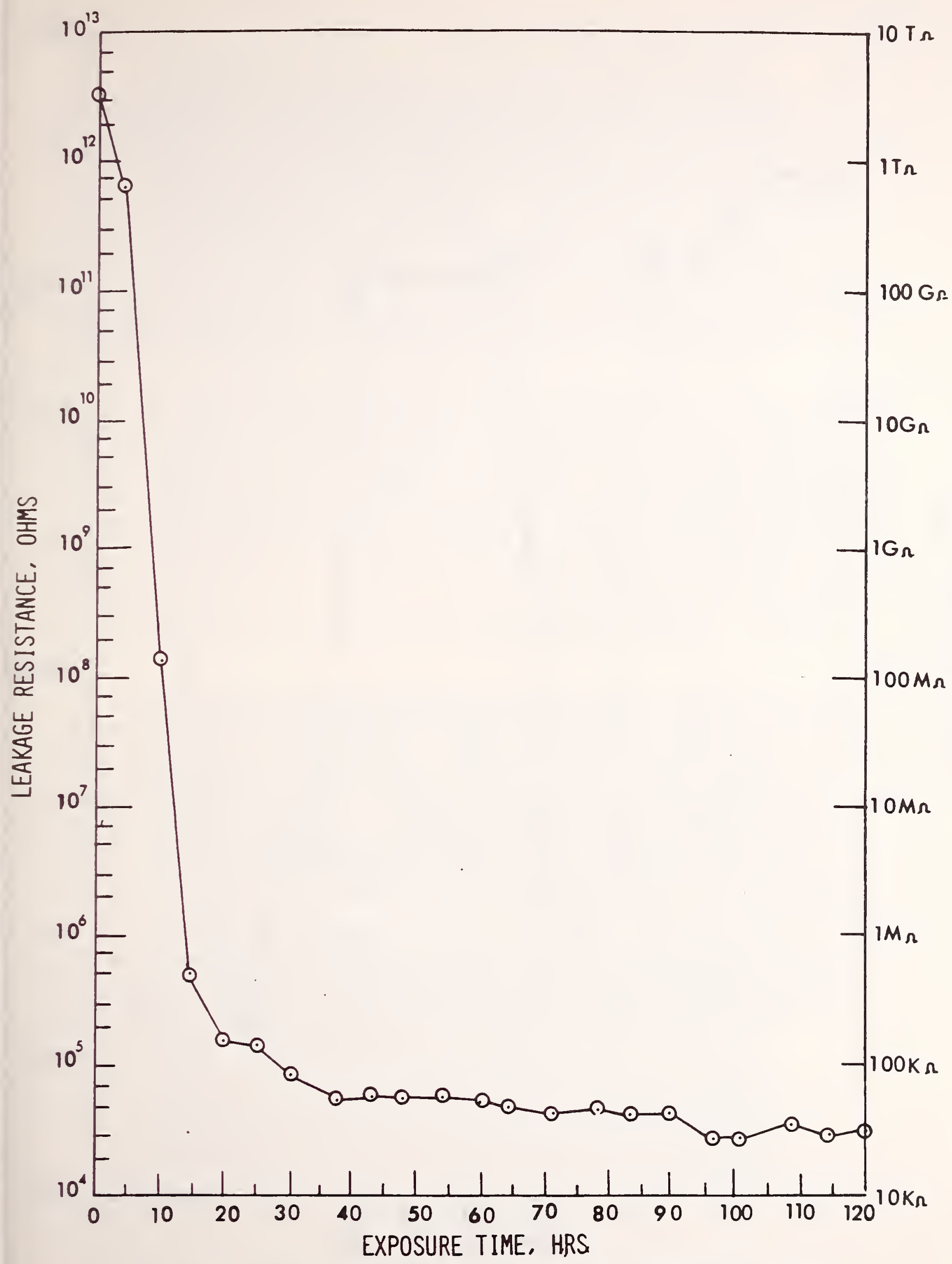

Figure 3f. Electrical leakage resistance for round transducer No. 6. 


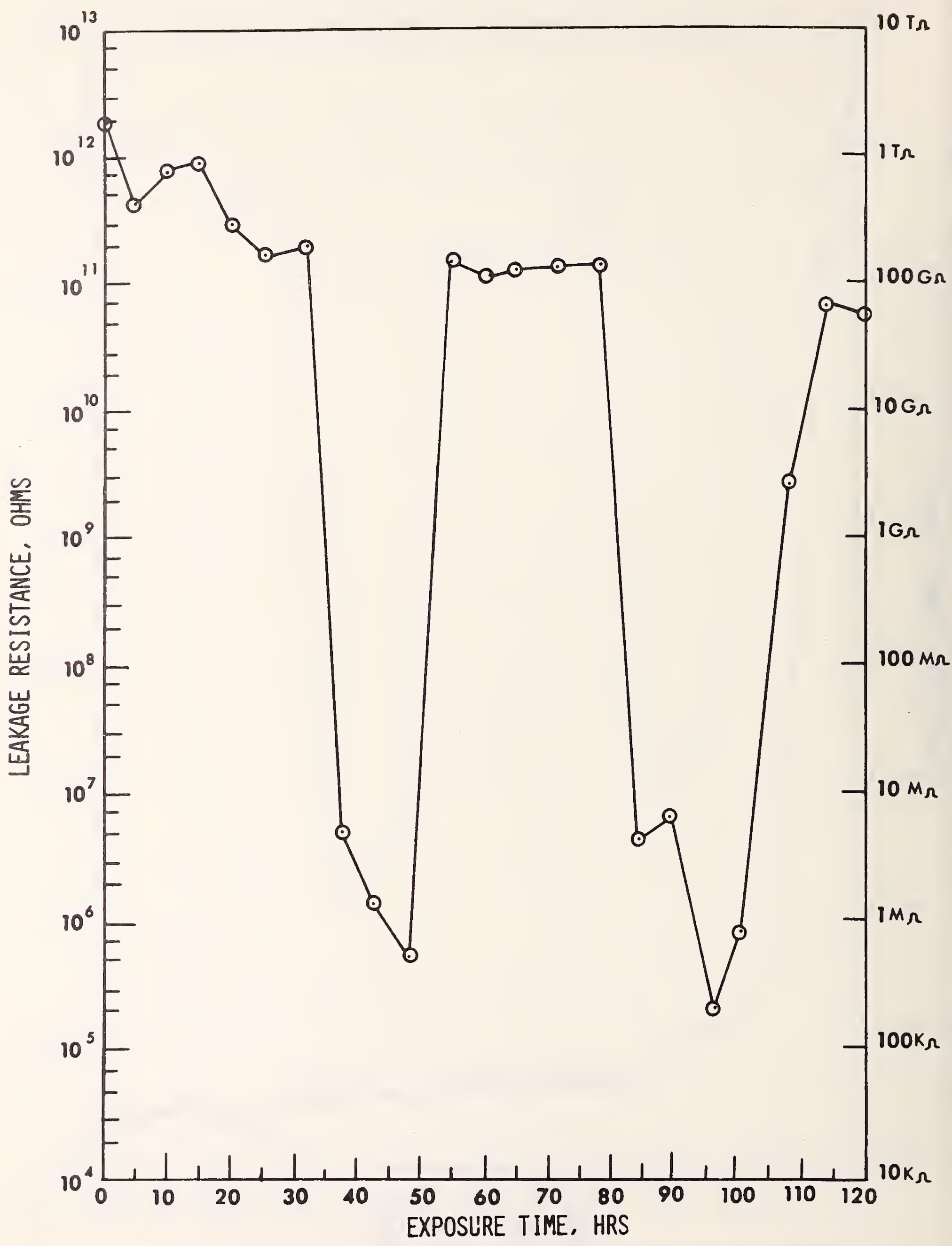

Figure 3g. Electrical leakage resistance for round transducer No. 7. 
and another decreased resistance from about 84 hours to 102 hours. These decreases were caused by periods of rain prior to and during the time the resistance measurements were taken. Appendix A gives relative humidity and rainfall data for the test period. A high degree of correlation exists between periods of high humidity and rain and the lower measured leakage resistances. It is felt that the active portion of the transducer was not affected by the rain, but rather the leads and the terminals where the megohm bridge was connected were sensitive to atmospheric moisture. This effect and the resulting decrease of resistance during rainy periods cannot be considered as normal transducer characteristics because these transducers had different terminations than those used in normal service.

If the lower readings caused by rain are ignored, then the leakage resistance appears better behaved and generally remained high during most of the 120-hour exposure time. One notable exception exists, namely, transducer No. 6. Figure $3 f$ and Table 1 show that the resistance decreased rapidly from the onset of testing. The resistance was measured at less than $100 \mathrm{k} \Omega$ over most of the test. Examination of this transducer after removal from the tank showed a gash in the outer polyurethane jacket which allowed large amounts of saline solution to enter the transducer. No other transducers exhibited the same kinds of characteristics during the test period. It is, therefore, concluded that none of the other round transducers had serious leaks and hence, did not fail.

The gash found in round transducer No. 6 is believed to have been caused by the steam feed line. Early in the testing program, it was noted that the feed line flailed inside the tank and repositioned itself. It is possible that the flailing steam line could have slashed this transducer jacket, causing the damage. Microscopic examination shows definite signs of cutting, and not tearing as might occur as a result of a pressurized rupture. Figure 4 shows the damaged polyurethane jacket. After removing the outer jacket, discolorations inside indicated that the solution had "traveled" the entire 2-m length of the transducer.

At several times during the test, the bridge test cable leads were measured for their leakage resistance. In all instances their resistance was very high, commonly greater than $1 \mathrm{~T} \Omega$. Thus, the test leads did not adversely affect the measurement process by shunting the transducer leakage resistance. 


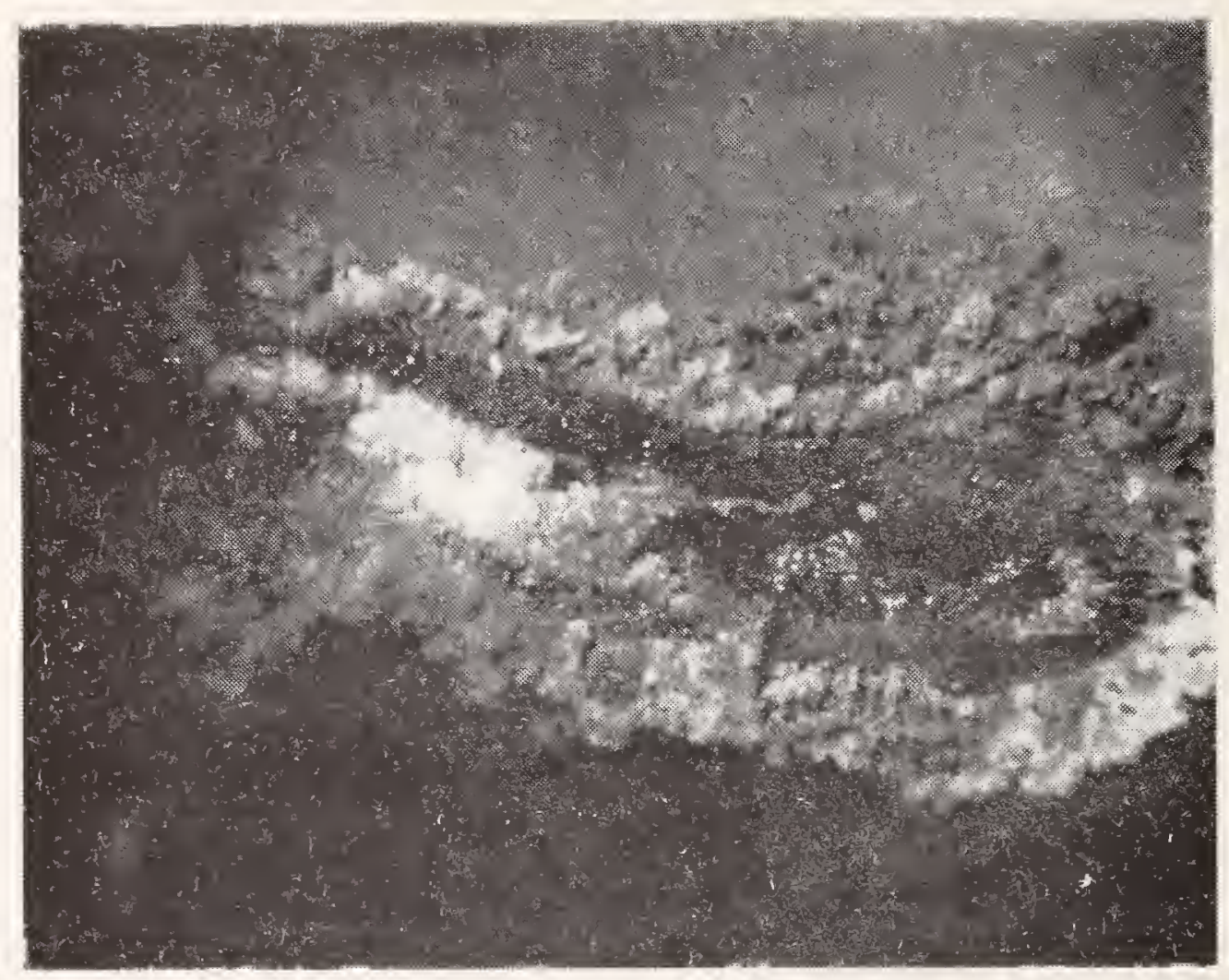

Figure 4a. Gash in polyurethane jacket of round transducer No. 6 prior to washing salt from transducer.

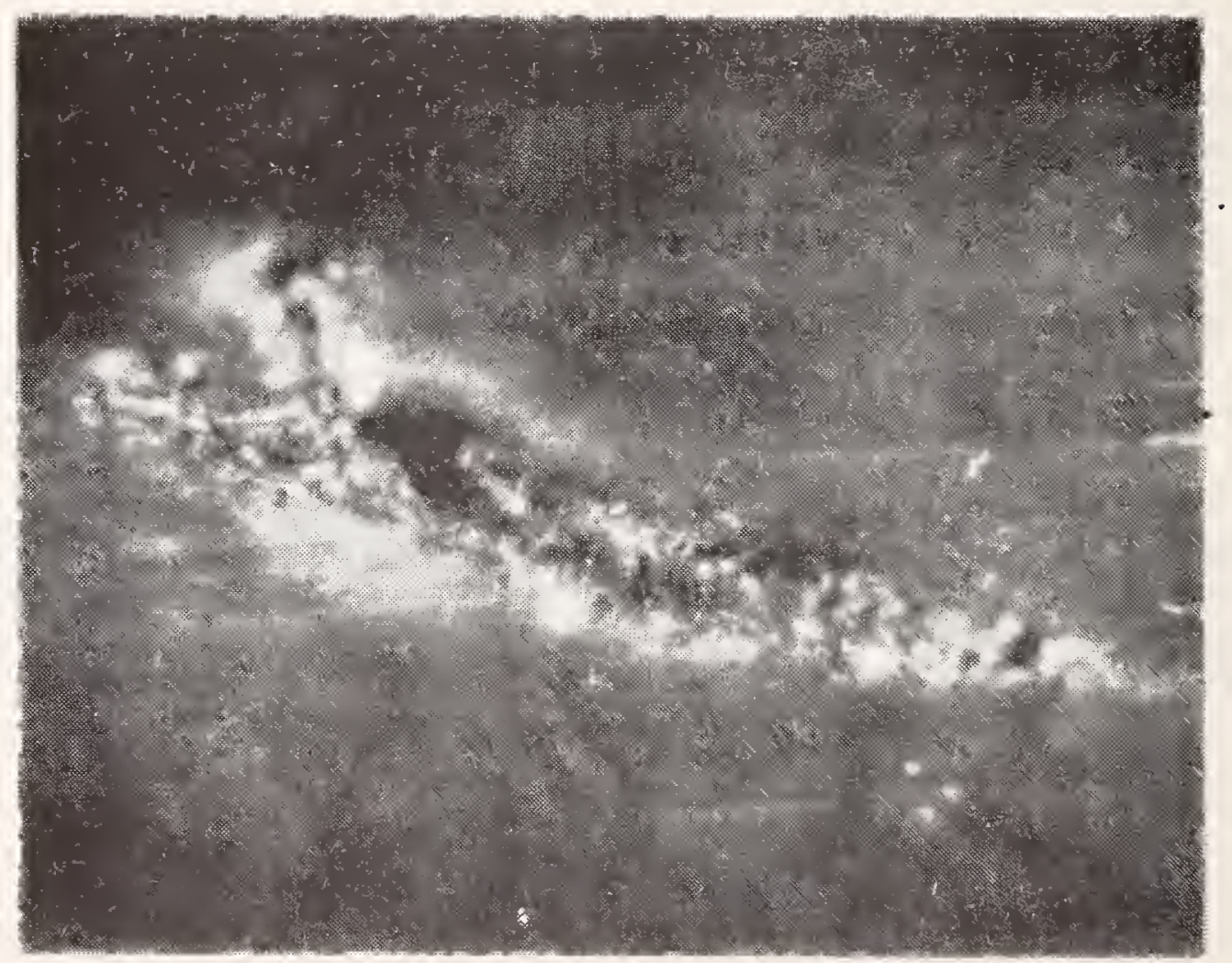

Figure 4b. Gash in polyurethane jacket of round transducer No. 6 after washing salt from transducer. 
The failure criteron for the round transducers was a leakage resistance of less than $100 \mathrm{M} \Omega .10,11$ Ignoring low resistance readings during the rainy periods as previously discussed, four of the round transducers (viz., transducer Nos. 1, 4, 5 and 7) maintained leakage resistances greater than $10 \mathrm{G} \Omega$. Two transducers (Nos. 2 and 3 ) had final leakage resistances of just over 1 M $\Omega$ each. Regarding the latter, additional measurements were made to verify that the lower resistances were inside the transducers and not in the transducer signal leads. Furthermore, a portion of the lead was removed and a fresh, clean portion of lead was stripped. The same resistance values were measured. The resistances were re-measured ( 14 days after the conclusion of the test) and, again, the values were low and approximately as before. The polyurethane jackets were then removed for visual inspection of the insides of the transducers. No indications of moisture were found. This suggests that either the insulation inside the transducers broke down (probably because of the temperature environment), or that undetected moisture did penetrate into the transducers. If the former is the case, further investigation would be required to determine just what was failing. If the latter is the case, then it would appear that the jacket or end seals failed, allowing moisture to enter. At this time, no firm conclusion can be drawn as to the cause of the decreased resistances for transducer Nos. 2 and 3.

\subsubsection{Corrosion of the Flat Transducers}

The flat stainless steel transducers which were tested in the saline solution all showed signs of corrosion. The most serious corrosive activity was localized in the region of the weld zone on the edges of the transducers. Figure 5 shows a cross section of the transducer sheath and indicates the region of most severe activity.

Microscopic examination of the transducer revealed pitting in many areas along the length of the transducer. Most of the severe pits were localized to the region beneath or near the overlapped lip of the weld zone, as indicated by Figure 5. The pit diameters ranged from the lower limit of the optical resolution, $0.25 \mu \mathrm{m}\left(10^{-4} \mathrm{in}\right)$, to about $25 \mu \mathrm{m}\left(10^{-3} \mathrm{in}\right)$. Pit depths ranged from some that were shallow and superficial to others that penetrated the full $125 \mu \mathrm{m}\left(5 \times 10^{-3}\right.$ in) sheath thickness. There seemed to be little correlation between pit diameter and pit depth. The pits which penetrated the sheath had diameters over the full range from 0.25 to $25 \mu \mathrm{m}$.

10 Manufacturer's information specifies $100 \mathrm{M} \Omega$; drawing No. 28107211, sheet 1 of 2 , dated 3-1-73, note 16 .

11 Proposed draft MIL spec MIL-T-XXXXX, Transducer, Motional Pickup TR-299/G( ) dated 4-10-75. Paragraph 3.3.1.6, specifies $100 \mathrm{M} \Omega$. 


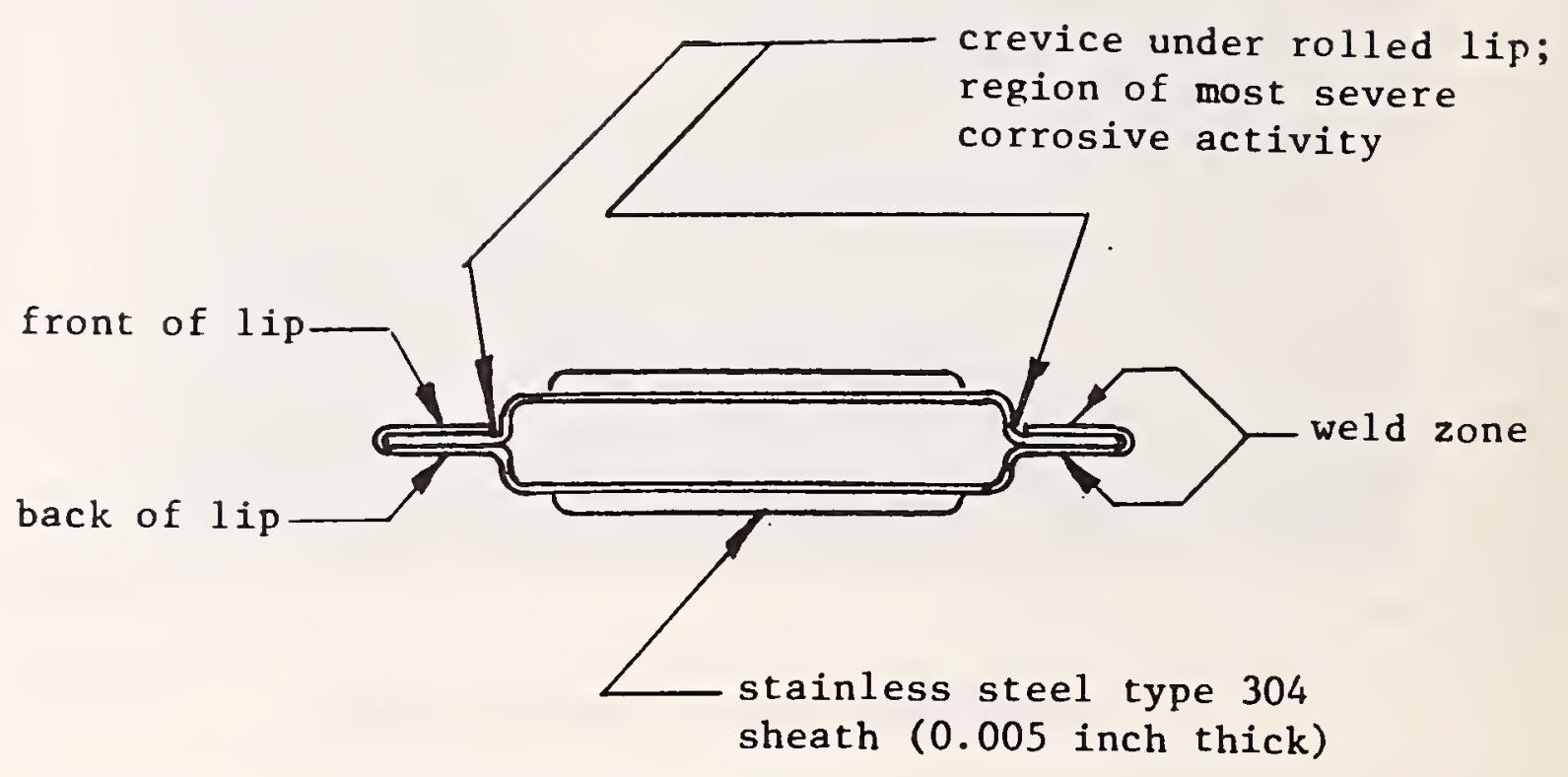

Figure 5. Cross section of a flat transducer showing region of most severe corrosion activity. 


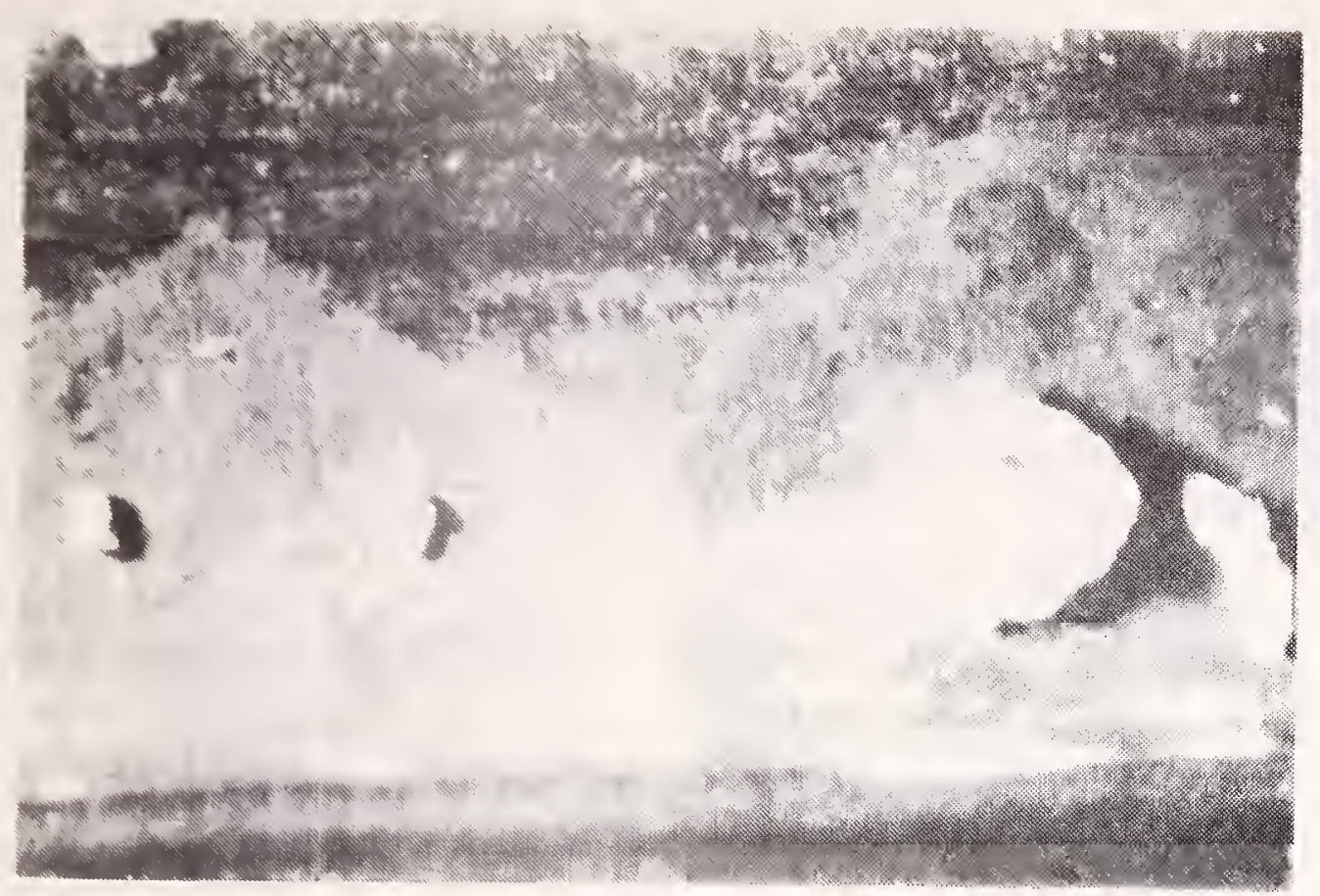

Figure 9. "Salt domes" and "whisker" on back of 1ip, transducer 7B, location 74 (20x magnification).

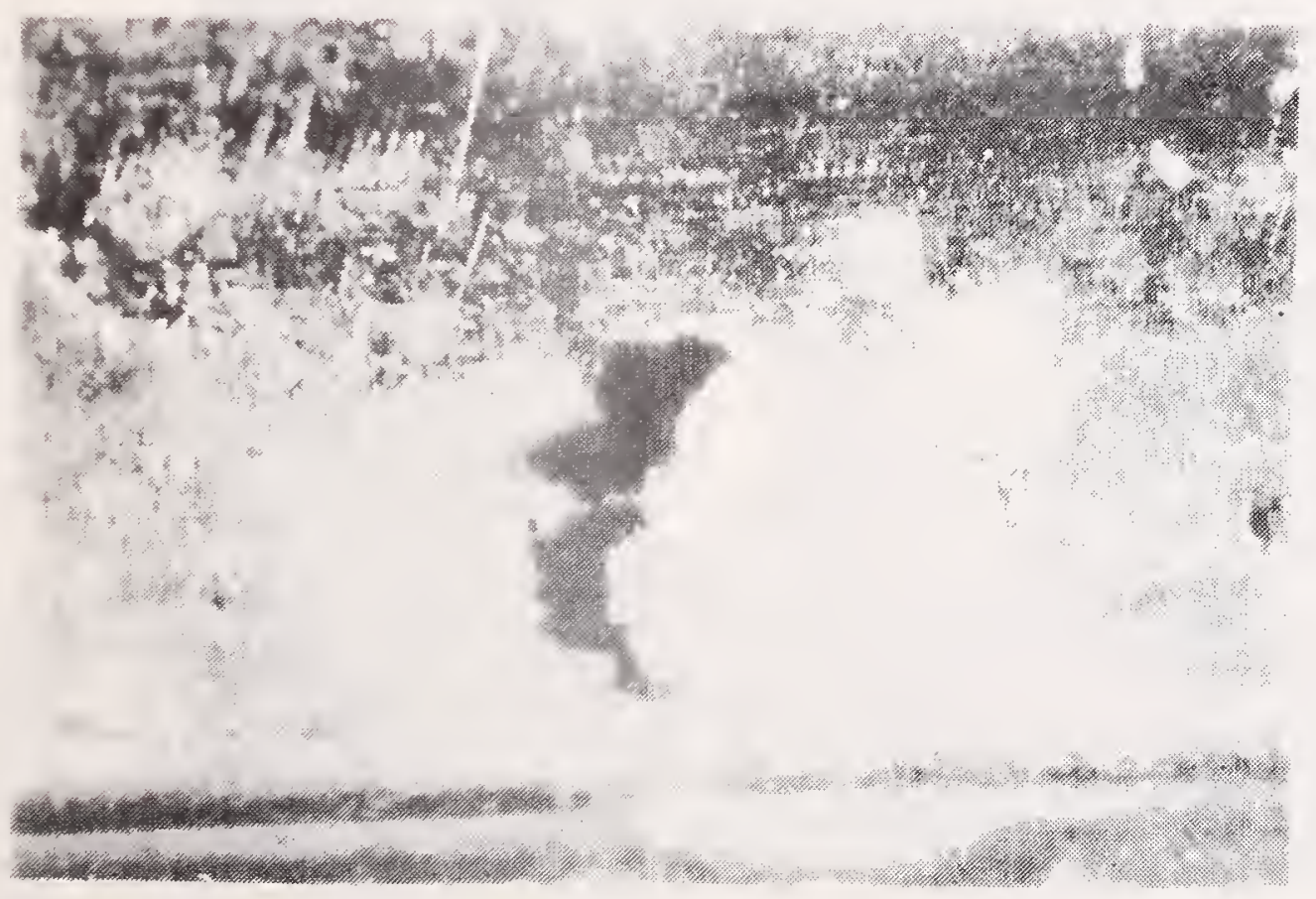

Figure 10. "Salt domes", front lip of transducer 7B, location 47 (20x magnification). 


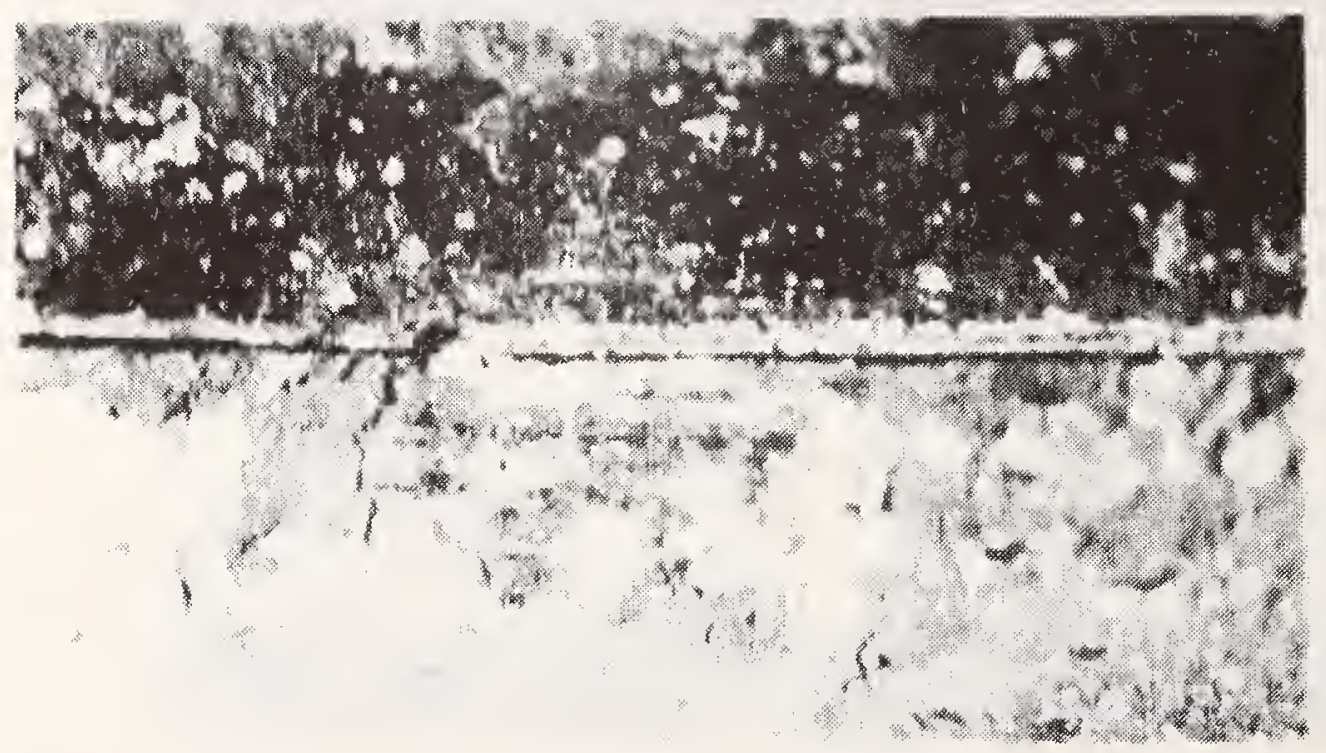

Figure 11. Severe pit corrosion at lip crevice, transducer 7B, location 47. Salt shown in Fig. 6 washed clear (80x magnification).

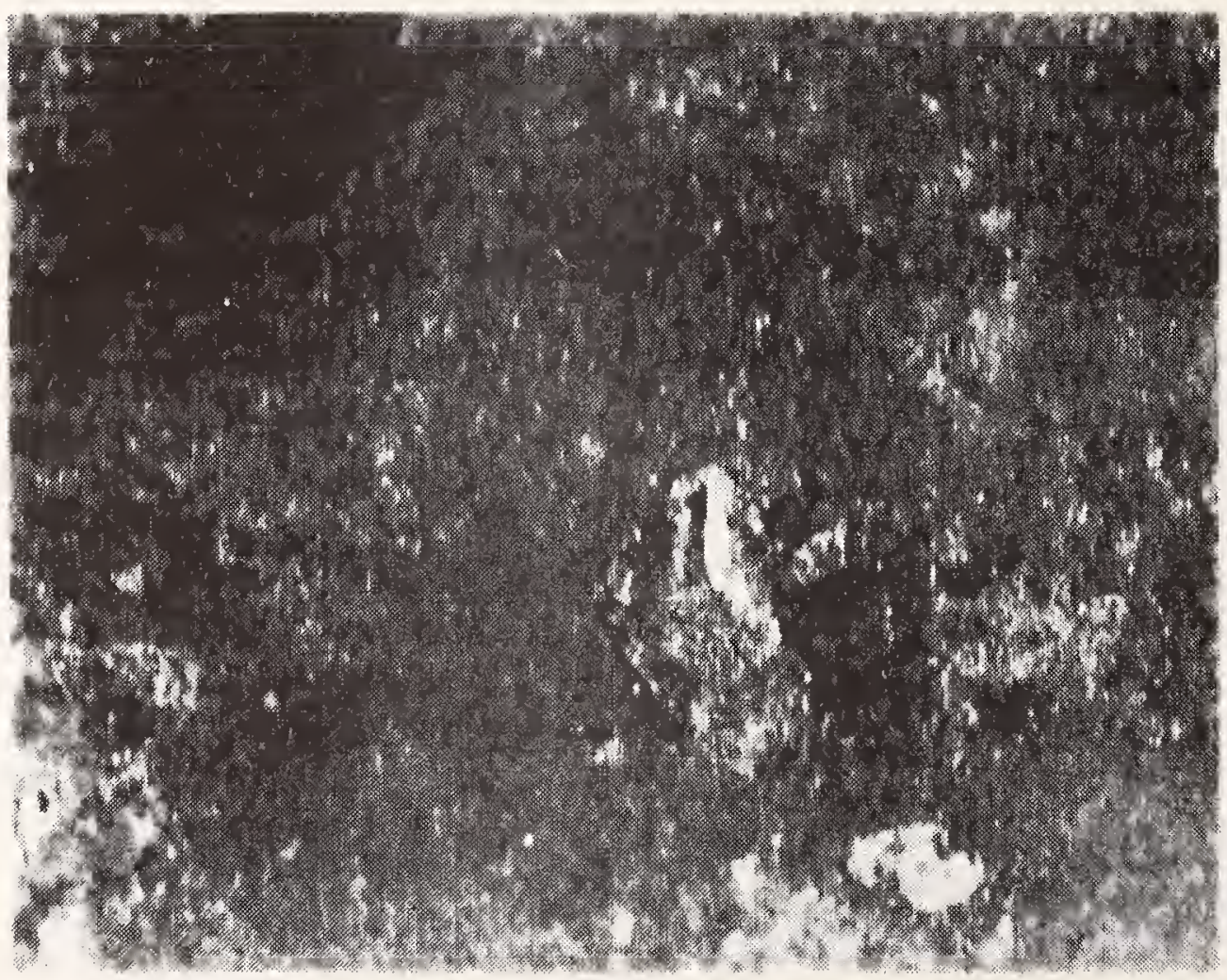

Figure 12. Small elongated pit which penetrated transducer 7B, location 74, back lip. Salt shown in Fig. 7 washed clear ( $80 \mathrm{x}$ magnification). 
The pits that penetrated the sheath allowed saline solution to enter, and the liquid then propagated inside the transducer. After removal of the transducers from the test tank, they were wiped clean with a sponge and water, and laid horizontally to dry. After several days, saline solution emerged from the penetrated pits and the salt dried, thus marking those particular pits which caused leaks. Figures 6 through 10 show small "salt domes" where the liquid had emerged and dried. Pits that did not penetrate the sheath did not contain sufficient saline solution to cause any noticable buildup of salt. This technique was successful in locating extremely small pits which had penetrated. For example, in Figure 9, note the two small salt domes to one side of the large hollow dome, and also the salt whisker to the other side. These microscopic pits are a small fraction of $25 \mu \mathrm{m}$ in diameter, yet penetrate the full thickness of the sheath.

Figures 11 and 12 show pits which penetrated. The corrosion shown in Figure 11 began in the crevice at the edge of the overlapped lip in the weld zone. In a length of about $400 \mu \mathrm{m}$, there were several pits which penetrated. Also note that the upper lip of the lap was corroded in a semicircular shape. Figure 6 shows this same region prior to removal of the salt, at somewhat less magnification. Figure 12 shows a cell which had a long slender track of corrosive activity. It had also penetrated the sheath. These illustrate typical corrosive pits found in the sheaths of the transducers.

It is well known that solutions containing chloride ions attack the family of 18-8 stainless steels. The pit-type of corrosion which occurs in type 304 stainless steel in sea water is well documented $[3,4,5]$. Pits begin by the failure of passivity at small selected regions at the surface. The breakdown is followed by the growth of an electrolytic cell, the anode of which is a microscopic area of active metal and the cathode is the large surrounding region of passive surface. Considerable current can flow in this small region, causing rapid corrosion at the small anode. The corrosion-resistant, passive metal surrounding the anode, and the passivity-destroying characteristics of the corrosion by-products within and very near the pit, force the corrosion to penetrate the metal rather than to spread along its surface.

The rate of pit penetration is influenced by many factors. Temperature, ion concentration, solution velocity, $\mathrm{pH}$, volume of dissolved oxygen, corrosion by-products, fouling, geometry, surface contamination, working history, residual stresses, heat treatment process, and weld process are the more important factors. It is difficult to control or to know each of the influencing factors in a test such as performed on the flat transducers.

It is impractical to attempt a comparison between the accelerated saline solution tests performed and real-life conditions because no meaningful time-scale factor is available. The most important results of the saline solution tests are knowing what kind of corrosion occurs and where it occurs. 


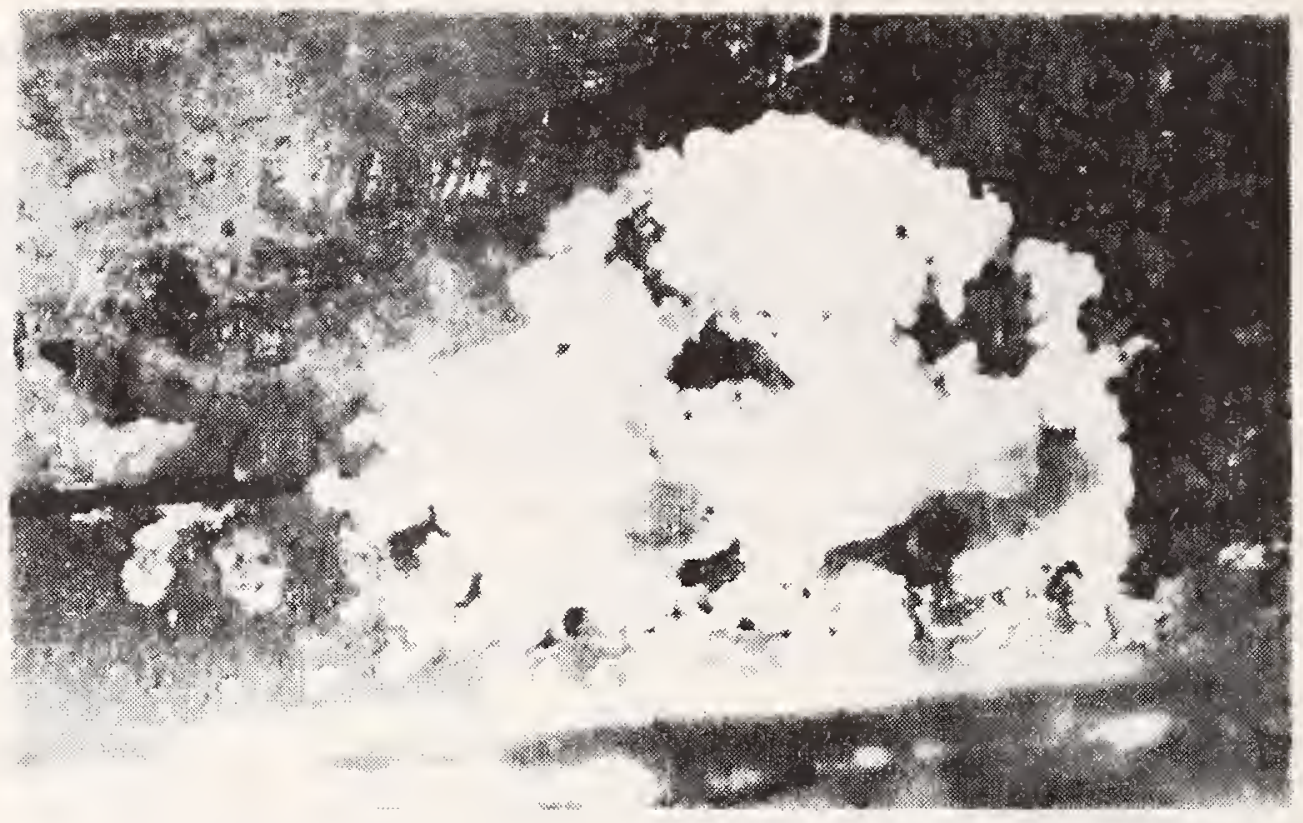

Figure 6. Dried "salt dome" on flat transducer 7B, location 47, at edge of overlapped weld zone.

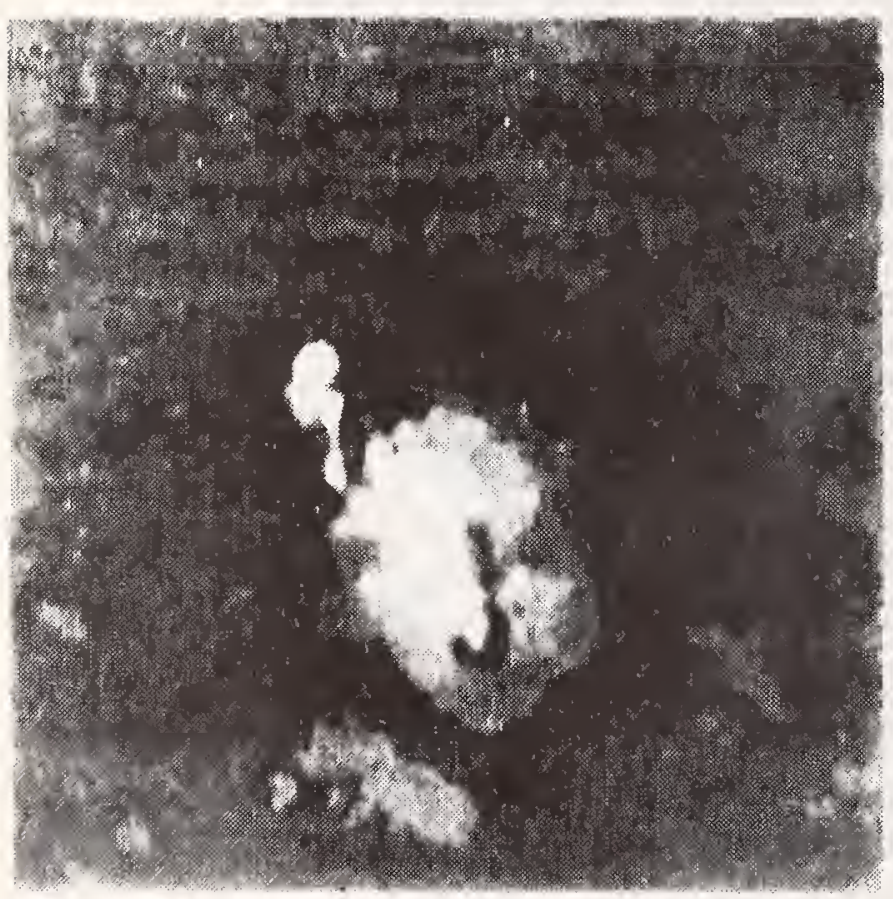

Figure 7. Small "salt domes" on flat transducer 7B, location 74, on back lip (40x magnification).

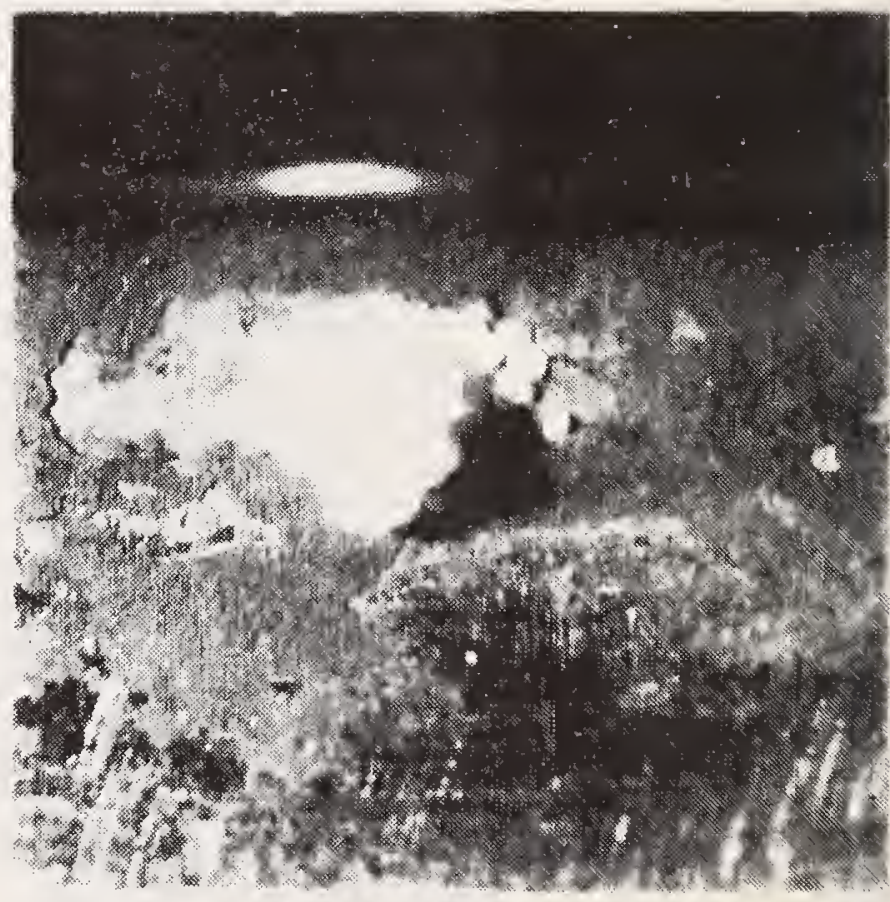

Figure 8. Small "salt dome", front lip of transducer 7B, location 47 (20x magnification). 
Buried transducers will not experience environments such as open sea water boiling saline solution. It is conceivable, however, that transducers will be deployed in beaches or other regions where salts (particularly chlorides) are in high concentration. It is, therefore, under these conditions that these results are relevent.

Comparisons can be made with other tests performed to evaluate the corrosion properties of type 304 stainless steel. Tests performed at kure Beach, N.C., in warm sea water just offshore, indicated pitdepth growth rates of about $1750 \mu \mathrm{m}\left(69 \times 10^{-3} \mathrm{in}\right)$ per year for type 304 stainless steel.12 At this rate, a $125 \mu \mathrm{m}\left(5 \times 10^{-3}\right.$ in) sheath thickness would be penetrated in about 26 days. Other references indicate severe pit-crevice corrosion under similar testing conditions, but fail to give pit-depth growth data.

Two other sources of information on the corrosion of stainless steel type 304 indicate somewhat different results. Reference 6.13 gives results for type 304 stainless steel buried for up to 14 years. It shows that the average maximum pit-depth penetration of the specimens ranged between 27.9 and $203 \mu \mathrm{m}\left(1.1 \times 10^{-3}\right.$ and $8 \times 10^{-3}$ in) per year. The average of all of the specimens over the entire 14-year period was about $56 \mu \mathrm{m}\left(2.2 \times 10^{-3}\right.$ in) per year. This suggests that a $125 \mu \mathrm{m}$ thick sheath could be penetrated in about two years under those conditions. The soil was classified as aerated, poorly drained, docas clay containing about 2 percent sodium chloride. It was also observed that the penetration rate was higher for the first six years of the test and that the rate slowed considerably after six years. No reason for the slowing was given. This is contrasted by a statement given in the same reference, pertaining to burial tests in other soils, that, "steels containing larger amounts of chromium and nickel (i.e., type 304)...were wholly resistant to corrosion. 14

Another reference [7] studied a variety of materials for use in shielding underground telephone cables. Stainless steel type 304 was among the materials examined. The test sites were selected to represent a wide variety of soil properties. The soil types were classified as, and located at:
Sagemoor sandy loam
Hagerstown loam
Clay
Lakewood sand
Coastal sand
Tidal marsh

Toppenish, Wash.
Loch Haven, Md.
Cape May, N.J.
Wildwood, N.J.
Wildwood, N.J.
Patuxent River, Md.

12 Reference 4, page 413, table 16 and associated discussion.

13 Reference 6, page 52, table 26, specimens $\mathrm{K}$ and $\mathrm{R}$.

14 Reference 6, page 49, discussion under High Alloy Steels. 
The chemical properties of these differ widely with respect to their composition and the amount of soluble salts. The $\mathrm{pH}$ of the soils ranged from about 4 to 8.8 . The electrical resistivity of the soils varied from about $55 \mathrm{ohm}-\mathrm{cm}$ (that of sea water) to about $30,000 \mathrm{ohm}-$ $\mathrm{cm}$. Aeration ranged from good to very poor. The soils selected included those which were known to be moderately corrosive to those which where very corrosive.

The stainless steel shields tested were parts of special cables intended for telephone usage. Six specimens were buried at each test site at depths of 3 to 4 feet. One specimen was withdrawn from each site each year for a total period of 6 years. The shielding material consisted of $125 \mu \mathrm{m}$ thick corrugated type 304 stainless steel sheath. 15

A rating system of 0 to 10 was used, where 0 meant total distruction of the specimen and 10 meant that the specimen was unaffected by corrosion, or "...excellent, unaffected, no indication of corrosion". 16

In all instances, these specimens were evaluated as having a rating of 10 for all soil test sites, including coastal sand and tidal marsh sites where chlorides are known to exist. Thus, in the 6 year perriod, no evidence of corrosion was apparent in 36 specimens buried at six different locations.17 Additionally, combinations of stainless steel and other materials used as composites were tested, with impressive results.

The apparent conclusion is that stainless steel type 304 is exce1lent for most applications of buried transducers but, according to reference 6 , one could expect to find soil and environmental conditions that might result in corrosion attack on the subject transducers. From the tests performed, it can also be concluded that if corrosion occurs, it will most likely be pit corrosion in the crevice region of the weld zone.

15 Reference 7, description of cables discussed under systems 17 and 18 .

16 Reference 7, Table 3.

17 The test in the coastal sand was for a period of 5 years. 


\subsubsection{Test for Stress Corrosion}

An important type of corrosion that needed examination was stress corrosion. To test for this, a $38-\mathrm{cm}$ (15-in) length of flat transducer was bent into a " $U$ " shape having a radius of about $4 \mathrm{~cm}$ ( $1.5 \mathrm{in}$ ). This produced a high tensile stress along the outer fibre of the transducer. The specimen was exposed to a boiling saline solution for an accumulated duration of 243 hours.

Microscopic examination of the transducer after exposure revealed no signs of stress corrosion; only pit and crevice corrosion, as previously described, was evident.

\subsubsection{Leaks at Ends of Flat Transducers}

Careful examinations were made at the terminations of both ends of each of the flat transducers. The "bell-shaped" adapter end fittings 18 at the end of the transducers, away from the cable, showed signs of leakage. The plugs ${ }^{19}$ soldered into the adapters were not water tight. The bonds on the transducers appeared sound, but the plugged ends leaked around the seam. It was the result of poor and inadequate soldering. The epoxy coatings over the ends did not help to any measurable amount. Several of the end plugs were physically removed, without heating, to permit inspection of the soldering and to check for signs of corrosion. The soldering was incomplete and, in several cases, the adapter ends were full of saline solution.

This is a serious source of leaks, especially because there are apparently no checks at this location during manufacturing. Leak tests are performed by the manufacturer prior to the soldering of the end plug into the adapter. A different method of applying the pressure for leak tests needs to be developed for use after the end plugs have soldered in place.

The adapter assemblies 20 and the hose adapters 21 at the cable ends of the transducers all appeared sound. All seven of the transducers which were exposed to the saline solution were inspected and none of them showed signs of leakage at this location.

18 Adapter end, manufacturer's part No. 28109835-001

19 Plug, manufacturer's part No. 28109836-001

20 Adapter assembly, manufacturer's part No. 28111427-001

21 Adapter hose, manufacturer's part No. 0103-4-4C 


\subsubsection{Changes in Polyurethane Jackets of Round Transducers}

Seven round transducers were subjected to the hot saline solution as described in section 2.1 of this report. Two physical changes of prinicipal interest was noted:

1) The hardnesses of polyurethane jackets decreased, and

2) The diameters of the jackets increased.

The main parameters of the test environment of interest are temperature and moisture. The saline content did not significantly affect the test results.

Jacket hardness was measured with a Shore A type A-2 dırometer. Care was taken to ensure that bridging of the measuring point did not influence the readings significantly. Also, great care was needed in placing the durometer on the curved surfaces. A technique was developed that proved sufficiently reliable. In addition, a number of readings were taken on each specimen at a number of different locations and the results averaged. Generally, no less than ten readings per specimen were used and readings occurring beyond one standard deviation from the first mean were removed from the final average.

Twenty-centimeter (8-in) specimens were tested in a beaker of boiling saline solution over a period of 320 hours prior to the beginning of the main saline solution test. The original hardness prior to exposure was measured as $88.5 \pm 0.1$. After 320 hours of accumulated exposure, the mean of the hardness measurements was $78.5 \pm 0.5$. (The uncertainties were computed on the basis of the one standard deviation values of the data.) This represents an average decrease in hardness number of 11.3 percent for 320 hours of exposure.

The specially fabricated 2.1-m long transducers (described in section 2.1) tested had an original Shore A durometer hardness of $86.8 \pm$ 2.3. After an accumulated exposure of 120 hours, the hardness was measured as $80.0 \pm 2.4$. This represents an average decrease of hardness number of 7.8 percent, for the 120-hour exposure, for the seventy locations measured.

Results contained in reference 8 for a number of polyether urethanes tested at various temperatures and humidities correlates reasonably well with these results. For example, a hardness decrease of 9 to 18 percent could be expected for testing performed at $97{ }^{\circ} \mathrm{C}$ and 95 percent relative humidity. It is known that immersion in boiling water is somewhat less severe than a noncondensing 95-percent relative humidity environment; therefore, a smaller decrease of hardness could be expected. The range of values measured in the present investigation are sufficiently close to those published results as to verify the test results. This is especially true when the specimen thicknesses and geometries are considered. 
References also showed that accelerated testing at elevated temperatures and moisture content follows the Arrhenius equation $[9,10]$. This equation permits the estimation of "failure" times at temperatures different from the test temperature. The Arrhenius equation is

$$
\ln \frac{t_{2}}{t_{1}}=c\left[\frac{T_{1}-T_{2}}{T_{1} T_{2}}\right] \text {. }
$$

Where $t_{1}=$ time to reach a criterion at temperature $T_{1}$,

$t_{2}=$ time to reach the same criterion at temperature $T_{2}$,

$\mathrm{T}_{1}=$ absolute temperature at which $\mathrm{t}_{1}$ was determined,

$\mathrm{T}_{2}=\mathrm{absolute}$ temperature at which $\mathrm{t}_{2}$ was determined, and

$C=$ a constant related to the chemical reaction rate and slope of the activation energy line.

The constant $C$ has been determined for a family of urethane polymers and is sufficiently close to $\mathrm{C}=8800 \mathrm{~K}$ so as to permit calculations based on this value.

It is desirable to find an estimate of time $t_{2}$ for which the jacket would have decreased its hardness by the same percentage (i.e., 7.8 percent) at some lower temperature, such as encountered in the soil, rather than the elevated test temperature. If it is assumed that the soil temperature were held at a constant $10^{\circ} \mathrm{C}\left(50^{\circ} \mathrm{F}\right)$, then

$$
\begin{aligned}
& \mathrm{T}_{1}=373 \mathrm{~K}, \\
& \mathrm{~T}_{2}=283 \mathrm{~K}, \\
& \mathrm{t}_{1}=120 \text { hours }=5 \text { days, and } \\
& \mathrm{C}=8800 \mathrm{~K} .
\end{aligned}
$$

Rearranging equation ( 1 ) and solving for time $t_{2}$,

$$
t_{2}=t_{1} \ln ^{-1} C\left[\frac{T_{1}-T_{2}}{T_{1} T_{2}}\right]
$$


From this equation and the values shown above $t_{2} \simeq 9066$ days $\simeq$ 25 years. Thus, at a temperature of $10^{\circ} \mathrm{C}$, the polyurethane jackets could be expected to decrease their hardness numbers from an original value of 86.8 to 80 in about 25 years. Under these conditions, the accelerating test factor is 1813; each 6 hours of test performed at $100{ }^{\circ} \mathrm{C}$ was equivalent to about 1.25 years of service at $10{ }^{\circ} \mathrm{C}$.

In some typical areas, where these transducers may be deployed, the soil temperature may exceed $10^{\circ} \mathrm{C}$ for periods of summer days and may cool to values less than $10^{\circ} \mathrm{C}$ in the night. Moreover, during winter months, the temperature will likely be less than $10{ }^{\circ} \mathrm{C}$. It is felt that the selection of $10{ }^{\circ} \mathrm{C}$ as an arbitrary value is conservative when an average temperature over a year's time is considered. The aging effect is cumulative and irreversible and, therefore, the slower aging rates at colder temperatures can be calculated with equation (2) and combined with the rates at higher temperatures to simulate different winter and summer aging.

The decrease in hardness number of about 8 percent, resulting from the 120 hours of test, does not constitute a failure limit of transducer usefulness. Certainly, some lower values of hardness could be tolerated, but how much is not known. It should be emphasized that hardness alone is not the sole parameter of jacket durability. The material may fail due to low values of tensile or compressive strength, tear strength, dielectric strength or other parameters. Relationships, if any, between Shore A hardness and these other parameters are not known. However, in the limit of durometer hardness of $\leq 1$, the estimated failure time for these materials at $10^{\circ} \mathrm{C}$ can be extrapolated to somewhere between 2000 and 60,000 years. Undoubtedly, some other failure mechanism would occur first. These examples do, however, serve to show that due to temperature and high humidity, polyurethane jacket material would not be expected to degrade seriously for several decades.

It was noted that the jackets of the transducers loosened around the braided shield beneath it. It was possible to slide the urethane jacket back and forth for a small distance along a transducer's length, or to twist the jacket around the transducer, after exposure to the test environment. Attempts to measure the change in jacket thickness (or jacket diameter) were unsuccessful. The transducers were sufficiently out-of-round as to require a multitude of dispersed measurements.

Furthermore, the urethane jacket material varied by as much as $2: 1$ in thickness on some of the transducers. The change of thickness or diameter due to testing is only a small part of these dimensional variations due to manufacturing inconsistencies. With some careful experimental planning, the dimensional changes needed to estimate material property changes could possible be determined, but it was felt not worthwhile at this time. 


\section{RESISTANCES TO FREEZE-THAW CYCLES}

This work was done to satisfy the requirement of Task B. Flat and round transducers were exposed to a cycling temperature environment over a range from nominally $-18{ }^{\circ} \mathrm{C}$ to $38^{\circ} \mathrm{C}\left(0^{\circ} \mathrm{F}\right.$ to $\left.100{ }^{\circ} \mathrm{F}\right)$. Electrical leakage resistance was measured on all of the transducers and strain was measured on selected flat transducers.

\subsection{Description of the Freeze-Thaw Cycling Test}

Seven flat and seven round transducers were specially fabricated for the freeze-thaw cycling test. The transducers had a 1.06-m (42in) active nominal length exclusive of their leads. The flat transducers had leads similar to a normal transducer. The round transducers had leads selected for this test and are the same as those on the round transducers tested in the corrosive moisture test. (See section 2.1 for a description.)

Three of the flat transducers had small foil-type resistance strain gages attached to the folded edge of the stainless steel sheath in the weld zone at about mid-length. Transducers $1 \mathrm{~A}$ and $5 \mathrm{~A}$ each had four gages mounted on them while transducer No. 2A had only two gages. The gages were sealed against moisture with wax.

Each of the fourteen transducers were packed separately in sandfilled aluminum trays. Approximately two inches of sand were put in the tray, followed by careful placement of the transducer on the bed of sand. The top of each tray was then filled with sand for a total depth of approximately four inches and the sand was saturated with water. This required a total of about 700 pounds of sand and 14 gallons of water. The rack assembly was located horizontally in a freezer chest. A 2600-watt heater and an air circulating fan was also placed in the bottom of the freeze chest. Air and sand temperatures were monitored with a thermocouple and a strip-chart recorder.

The freeze portion of the cycle required about three days for the wet sand to reach $-18{ }^{\circ} \mathrm{C}$. It was kept at this low temperature for an additional day, making the freeze portion of the cycle normally four days long. The heating capacity was greater than the cooling capacity. It was, therefore, possible to thaw the frozen sand and raise its temperature to $37{ }^{\circ} \mathrm{C}$ easily, within one day. Thus, a normal freeze-thaw cycle was 5 days. ${ }^{22}$ The test profile provided ten complete freeze-thaw cycles.

22 On several occasions, the freeze portion of the cycle was extended by one or more days because of weekend or holiday schedules. In no instance was the heating portion of the cycle permitted to exceed one day. 


\subsection{Results of Freeze-Thaw Cycling \\ 3.2.1 Electrical Leakage Resistance}

Electrical leakage resistance was measured on each of the fourteen transducers subjected to the freeze-thaw cycling test. The resistance was measured between the shield and the sense coil/core circuits. The measurements were made similar to those for the hot saline solution test. 23

Table 3 gives the results of the measurements. Measurements were made at the end of each 4-day freeze period and at the end of each 1-day thaw period. (Measurements for the first and second freeze cycles were not made, only the "thawed" leakage resistances were taken.) A general trend was that the cold leakage resistance was usually somewhat greater than the warm resistance during thaw. The leakage at the low temperature was greater than $15 \mathrm{G} \Omega$ for transducers which did not fail. The leakage at the warmer temperatures was greater than $20 \mathrm{G} \Omega$ in most instances.

Notable exceptions are shown for flat transducers $2 \mathrm{~A}$ and $7 \mathrm{~A}$ and round transducer 27 . The resistance fell rapidly in transducer $2 \mathrm{~A}$ by the third freeze cycle. It was later determined that moisture had, indeed, penetrated the stainless steel jacket. No explanation for the lower "thawed" resistances in transducer $7 \mathrm{~A}$ is offered. The value did not fall below about $6 \mathrm{G} \Omega$ at anytime and, therefore, it was not considered a "failure". Round transducer 27 showed an unusual decrease at thaw in Cycle No. 4 and at freeze in Cycle No. 9. It is suspected that the recorded value of $420 \mathrm{k} \Omega$ should have been $420 \mathrm{G} \Omega$ and can, perhaps, be ignored as an anomaly. However, the value of $6 \mathrm{G} \Omega$ at cycle No. 9 was rechecked several times and did, in fact, exist. Apparently, the temperature cycling repositioned portions of the insulation, thus temporarily changing the internal leakage paths.

Overall, only one flat transducer (transducer $2 \mathrm{~A}$ ) and none of the round transducers failed.

\subsubsection{Mechanical Strain Measurements}

Flat transducer No. 2A was later pressure tested to find the location of the leak. Microscopic examination revealed it to be a crack in the weld zone very near the inside of the welded lip. It appeared that the jacket had skewed sideways by a small amount during the welding process and "weld nuggets" had been formed beyond the region normally welded. It is likely that residual stresses were present in this macro region. Reeling and unreeling in normal handling may also have aggrevated the region and initiated the small crack.

23 See section 2.2 .1 for a description of the measurements. 


\begin{tabular}{|c|c|c|c|c|}
\hline & 의 & 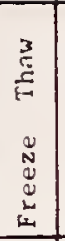 & 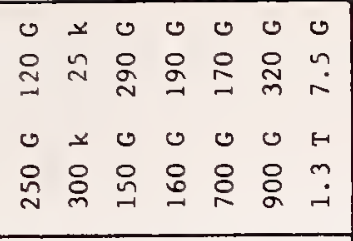 & 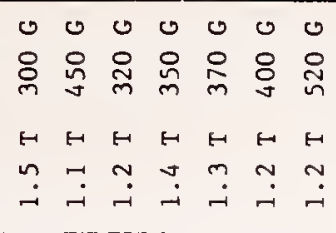 \\
\hline 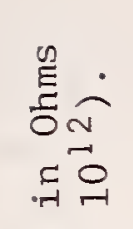 & $\sigma$ & 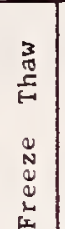 & 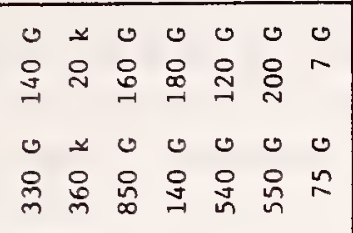 & 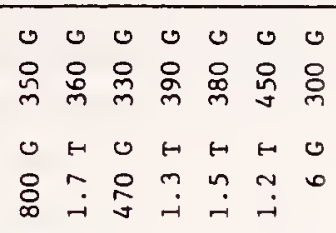 \\
\hline 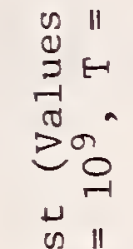 & $\infty$ & 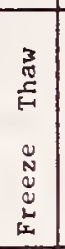 & 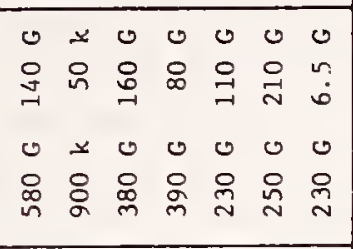 & 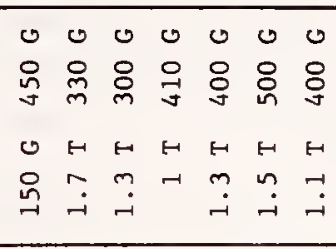 \\
\hline 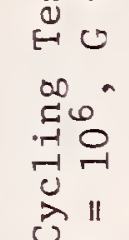 & & 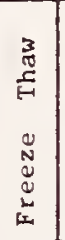 & 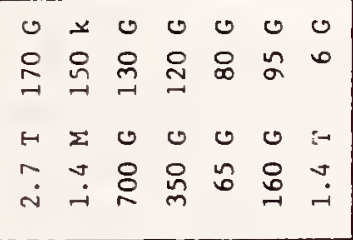 & 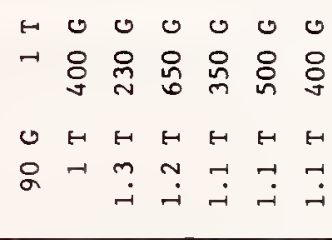 \\
\hline 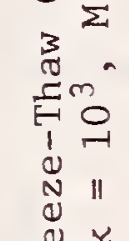 & $\therefore$ & 疍 & 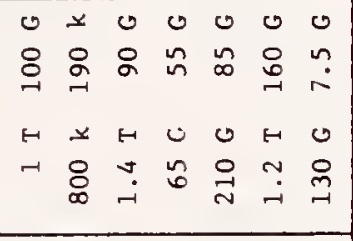 & 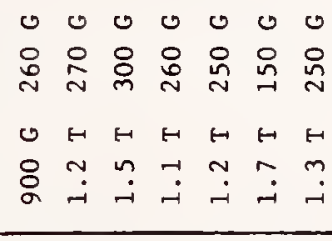 \\
\hline 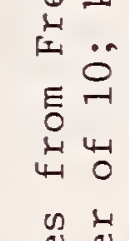 & - & 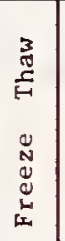 & 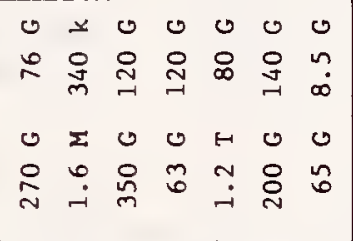 & 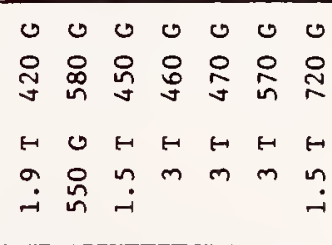 \\
\hline 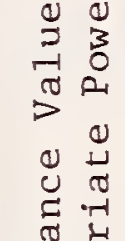 & & 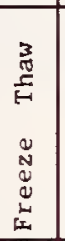 & 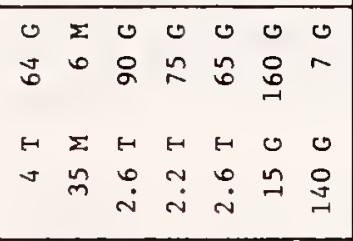 & 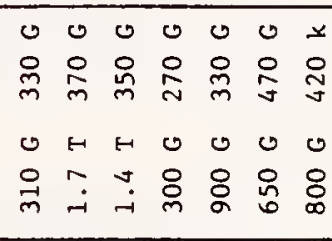 \\
\hline 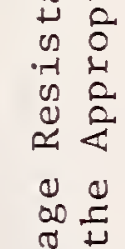 & & 蛋 & 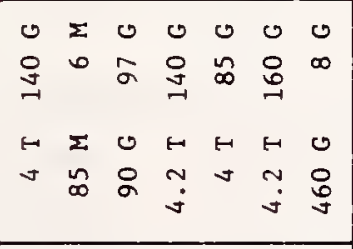 & 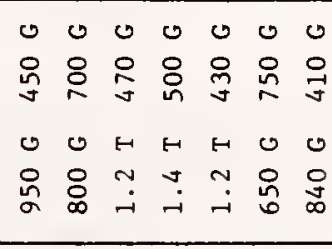 \\
\hline 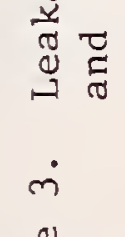 & & 总 & 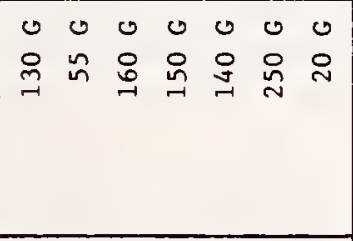 & 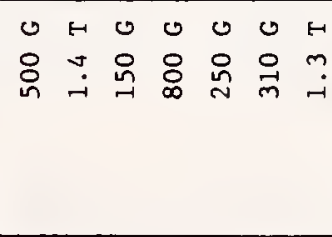 \\
\hline 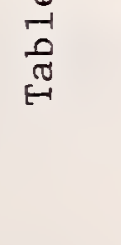 & & 蛋 & 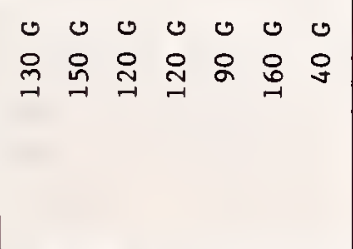 & 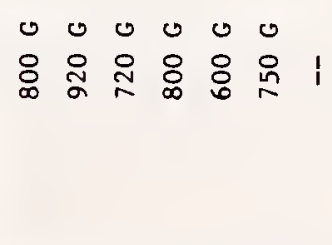 \\
\hline & & & 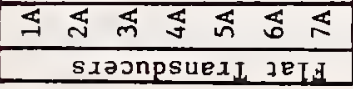 & 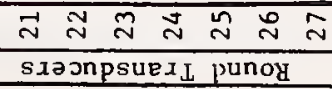 \\
\hline
\end{tabular}


Table 4 gives values of strain as measured on the three transducers instrumented with gages. In most cases, the strain increased with time. It is likely that the continual increase in measured strain was due to a slow repositioning of the transducers within the sand. The freezing and thawing action of the wet sand produced heaving, which could have caused the transducers to slowly change position. The first column of Table 4 shows the mean of the differences between the strains measured when frozen and when thawed. The maximum difference measured was $1526 \mathrm{x}$ $10^{-6}$ in/in. This occurred on transducer No. 2A during Cycle No. 4. The mean differences for transducer Nos. $1 \mathrm{~A}$ and $5 \mathrm{~A}$ were between about 300 and $500 \times 10^{-6} \mathrm{in} / \mathrm{in}$. The mean for transducer No. $2 \mathrm{~A}$ was $800 \times 10^{-6}$ in/in for Gage 2. There is some indication that transducer No. 2A experienced more strain than the other two; no reason is apparent.

The thermal expansion calculated from a linear coefficient of $8 \mathrm{x}$ $10^{-6}$ to $9 \times 10^{-6}$ (in/in) $/{ }^{\circ} \mathrm{F}$ for the full $100^{\circ} \mathrm{F}$ temperature difference is $800 \times 10^{-6}$ to $900 \times 10^{-6}$ in/in. This compares favorably with the measured values of strain difference which lie between $300 \times 10^{-6}$ and $800 \times 10^{-6}$ in/in on the average. The calculated values do not account for such factors as heaving of the freezing sand, nor that the ends were frozen in place prior to the center span of the transducers. If it is assumed that the transducers were free to expand and contract due to change of temperature while the sand was fully thawed, and that the two ends of each transducer were rigidly locked at the freezing point (i.e., $0{ }^{\circ} \mathrm{C}$ ), then the maximum tensile load would be about $311 \mathrm{~N}$ (70 1bf), based on the entire cross sectional area of the transducer. This, compared with the ultimate load capability of nearly $4900 \mathrm{~N}$ (1100 $1 \mathrm{bf})$, does not explain the crack noted in the weld zone. ${ }^{24}$ It is probable that the crack was initiated by handing or other effects, and that the freeze-thaw action merely aggravated it to where moisture could enter the transducer.

\section{RESISTANCE TO ROCK DAMAGE}

This work was done to satisfy the requirements of Task C. Both round and flat transducers were transversely loaded to determine the ultimate loads that could be sustained up to failure. Then, a number of specimens of round and flat transducers were loaded at one-half of their respective ultimate loads for a period of 100 hours. Comparisons of the types of failures are noted and discussed.

\subsection{Test Specimen Description and Test Procedure}

Ten round and ten flat sections of the transducers, nominally $25 \mathrm{~cm}$ (10 in) long, were prepared for the first portion of this test. The shields and outer insulation were removed from both ends of the

24 See section 6.1 of this report for the yield and ultimate load values determined by testing of the flat transducers. 
Table 4. Strain Measurements for Freeze-Thaw Cycle Tests Values given in table are strain in units of $10^{-6}$ in./in.

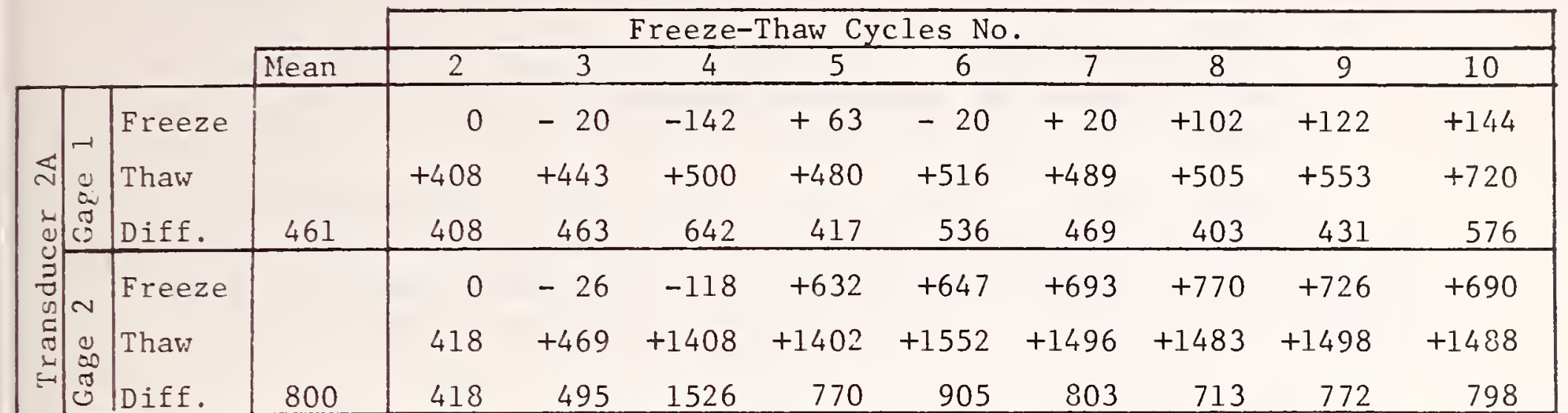

\begin{tabular}{|c|c|c|c|c|c|c|c|c|c|c|c|c|}
\hline & - & Freeze & & 0 & +58 & -57 & +112 & +8 & +71 & +100 & +35 & +60 \\
\hline & $\infty$ & Thaw & & +388 & +430 & +448 & +465 & +448 & +393 & +370 & +398 & +387 \\
\hline & 8 & Diff. & 366 & 388 & 372 & 505 & 353 & 440 & 322 & 270 & 363 & 327 \\
\hline$<1$ & 0 & Freeze & & 0 & 40 & -42 & 125 & 323 & 401 & 488 & 634 & 1185 \\
\hline-1 & $\underset{\infty}{0}$ & Thaw & & 349 & 395 & 464 & 408 & 785 & 768 & 922 & 1720 & 1862 \\
\hline 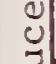 & 0 & Diff. & 502 & 349 & 355 & 502 & 283 & 462 & 367 & 434 & 1086 & 677 \\
\hline : & in & Freeze & & 0 & 40 & -42 & 125 & 36 & 95 & 203 & 105 & 242 \\
\hline$\underset{n}{\pi}$ & 0 & Thaw & & 349 & 395 & 464 & 408 & 467 & 442 & 455 & 482 & 508 \\
\hline & $\tilde{0}$ & Diff. & 351 & 349 & 355 & 506 & 283 & 431 & 347 & 247 & 377 & 266 \\
\hline & $m$ & Freeze & & 0 & 498 & -36 & 70 & -28 & 24 & 158 & 234 & 205 \\
\hline & $\underset{\infty}{\infty}$ & Thaw & & 338 & 414 & 547 & 358 & 393 & 412 & 448 & 511 & 477 \\
\hline & 0 & Diff. & 308 & 338 & -84 & 583 & 288 & 421 & 388 & 290 & 277 & 272 \\
\hline
\end{tabular}

\begin{tabular}{|c|c|c|c|c|c|c|c|c|c|c|c|c|}
\hline \multirow{3}{*}{\multicolumn{2}{|c|}{$\begin{array}{l}0 \\
-1 \\
0 \\
0 \\
0 \\
0\end{array}$}} & Freeze & & 0 & 198 & -106 & 125 & 87 & 111 & 164 & 196 & 192 \\
\hline & & Thaw & & 437 & 987 & 582 & 534 & 565 & 560 & 562 & 630 & 612 \\
\hline & & Diff. & 500 & 437 & 789 & 688 & 409 & 478 & 449 & 398 & 434 & 420 \\
\hline \multirow{3}{*}{\begin{tabular}{l}
\multirow{n}{n}{} \\
0 \\
0 \\
0 \\
0
\end{tabular}} & $\infty$ & Freeze & & 0 & 75 & 15 & 482 & 470 & 544 & 694 & 790 & 833 \\
\hline & & Thaw & & 487 & 554 & 853 & 878 & 960 & 1000 & 1062 & 1273 & 1336 \\
\hline & & Diff. & 501 & 487 & 479 & 843 & 396 & 490 & 456 & 368 & 483 & 503 \\
\hline \multirow{6}{*}{ 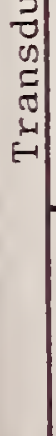 } & & Freeze & & 0 & -36 & 167 & 25 & -41 & -12 & 24 & 12 & 10 \\
\hline & $\begin{array}{l}0 \\
0 \\
0\end{array}$ & Thaw & & 492 & 497 & 530 & 468 & 455 & 432 & 415 & 431 & 428 \\
\hline & 0 & Diff. & 444 & 492 & 533 & 363 & 443 & 496 & 444 & 391 & $4: 19$ & 418 \\
\hline & & Freeze & & 0 & 11 & -92 & 100 & 54 & 72 & 132 & 103 & 98 \\
\hline & 0 & Thaw & & 287 & 307 & 375 & 366 & 388 & 368 & 366 & 377 & 388 \\
\hline & 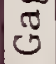 & Diff. & 305 & 237 & 296 & 467 & 266 & 334 & 296 & 234 & 274 & 290 \\
\hline
\end{tabular}


specimens. The shield, coil and core were then each made available separately for connecting into a test circuit. Three modes of failure could be detected:

an open sense coil,

a short between the shield and the coil, and

a short between the coil and the core.

A simple neon-lamp test circuit was assembled to indicate "shorts" and "opens" and is shown in Figure 13. As soon as the leakage resistances in the shield-to-coil or the coil-to-core circuits decreased to 200 $\mathrm{k} \Omega$ or less, the "short" indicators would illuminate. The open-coil indicator illuminate on as soon as the coil was cut open.

Both the round and flat MILES Transducer specimens were initially tested for simulated rock-damage resistance by impressing a known load transversely across them with a $6.4 \mathrm{~mm}$ ( $0.25 \mathrm{in})$ diameter, round steel rod. The steel rod was placed transversely to the length of the transducer at about its mid-length. The bottom of the transducers were supported on a simple flat steel surface. The load was smoothly increased with a universal testing machine until a failure was indicated.

Twelve specimens each of the round and the flat transducers, nominally $20 \mathrm{~cm}$ ( $8 \mathrm{in}$ ) long, were then continuously loaded at nominally one-half of their respective average failure loads for a duration of 100 hours. The failures were noted.

\subsection{Results of the Rock Damage Tests}

\subsubsection{Initial Tests}

For the ten round transducers tested first, the average ultimate load was $3.22 \mathrm{kN}(725 \mathrm{lbf})$, with a range of 2.29 to $4.29 \mathrm{kN}$ (515 to 965 lbf). Table 5 shows the failure loads and the types of failure. In three of the ten specimens, the failure was an open sense coil. In six of the ten specimens, the failure was a short between the shield and the sense coil. In one specimen, the sense coil opened simultaneously with a shield-to-coil short. There were no failures due to a short between the sense coil and the core.

For the ten flat transducers tested first, the average ultimate load was $17.66 \mathrm{kN}(3970 \mathrm{lbf})$ with a range of 16.04 to $18.90 \mathrm{kN}$ (3605 to $4250 \mathrm{lbf})$. The lower half of Table 5 shows the failure loads and the types of failure. In six of the ten specimens, the failure was a shield-to-coil short. For three of the ten, the failure was a coilto-core short. In one test, a shield-to-coil short occurred simultaneously with a coil-to-core short. There were no failures due to an open sense coil. 


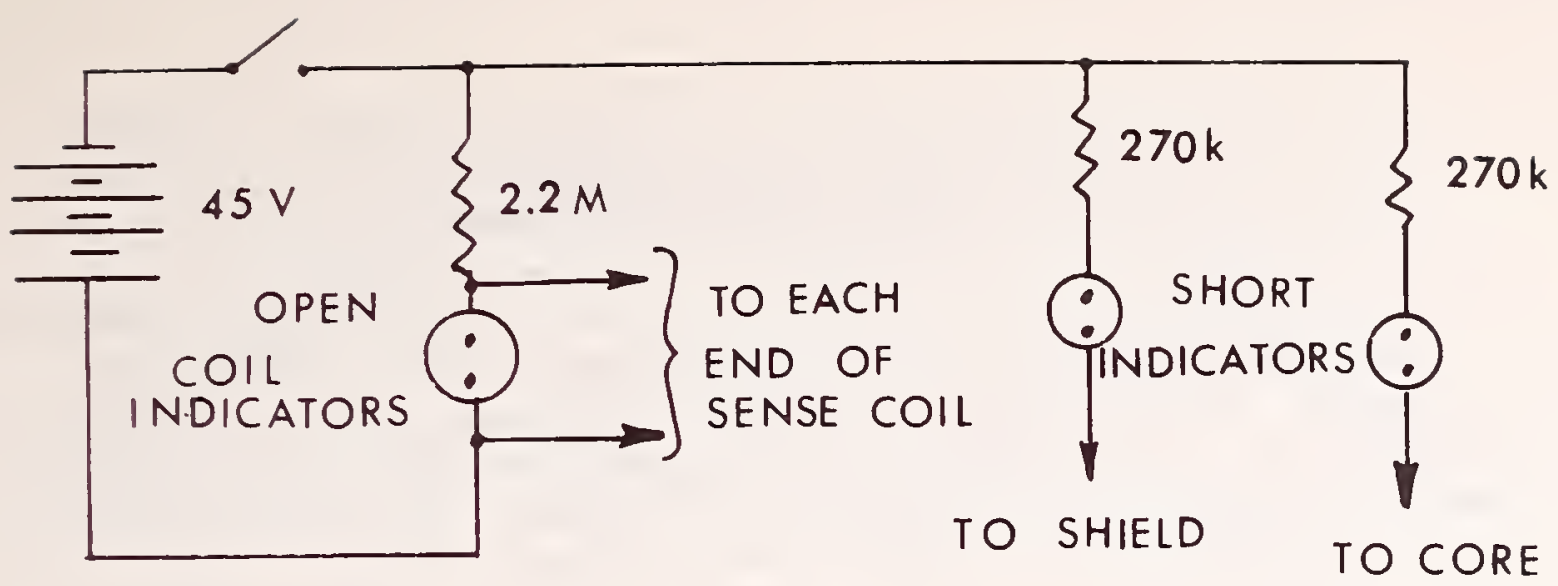

Figure 13. Simple indicator used in rock damage tests for detecting open coil or short between shield and coil or coil and core.

Table 5. Failure Loads for the $25 \mathrm{~cm}$ Specimens for Ultimate Load. (Rock Damage Tests)

\begin{tabular}{|c|c|c|c|c|c|}
\hline & & \multicolumn{3}{|c|}{ Failure Load, lbf } & \\
\hline & \multirow{2}{*}{$\begin{array}{l}\text { Specimen } \\
\text { Number }\end{array}$} & \multirow{2}{*}{$\begin{array}{l}\text { Open } \\
\text { Sense Coil }\end{array}$} & \multicolumn{2}{|c|}{ Short } & \\
\hline & & & Shield-to-Coil & Coil-to-Core & \\
\hline \multirow{10}{*}{ 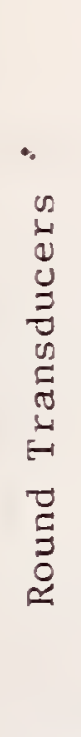 } & 31 & \multirow{10}{*}{685} & 920 & & 4 \\
\hline & 32 & & 770 & & in \\
\hline & 33 & & & & $\dot{d}$ \\
\hline & 34 & & 650 & & $\bar{n}$ \\
\hline & 35 & & 590 & & ]$_{\pi}^{\pi}$ \\
\hline & 36 & & 620 & & 急 \\
\hline & 37 & & 965 & & $\ddot{\Xi}$ \\
\hline & 38 & & & & $\overbrace{-\pi}^{-1}$ \\
\hline & 39 & & & & 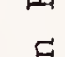 \\
\hline & 40 & & 725 & & $\sum_{\Sigma}^{\infty}$ \\
\hline \multirow{10}{*}{ 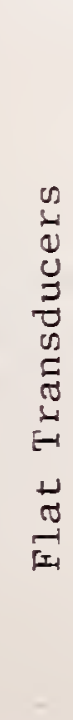 } & 41 & & & 3800 & $w$ \\
\hline & 42 & & & 3825 & 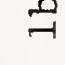 \\
\hline & 43 & & 3930 & & $\overbrace{n}^{2}$ \\
\hline & 44 & & 4250 & & $\|$ \\
\hline & 45 & & 4090 & & $\vec{\pi}$ \\
\hline & 46 & & 4205 & & 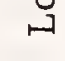 \\
\hline & 47 & & 3950 & & 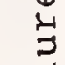 \\
\hline & 48 & & 3335 & & $\pi$ \\
\hline & 49 & & & 3605 & $E$ \\
\hline & 50 & & 4180 & 4180 & $\stackrel{⿱ 丷 N}{\Sigma}$ \\
\hline
\end{tabular}




\subsubsection{One Hundred-Hour Tests}

During the 100-hour, half-load test, one of the twelve round transducers failed immediately upon the application of the "half load". The "half load" for the round transducers was nominally $1.670 \mathrm{kN}$ (375 $1 \mathrm{bf})$ and $9.074 \mathrm{kN}(2040 \mathrm{lbf})$ for the flat transducers. Each transducer was checked seven hours later and no additional failures were noted. At the end of 100 hours, two additional failures had occurred. In each of the three failures of the round transducers, the failure was a short between shield and the coil. Table 6 shows the times to failure for the 100-hour test.

For the flat transducers during the 100-hour test, two failed immediately upon the application of the "half load"; both were coilto-core shorts. At the end of seven hours, another flat specimen failed; it was a shield-to-coil short. At the end of 100 hours, no further failures had occurred. In.all, three flat transducers failed. Table 6 shows the times to failure for the 100-hour test.

Figure 14 shows a photograph of the damaged shield of round transducer specimen No. 52 after the conclusion of the 100-hour test. This was typical of all of the round transducers. The braided shield is deformed with a number of individual strands cut.

Figure 15 is a photograph of round transducer specimen No. 37. The urethane jacket, braided shield, polyester insultation and polytetrafluoroethylene insulation have been removed from over the sense coil. A break in the sense coil can be seen. Also, one strand of the inner core can be seen directly beneath the broken sense coil. In all instances where the coil opened, it was a result of the load crushing a turn of the coil against a predominant strand of the inner core. In this particular case, a coil-to-core short also occurred.

Figure 16 shows the sense coil of flat transducer specimen No. 71 after the 100-hour test. Note how the turn of the coil has been flattened and spread apart. Figure 17 shows the same transducer with greater magnification. The insulation on the coil wire can be seen to be "blistered". This is a result of the copper wire being flattened and the insulation being unable to "stretch" as much as the wire. This left holes in the insulation where bare copper material is exposed. This happened on both sides of the copper conductor.

A polyester tape was used as an insulating material between the coil and the core. When a coil-to-core short occurred, the polyester tape insulation was squeezed so thin that it finally spread open, leaving the core bare. Figure 18 shows an instance where the core was exposed through small holes in the polyester tape for flat transducer specimen No. 72 . 
Table 6. Time to Failure for Half-Ultimate Load $20 \mathrm{~cm}$ Specimens, Rock Damage Tests. (Load on round transducers $=37 \mathrm{~b} 1 \mathrm{bf}$; load on flat transducer $=2043 \mathrm{lbf}$ )

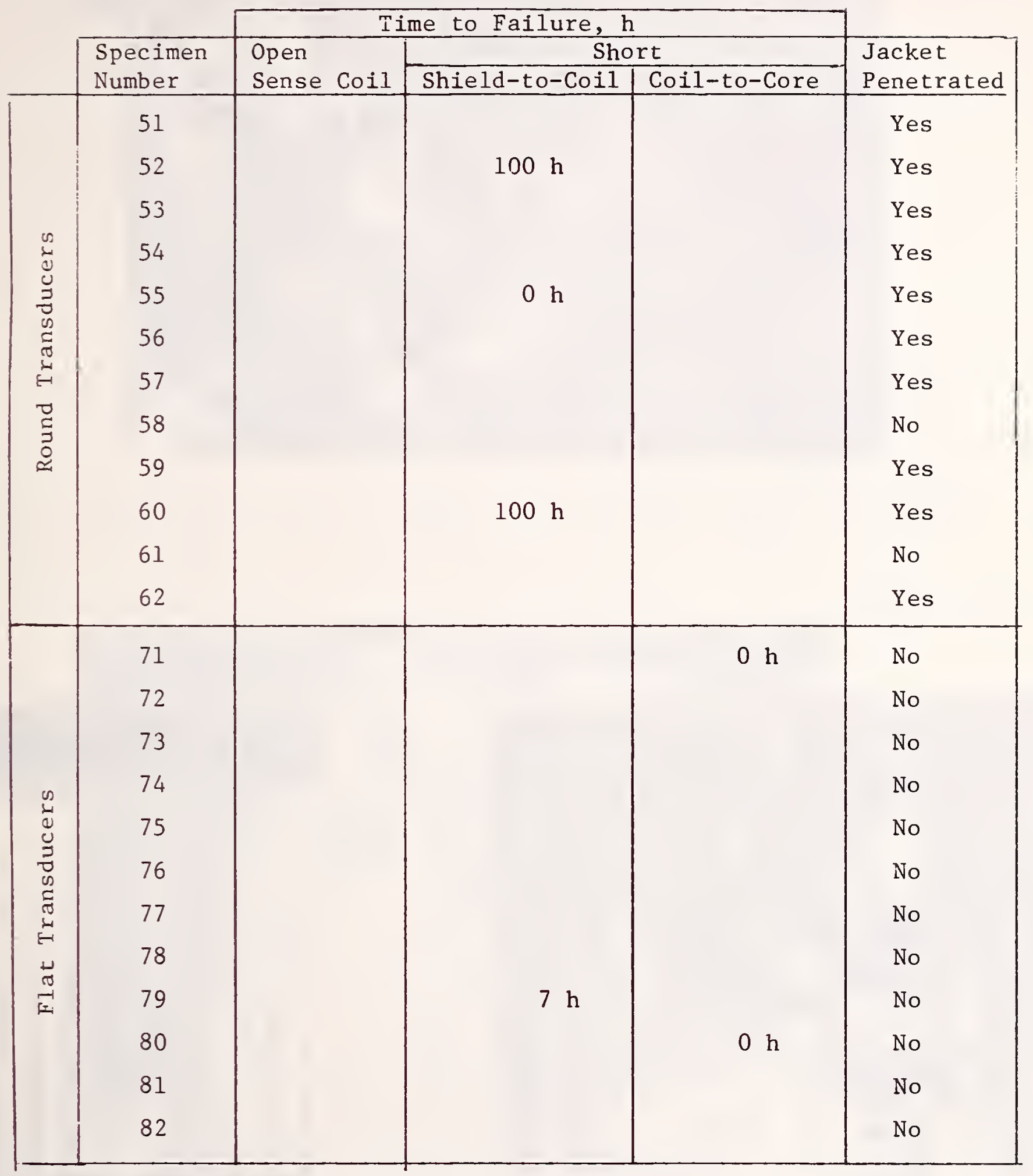




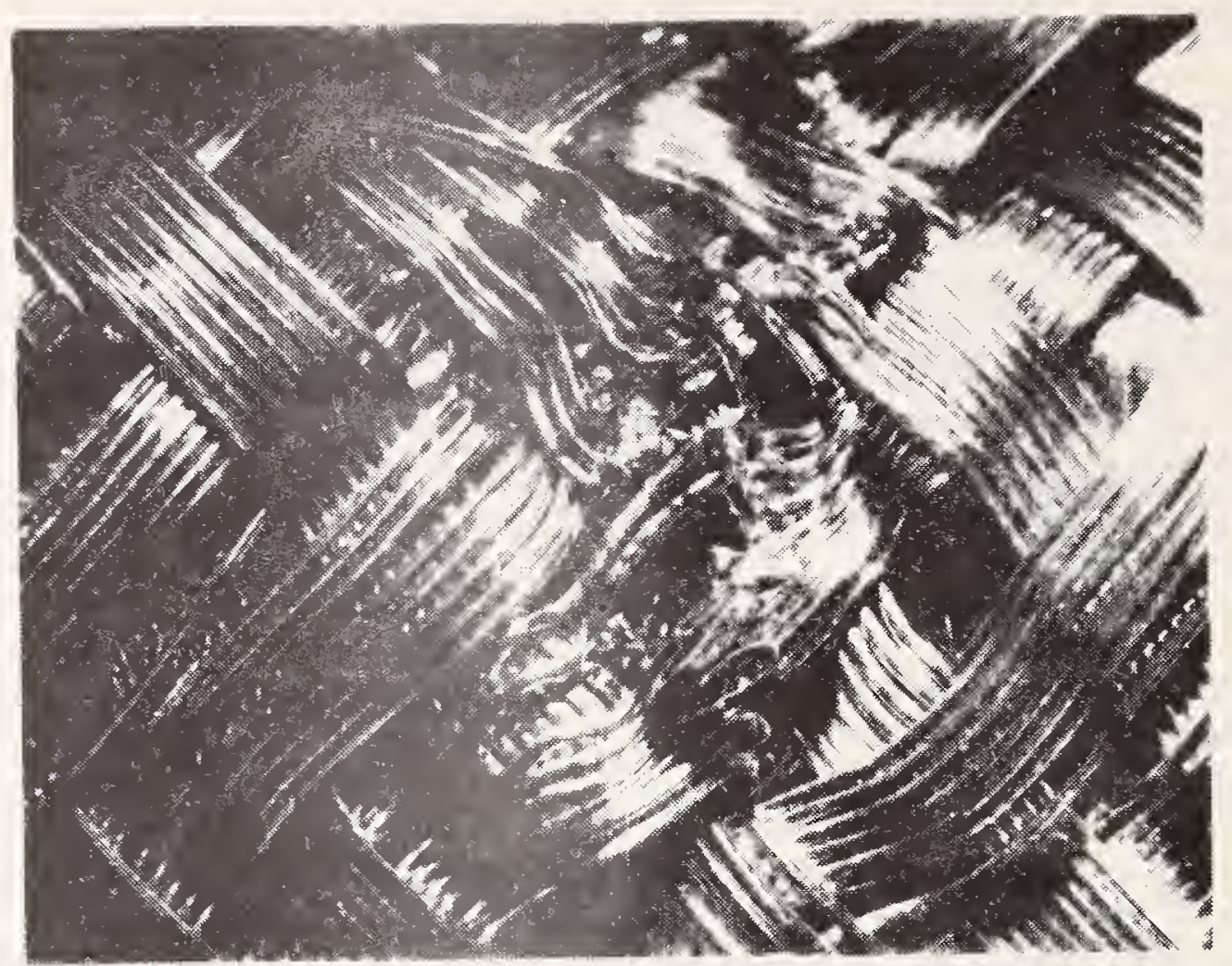

Figure 14. Damaged braid shield of round transducer specimen No. 52 after a 100-hour exposure at a 375-1bf load.

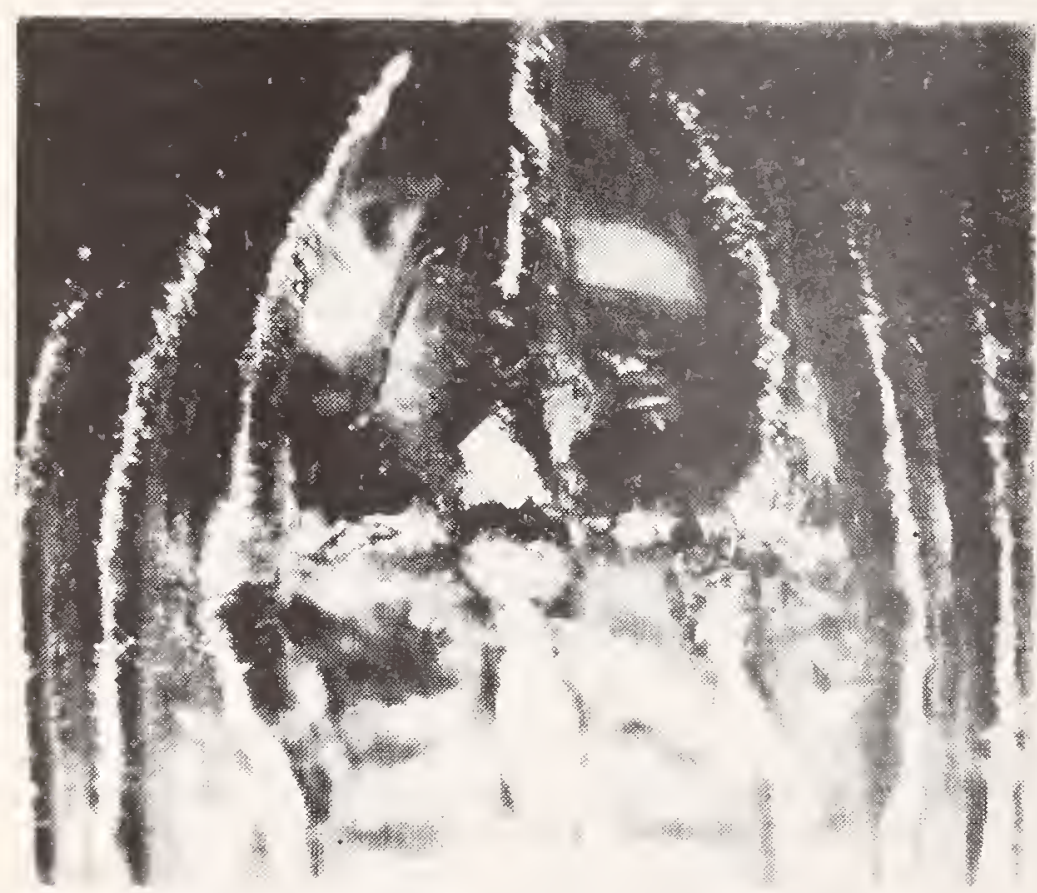

Figure 15. An open sense-coil winding of round transducer specimen No. 37.

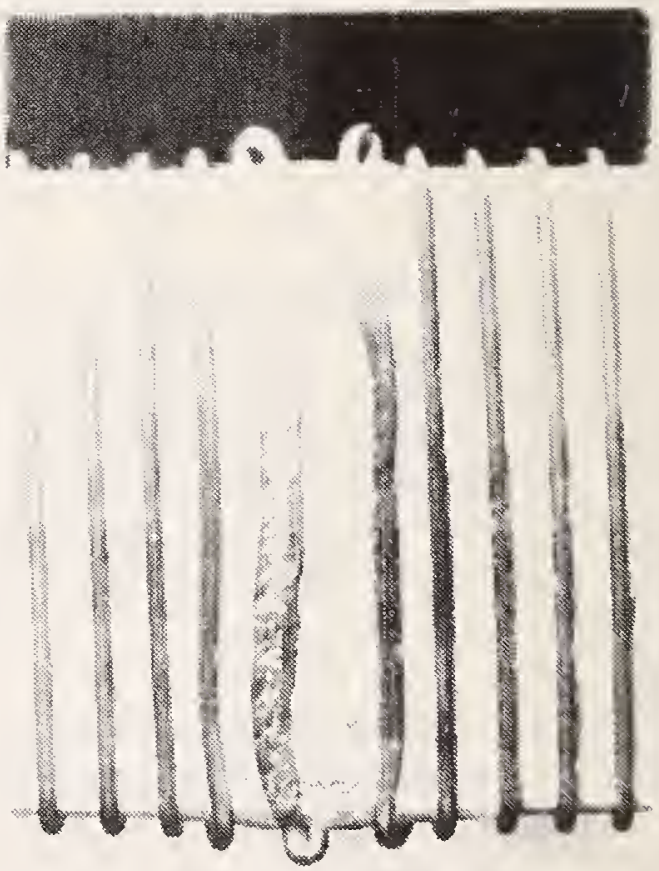

Figure 16. The sense-coil winding of flat transducer specimen No. 71 after a 100-hour exposure at a 2043-lbe load. 


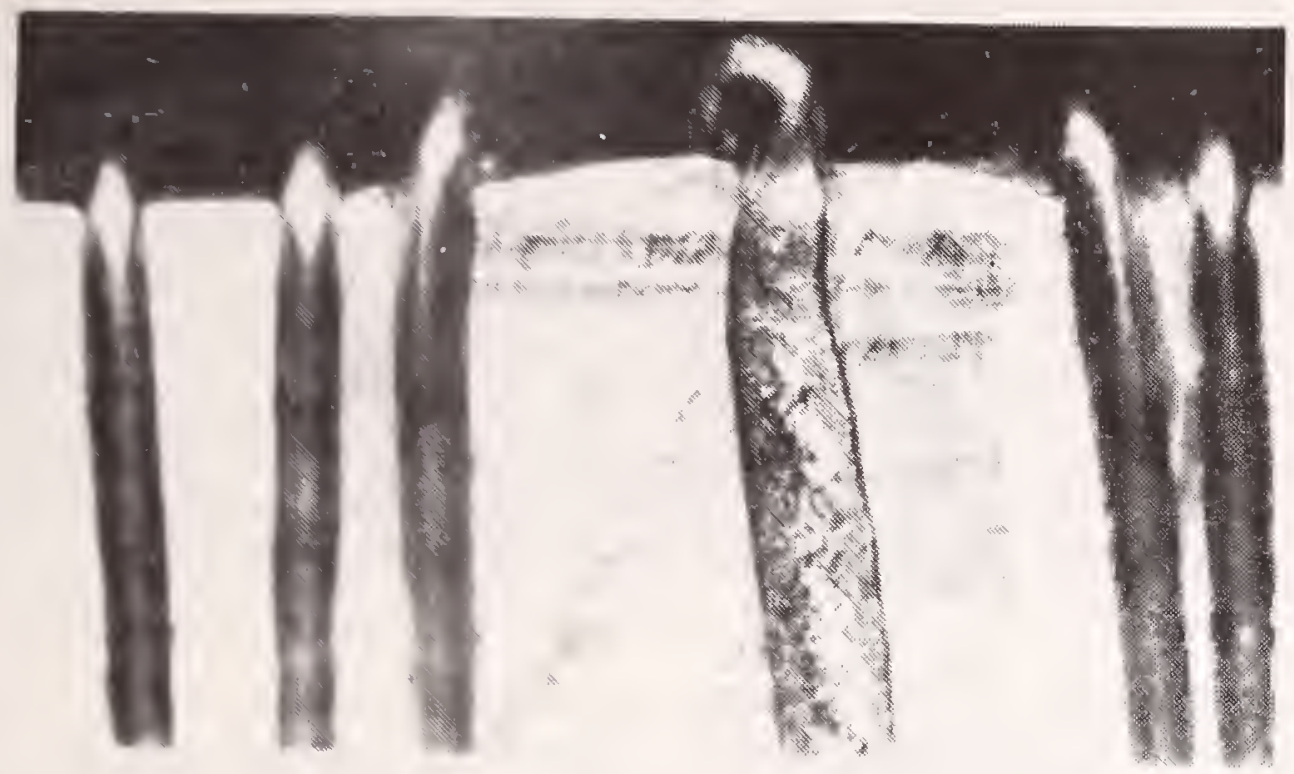

Figure 17. Smashed sense coil for flat transducer specimen No. 71 after an exposure ós 100 hours at a 2043-1bf load.

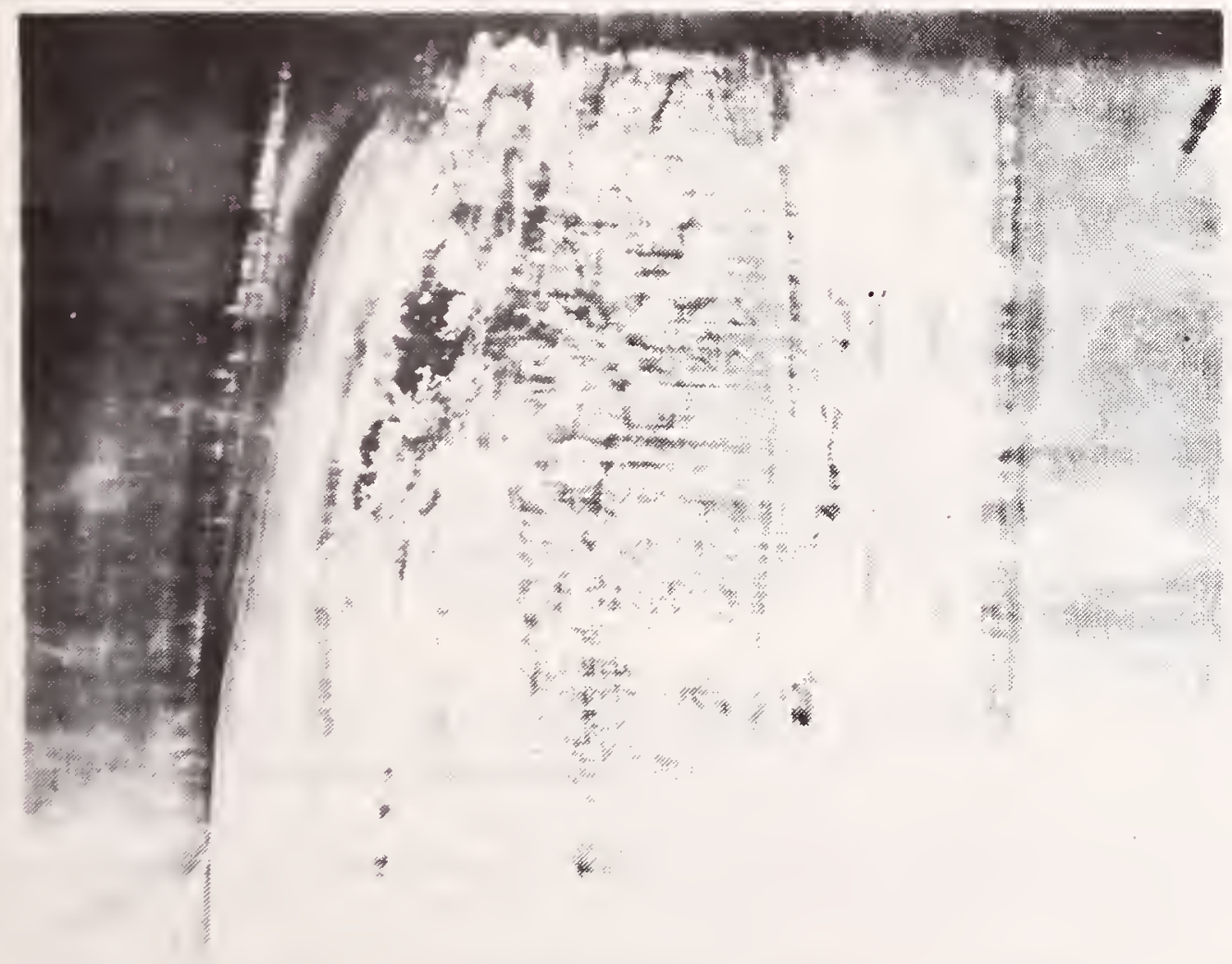

Figure 18. Damaged polyester tape insulation on flat transducer specimen No. 72. Note holes exposing core material beneath insulation. 
For each of the ten round transducer specimens tested to a "full load" failure, nine of the ten polyurethane jackets crushed to the point where a hole had penetrated completely through the outer jacket material. For the "half load" tests, ten of the twelve jackets ruptured. So, even though only a few had failed electrically, ten would have been rendered unuseable because of a penetrated jacket. Therefore, the true failure of the round transducers was not the electrical opens and shorts but more importantly, the penetrations of the outer polyurethane jacket material. The load at which the jacket was penetrated was not determined, but was generally less than the $1.670 \mathrm{kN}$ (375 1bf) test load used. In no instances were the stainless steel sheaths penetrated in these tests, not even under the full ultimate loading of as much as $18.90 \mathrm{kN}$ (4250 1bf).

A variety of load-bearing geometries could have been used; however, a comparative test of both the round and the flat transducers was desired, under similar test conditions. In a test performed by other experimenters, ${ }^{25}$ the use of a $8 \mathrm{~mm}$ (5/16 in) diameter round rod led to an average load-bearing strength of $1.61 \mathrm{kN}(363 \mathrm{lbf})$ for the round transducers. They also stated that the flat transducers appeared to be at least 150 percent stronger than the round transducers. These conclusions are supported by the testing discussed in this report.

Overall, and under the conditions of these tests, the flat stainless steel transducers proved far superior to the round transducers. The flat transducers could sustain a load more than five times that of the round transducers.

\section{DURABILITY OF POLYURETHANE JACKETING}

The jacketing material is a modified tetramethylene-ether glycolmethylene bis (4-phenyl diisocyanate) polyurethane elastomer. It seems to have almost every desirable quality for this application except a high resistance to penetration by sharp objects. Its weatherability is only slightly less than that of some polyethylene materials. The polyurethane has certain advantages where good sealing is important, such as for the MILES transducers. Its tear resistance is high and, most important of all, it exhibits excellent hydrolytic stability, that is, moisture affects its physical or chemical properties only to a very minor extent.

The physical and chemical properties are maintained over a very wide temperature range. For example, the Shore A hardness and tensile strength measured at $300^{\circ} \mathrm{F}$ are about 80 percent and 50 percent of the room temperature values, respectively. Experimental measurements

25 Manufacturer's Report No. 6464, dated January 18, 1974. 
after exposure to $300^{\circ} \mathrm{F}$ for 1500 hours in an aging test showed "...virtually no loss in tensile strength through 1000 hours of exposure" [11]. Testing in an environment of elevated gas pressures (air and oxygen) as required by Underwriters Laboratories, as well as for military and utilities test specifications, shows little loss of tensile strength or elongation. The polyurethane polymer maintains good flexibility at temperatures as low as $-60^{\circ} \mathrm{F}$; embrittlement does not occur until a temperature of about $-80^{\circ} \mathrm{F}$ is reached. Weatherometer and fadeometer tests show comparable or better resistance to the natural elements than cross-linked polyethylene, which is known to be excellent. The electrical properties are essentially the same as for cross-linked polyethylene. Tests predict ambient-temperature lives ranging from several decades to several centuries (even in high humidity conditions) $[8,12]$.

An important weakness of the polyurethane jacket is its inability to resist penetration by sharp objects, such as rocks or rodent teeth. It offers almost no protection against gophers, for example. Three genera of pocket gophers are reported to be the principal offenders: Thomonys, Geomys, and Cratogeomys [13]. The plains gopher, Geomys bursarius is generally the largest and most widely distributed of the three. It is an accepted hypothesis that gophers are attracted to freshly disturbed soils such as those around new cable installations. One theory explains gopher damage as a result of the animals' natural chewing on soft cables, believing them to be roots from which they expect water [14]. Another theory states that gophers chew to maintain sharp incisors and to keep them from growing too long. The depths that gopher damage occurs at the greatest incidence is between 12 and $38 \mathrm{~cm}$ (5 and $15 \mathrm{in}$ ) and again at a depth of $1 \mathrm{~m}$ (40 in). They have been found as deep as $150 \mathrm{~cm}$ (60 in).26

The types of soils also have been found to be a significant factor in gopher damage. While few voids are left by back-filling sandy soils, 5 to $13-\mathrm{cm}$ (2 to $5-i n$ ) voids are often left in back-filled hard clay soils, providing natural tunnels for the gophers. 27 Rodent-repellent soil treatment using kerosene diluted tert-butylsulfenyl dimethyldithiocarbonate applied in a $5 \mathrm{~cm}$ region surrounding the buried cable is reported as an effective gopher deterrent [15].

26 Welch, J. F., "Investigation of Pocket Gopher Damage to Buried Telephone Cable in Nebraska", unpublished report 16, December 1943, Denver Wildlife Research Center.

27 Issac, R. L., "Pocket Gopher Damage to Underground Telewire in Caddo County, Oklahoma", unpublished report, Division of Wildlife Services, Oklahoma City, Oklahoma, December 1956. 
Tests on both armored and unarmored buried cables of various sizes show that cable diameters greater than $5.33 \mathrm{~cm}(2.10 \mathrm{in})$ are unaffected by gophers. The degree of damage is inversely proportional to the diameter [16]. In view of this, the round MILES transducers, whose nominal diameter is about $1.14 \mathrm{~cm}\left(0.45^{\circ} \mathrm{in}\right)$, would be subject to catastrophic gopher damage if deployed in areas where gophers exist. The polyurethane jacketing material, although excellent from the hyrolytic stability standpoint, will not withstand gopher attack.

Prior studies of this subject by others concluded that the only effective protection against gophers and rodents was a metallic armor such as stainless steel [16,17]. However, it was reported that polyurethane jacket penetrations due to rodent attack or rock damage account for only a very few of the field failures of deployed round transducers. 28 However, gopher population density was not known, but it is hypothesized to be low, otherwise damage and failures would be known.

Several buried transducers in a test field site at Griffis Air Force Base Site 2D were closely examined.29 Rodent damage was not present but other defects were. Of particular interest was a transducer designated as MILES 96R-1. It has been buried in that site continuously since its installation in June, 1972. Microscopic investigations revealed different "blemishes" on the surface of the polyurethane jacket which can be described as scratches, abrasions, dents, pores, pits and cracks. All except the cracks were superficially shallow, perhaps a small fraction of a millimeter in depth, and thus considered insignificant. The cracks, on the other hand, were much larger and deeper.

Figure 19 shows a field of small "pits" on the surface of the jacket. This is typical of pitting seen at several places along the transducer. The pit diameters are approximately 0.04 to $0.09 \mathrm{~mm}(1.5$ to $3.4 \times 10^{-3}$ in) and the depths appear to be about equal to the diameters. Although these pits are, indeed, very shallow, they occur often enough in "clusters" to make one wonder what their origins are and, further, to raise the question of their growth rate, if any.

Figure 20 shows a large crack running in the direction of the transducer's length. ${ }^{30}$ Close inspection reveals that it is a split of some type, and not a clean cut. It is approximately $8.6 \mathrm{~mm}(0.340$ in) long and $0.32 \mathrm{~mm}(0.013 \mathrm{in})$ wide. The depth appears to be nearly the entire thickness of the polyurethane jacket, which is nominally

28 Discussion held at a briefing session, Hanscom Air Force Base, Aug. 19, 1976.

29 On site inspection was done on December 17, 1975.

30 The large crack is located approximately $152 \mathrm{~cm}$ (60 in) from the cylindrical boot near the cable end of the transducer. 


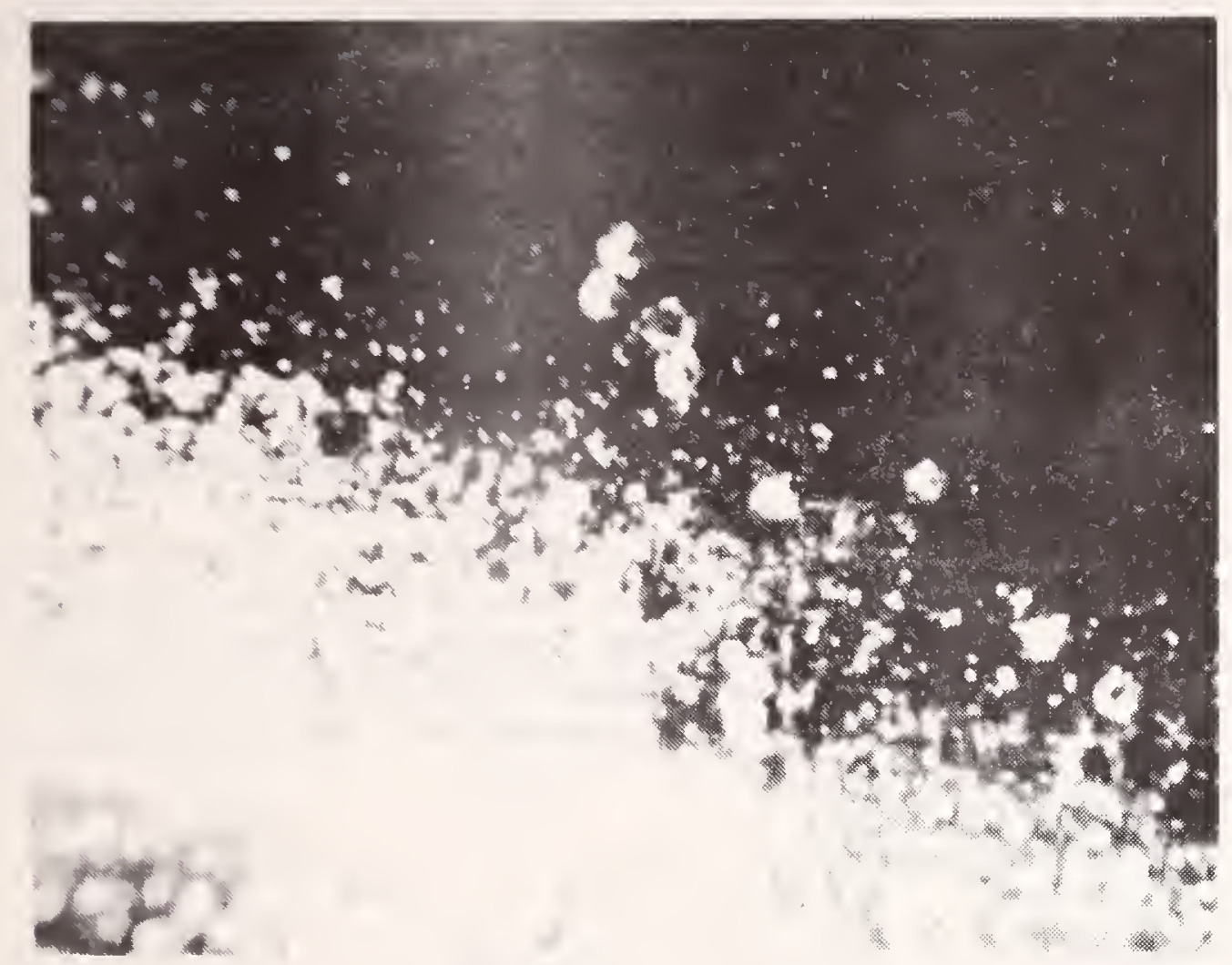

Figure 19. A field of small pits observed on transducer MILES 96R-1 at Griffis Air Force Base. Pit diameters are approximately 0.04 to $0.09 \mathrm{~mm}$ ( 1.5 to $\left.3.4 \times 10^{-3} \mathrm{in}\right)$.

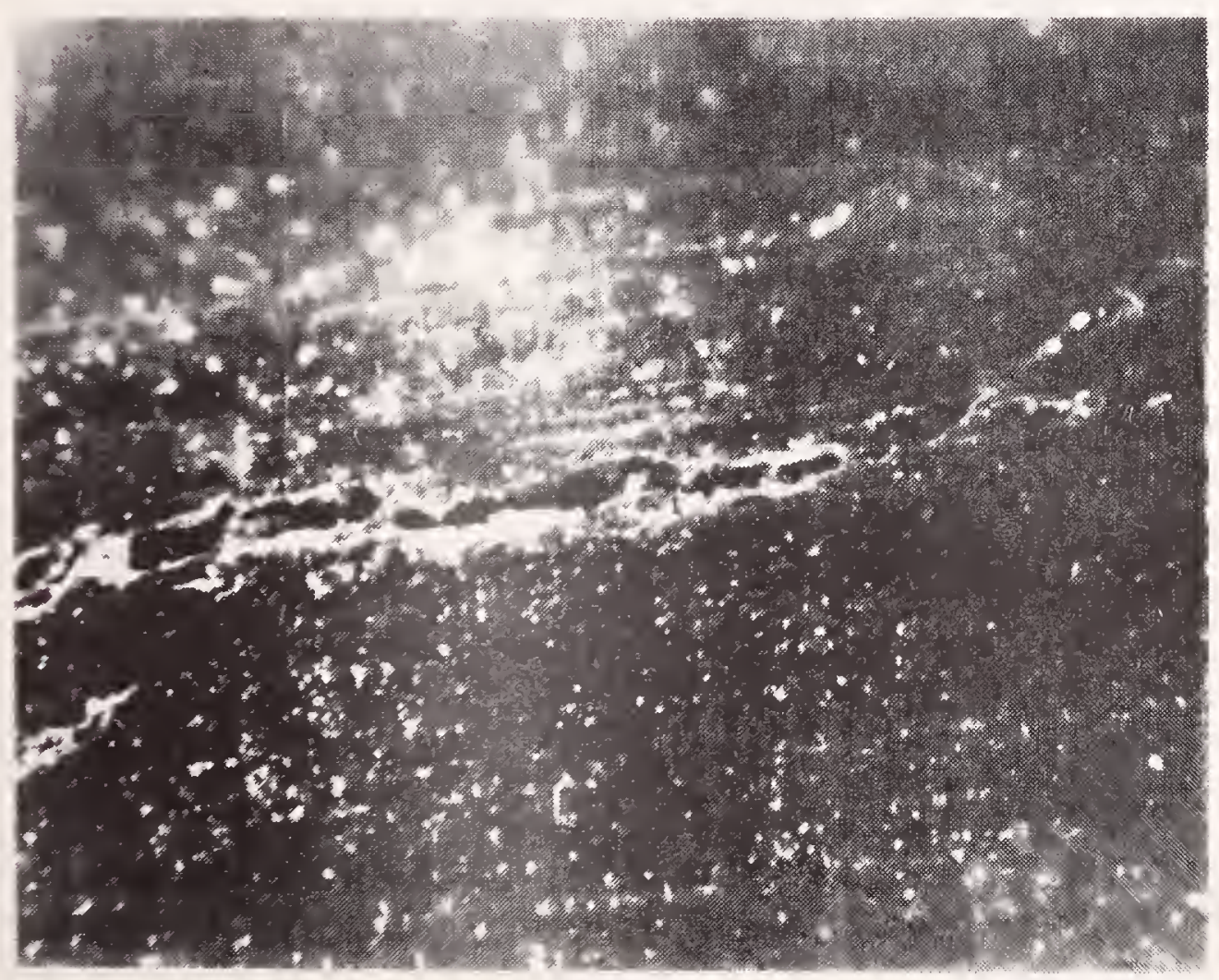

Figure 20. Large crack in the polyurethane jacket of transducer MILES 96R-1 located at Criffis Air Force Base. 
$1.1 \mathrm{~mm}$ (0.045 in) thick. The origin of this crack is not known, but it constitutes a near failure of this particular transducer. Only one such crack was discovered in the several-meter length examined.

At this time, no other rubber-like materials are known which would be more suitable for this application. The selèction of this particular polyether-based urethane appears to be an excellent choice. Appendix $B$ gives information on other materials that offer gopher protection, and some which are known to be vunerable to gopher attack.

\section{REELING AND UNREELING DURABILITY OF FLAT TRANSDUCERS}

This work was done to satisfy the requirements of Task E. This task was divided into two major parts: 1) determining the physical strengths and characteristics of the flat transducer stainless steel sheaths, and 2) determining the strains and equivalent forces that the flat transducers experience during typical reeling and unreeling operations.

\subsection{Mechanical Characteristics and Strengths}

Seven specimens, about $107 \mathrm{~cm}$ (42 in) long, of the flat transducers were used to determine the mechanical characteristics and strength of the stainless steel sheath. The specimens were prepared by removing the inner core, the sense coil and all insulation material, leaving only the stainless steel jacket. Three of the seven specimens were instrumented with small, foil-type, resistance strain gages. Each gaged specimen had four gages located on both edges and both sides at about their mid-lengths. All specimens were tested in tension in a universal testing machine. Table 7 shows results of the laboratory measurements and subsequent calculations. The listing below summarizes the findings and also makes comparisons with expected values, given in references 18 through 21, for austenitic stainless steel type 304 .

\section{Parameter}

Yield load, (0.2\% off set) lbf

Measured or calculated value (for transducer sheath)

Yield strength $(0.2 \%$ offset $)$ psi

Ultimate load, lbf

Ultimate strength, psi

Elongation, \%

Effective Modules, psi

Cross-sectional area, in ${ }^{2}$
681

$$
57,917
$$

$1096 \pm 32$

$93,250 \pm 2710$

21.7 (in 18 inches)

$20.1 \times 10^{6}$

0.01175

\section{Expected value (for flat strip)}

28,000 to 44,000

75,000 to 100,000

40 to 71 (in 2 inches)

$28 \times 10^{6}$ to $30 \times 10^{6}$ 
Table 7. Results of Tensile Tests on Stainless Steel Sheaths from Flat Transducers.

\begin{tabular}{|c|c|c|c|c|c|}
\hline $\begin{array}{l}\text { Specimen } \\
\text { Number }\end{array}$ & $\begin{array}{l}\text { Yield Load } \\
0.2 \% \text { offset } \\
\text { Ibf }\end{array}$ & $\begin{array}{c}\text { Yield Strength } \\
0.2 \% \text { Offset } \\
\mathrm{psi}^{\mathrm{b}} \\
\end{array}$ & $\begin{array}{c}\text { Ultimate } \\
\text { Load } \\
\text { Ibf } \\
\end{array}$ & $\begin{array}{c}\text { Ultimate } \\
\text { Strength } \\
\text { psib }\end{array}$ & $\begin{array}{c}\text { Elongation } \\
\% \text { in } \\
18 \text { inches }\end{array}$ \\
\hline A & -- & -- & 1055 & 89,800 & 23.3 \\
\hline$A_{i}$ & -- & -- & 1130 & 96,200 & -- \\
\hline B & 708 & 60,250 & 897 & 76,300 & 6.3 \\
\hline $\mathrm{B}_{i}$ & -- & -- & 1135 & 96,600 & -- \\
\hline $\mathrm{C}$ & 664 & 56,500 & 1090 & 92,800 & 20.2 \\
\hline $\mathrm{H}$ & -- & -- & 1093 & 93,000 & 22.3 \\
\hline I & 670 & 57,000 & 1070 & 91,100 & 20,8 \\
\hline Mean & 681 & 57,917 & $1096^{a}$ & $93,250^{a}$ & $21.7^{\mathrm{a}}$ \\
\hline Std.Dev. & -- & -- & $+32^{a}$ & $+2710^{a}$ & - \\
\hline
\end{tabular}

Footnote a: Values from specimen number $B$ were not used in calculating the means.

$\mathrm{b}$ : A cross sectional area of 0.01175 in. ${ }^{2}$ was used in calculating yield and ultimate strengths. 
The yield strength as determined by the 0.2 percent offset method was almost $58,000 \mathrm{psi}$. The expected range of values is 28,000 to 44,000 psi. The high value determined by testing is the result of a different geometry than the flat strips used for the reference values. The corrugated central portion of the transducers must all stretch out prior to the outer lips picking up the load. This same effect causes a lower elongation and modulus than expected for flat strip specimens.

The value used for the cross-sectional area was calculated as $0.01175 \mathrm{in}^{2}$. This value was determined from the dimensions given by the manufacturer of the material from which the transducer sheath is made. There is a chance of considerable error in the value due to the dimensional tolerances allowed. The maximum and minimum values for the area are (based on the manufacturer's dimensional tolerances):

$$
\begin{array}{ll}
\text { Maximum area: } & 0.01298 \mathrm{in}^{2} \\
\text { Nominal area: } & 0.01175 \mathrm{in}^{2}, \text { and } \\
\text { Minimum area: } & 0.01053 \mathrm{in}^{2}
\end{array}
$$

There could be as much as a 23 percent range in the value used for the area, based on this method of calculation. Two specimens were carefully measured in the laboratory to experimentally determine the cross-sectional area. It was based on a measured length, measured weight, and a reference value for density. ${ }^{31}$ The value obtained by this method was 0.01090 in $^{2}$, with a probable uncertainty of less than \pm 1 percent. This value agrees with the formerly calculated value to within about 7.2 percent. The value of $0.01175 \mathrm{in}^{2}$ was used for all of the calculations requiring the cross-sectional area since it seemed reasonably close to the expected value.

\subsection{Reeling and Unreeling Laboratory Tests}

A 30-m length of flat MILES transducer was used during reeling and unreeling tests. Two small, foil-type, resistance strain gages were placed on the welded lips of the transducer at $7.5 \mathrm{~m}$, and another two gages at $15 \mathrm{~m}$, from the free end. Gages 1 and 2 were at the 15m location; gage 1 was on the "outside" of the rolled transducer and gage 2 was on the inside when rolled. Gages 3 and 4 were at the 7.5m location; gage 3 was on the inside and gage 4 was on the outside when the transducer was rolled. The strain-gage bridge circuitry was zeroed in the initial rolled-up configuration. The free end of the transducer had a "pop rivet" placed through its thickness to help prevent the core and sense coil from sliding in and out during the reeling

31 An average density value of $0.28951 \mathrm{bf} / \mathrm{in}^{3}$ was used. 
and unreeling operations. The transducer was unreeled and reeled a total of seven times to determine the strain differences. The transducer was reeled and unreeled on a spool that the manufacturer typically uses for shipping. The radius of curvature was never less than about $0.4 \mathrm{~m}$ (17 in).

The strain assumed some permanent shift in the second and third tests, as shown in Table 8 . The column means and standard deviations shown do not include the values from test Nos. 1, 2 or 3 . The strain differences between the unrolled and rolled conditions were determined and are shown at the bottom of the table. The grand mean of the absolute strain differences was $463 \times 10^{-6} \mathrm{in} / \mathrm{in}$.

This average strain difference implies a calculated stress of about 13,900 psi. This, compared with the yield strength of 57,900 psi determined earlier, appears reasonably low, and careful reeling and unreeling would not be expected to cause serious problems. Taking an extreme case where the measured strain difference was about $1000 \times 10^{-6}$ in/in, the calculated stress would be about 29,000 psi. This is about 50 percent of the yield strength. It is conceivable that local stresses could be higher, especially if the transducer were bent or twisted beyond the $0.4-\mathrm{m}$ radius limit.

Indications of exceeding the yield strength were evident from instances where "buckling" and "wrinkling" of the stainless steel sheath occurred. It was noted that severe permanent buckling could easily occur in the steel jacket by very slight twisting of the transducer. In fact, in careful laboratory handling, it was difficult not to induce buckling which caused permanent "wrinkles" in the stainless steel sheath. Similar wrinkles were noted on transducers examined at Griffis Air Force Base Site 2D. The end effect or seriousness of such wrinkles was not evaluated, but it is evident that stresses greater than the yield strength were present to cause the permanent deformations. Figures $2 l a, b$ and $c$ show typical wrinkles of the stainless steel sheath. The transducer was received from the manufacturer with some wrinkles present, while additional wrinkling occurred in the course of the laboratory testing.

Microscopic examination of the flat transducer prior to, and after, the multiple reeling and unreeling revealed no detectable cracking anywhere along the lengths examined. However, crack detection by optical means is difficult, at best, and small cracks may have formed and were not detected. This would mean, of course, that the localized stresses were greater than the ultimate material strength at the point of cracking. The only difference noted, when the transducers were examined optically, were additional shallow abrasions caused by dragging the transducer across the concrete laboratory floor. 

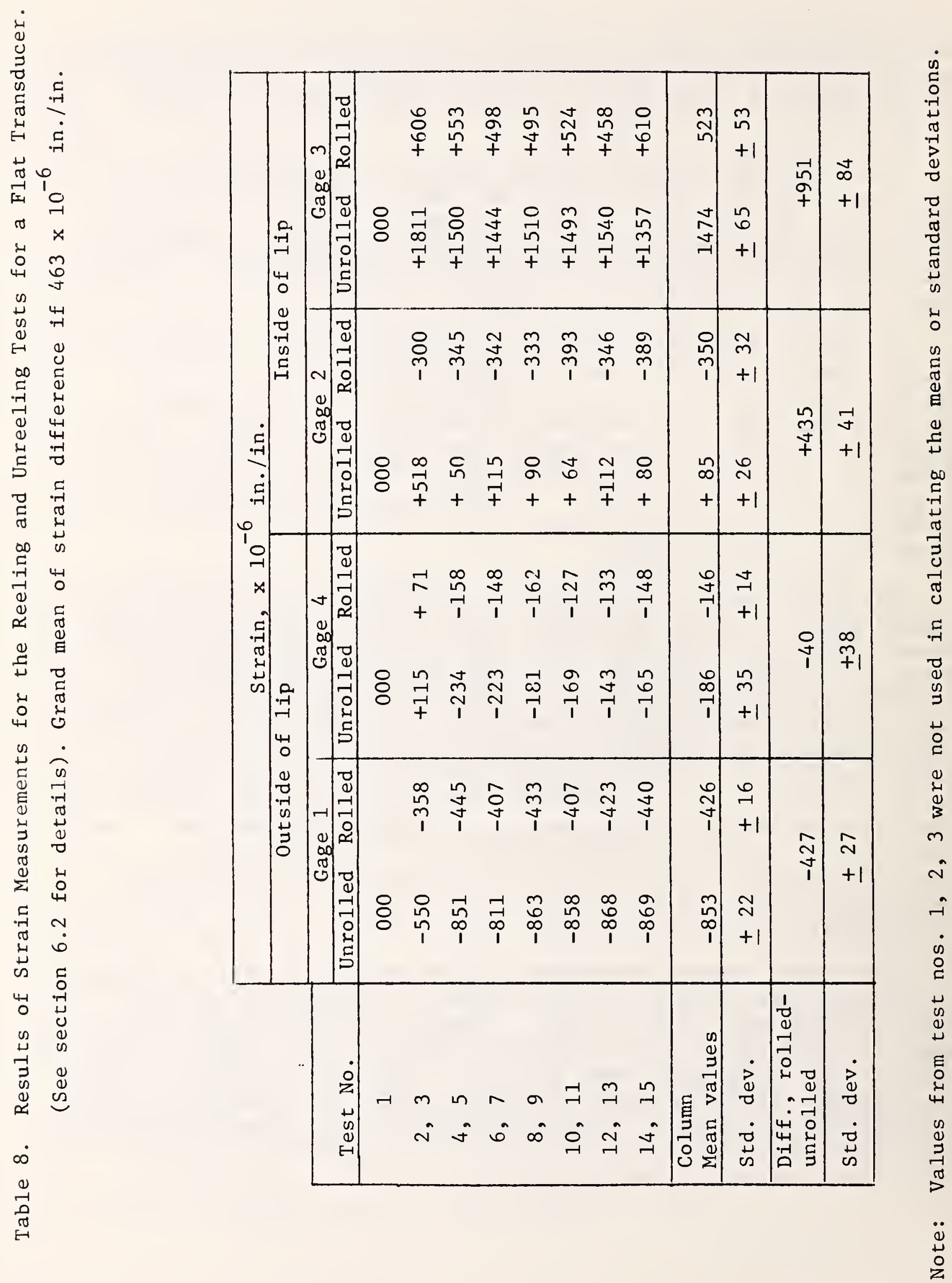


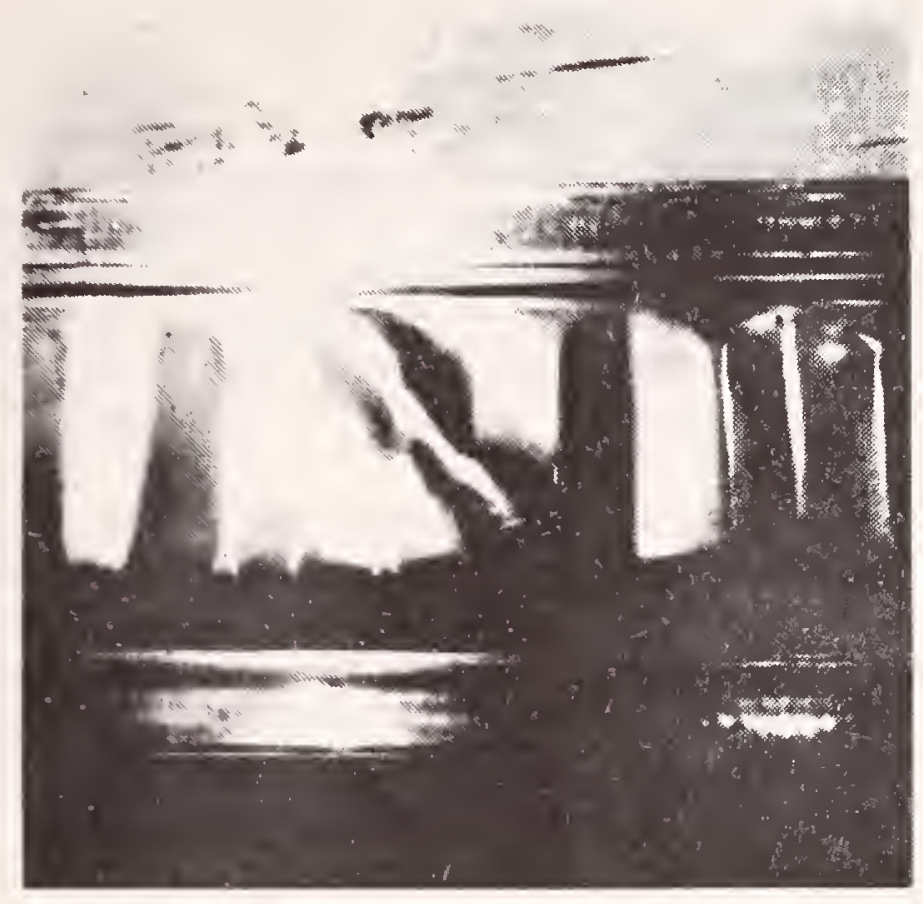

Figure 2la. Diagonal wrinkle in transducer stainless steel sheath.

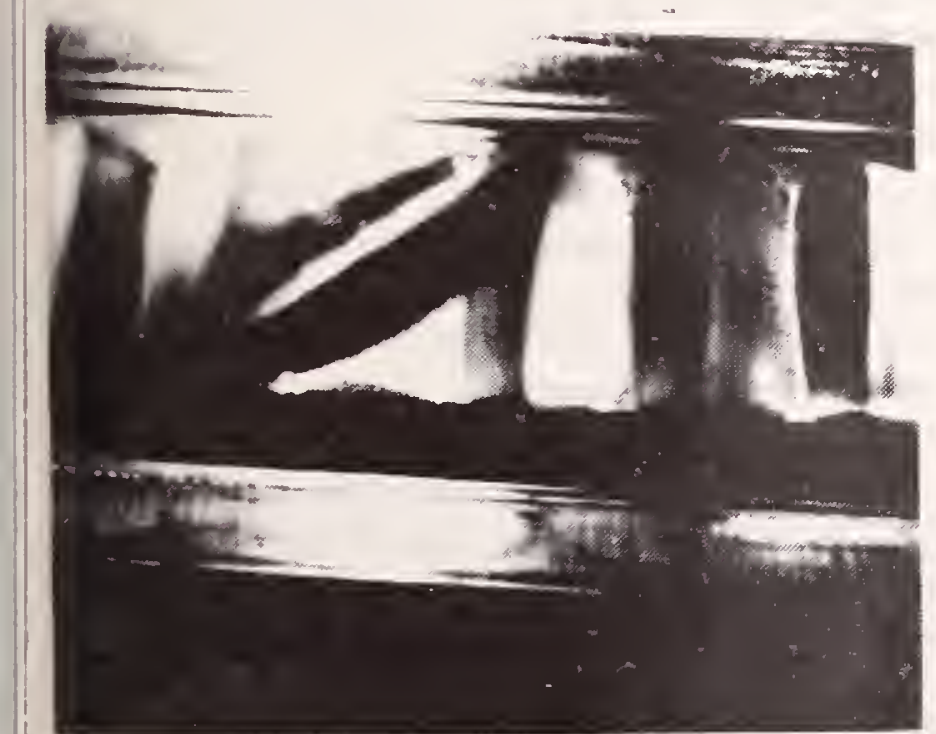

tre 21b. Diagonal wrinkle in transducer stainless steel sheath.

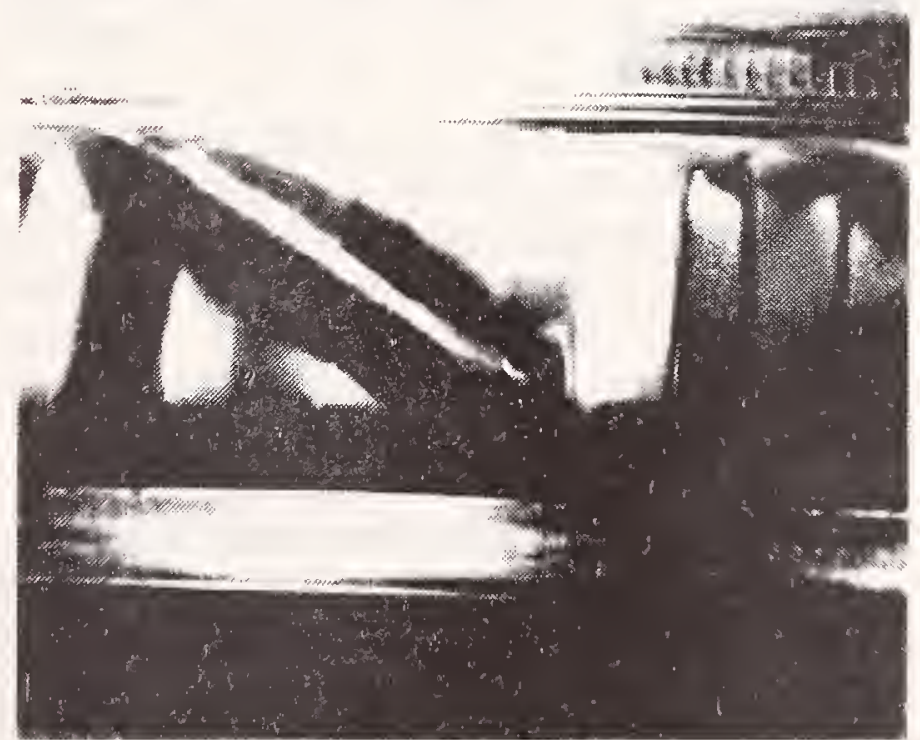

Figure 21c. Diagonal wrinkle in transducer stainless steel sheath. 


\section{COST EFFECTIVENESS ANALYSIS}

The ownership costs of MILES transducers include many factors. Original hardware costs (transducer and accompanying electronics), test equipment, maintenance, procurement costs, installation costs, training and replacement costs are considered the major cost items. of these items several are essentially the same for either the flat or the round transducer, namely, procurement, installation, training and a portion of replacement costs.

Test equipment, more than likely, would also be the same, with the exception that some modifications would probably be required for the flat transducer and, in fact, some duplication of test equipment may be needed in areas where both flat and round transducers are deployed. The transducers themselves should not require significant maintenance over their lifetimes; however, the soil region at and near a transducer's location does require periodic maintenance such as grass cutting, weed removal, soil replacement in cases of erosion, etc. Combatting rodents and other pests could also be included under the maintenance costs. These routine maintenance costs are essentially the same for either the flat or the round transducers with the expection of pest control, where the stainless steel armor would be expected to offer significantly more protection and, thus, require fewer precautions and a lower maintenance cost.

Providing that the above assumptions are correct, the items that would have a major cost difference reduce to the original transducer cost, the original electronics costs, and the life expectancies of the transducer and the electronics. A further assumption is that the replacement of batteries, and other minor maintenance, for the deployed electronics is the same for either type of transducer system.

\subsection{Original Cost-Estimate Comparisons}

The original transducer costs can be compared in terms of ratios, thus removing factors due to inflation, assuming that the same inflationary factor applies to both. Ratios between the flat and the round transducers, and for different quantities, have been estimated.

In order for a manufacturer to begin production of stainless steel flat transducers, there are a number of costs associated with the first production year. These costs can be grouped into the following three categories having the approximate proportion of costs as indicated: 


\author{
Data upgrading \\ Tooling \\ Test equipment \\ Training
}

Misc. nonrecurring

$\left.\begin{array}{l}\text { Electronics } \\ \text { Modification to electronics }\end{array}\right\}$

$47 \%$

The percentages will vary slightly from the above figures depending on quantities. What is important to note is that the transducer and the electronics costs are nearly equal and are the major items and thus are. the controlling considerations in this cost analysis.

For the second, third and fourth production years, several of the initial costs will have been paid and the overall system costs decrease. These can be grouped into the two major categories and estimated as:

$\begin{array}{lr}\text { Transducer }(100 \mathrm{~m}) & 46 \% \\ \text { Electronics } & 54 \%\end{array}$

Thus, after full production begins and continues, the relative costs of the transducer and the electronics are about equal. Considering all of the factors given above, the cost-estimate comparisons for both the flat and the round transducers are given in Table 9 for the indicated production year and for the quantities shown. The cost values have been normalized to the system cost of the flat thansducer systems in quantities of 2500. Both the round and the flat systems include an estimated cost of $\$ 750$ for the necessary electronics. No discounts were assumed for increased quantities of the electronics. The values 
Table 9. Estimated Cost Comparison for New Round and Flat Transducer Systems. (See text and footnotes for the assumptions made.)

\begin{tabular}{|c|c|c|c|c|c|}
\hline \multirow{2}{*}{ Production Yr. } & \multirow{2}{*}{ Quantity } & \multicolumn{2}{|c|}{ Cost Estimate ${ }^{a}$} & \multirow{2}{*}{$\begin{array}{c}\text { Cost Ratio } \\
\text { Flat/ } \\
\text { Round } \\
\end{array}$} & \multirow{2}{*}{$\begin{array}{c}\text { Savings/ } \\
\$ 1000^{\mathrm{d}} \\
\end{array}$} \\
\hline & & Round $^{b}$ & Flat ${ }^{c}$ & & \\
\hline \multirow{4}{*}{ First } & 1500 & 1.150 & 1.071 & 0.931 & 103,500 \\
\hline & 2000 & 1.137 & 1.026 & 0.902 & 196,000 \\
\hline & 2500 & 1.134 & 1.000 & 0.882 & 295,000 \\
\hline & 3000 & 1.131 & 0.978 & 0.865 & 405,000 \\
\hline Second & 2500 & 1.113 & 0.864 & 0.776 & 560,000 \\
\hline Third & 2500 & 1.101 & 0.845 & 0.767 & 582,500 \\
\hline Fourth & 2000 & 1.089 & 0.830 & 0.762 & 476,000 \\
\hline
\end{tabular}

Footnotes: a. Cost estimate is given in normalized values using the estimated cost of flat transducers in quantities of 2500 as the normalization factor.

b. Includes the cost of the tranducer plus a value of $\$ 750$ for electronics.

c. Includes the cost of the transducer plus a value of $\$ 750$ for electronics plus other production costs for the first year.

d. Dollar amounts shown are based on the cost of the flat transducer system in quantities of 2500 expressed per $\$ 1000$ of cost. For example, if the transducer system costs $\$ 1650$, the net savings can be computed by multiplying the savings/\$1000 by 1.650 which equals $\$ 486,750$. 
also include a profit factor of 15 percent. Quantity discounts for the round transducers follow a 96 percent curve while the discount for the flat transducers follow a 92 percent curve. The column headed "Savings/\$1000", in Table 9, indicates the estimated cost savings for a transducer and the electronics package, expressed in terms of the per-\$1000 cost in the quantities indicated.

Estimated savings can be calculated, using Table 9, for any of the quantities shown when the cost per system is known. It is obvious, from examining the table, that the greatest savings, when buying complete new systems, occur after the first production year and when the quantities are the greatest.

A second aspect to be considered is the situation where only a portion of the system is to be replaced, namely, the transducer, and the original electronics package is only modified to be compatible with the new transducer. It is assumed, for the sake of this analysis, that an old round transducer is being replaced with a new flat transducer. It is also assumed that production quantities are already being delivered and that the additional replacement transducers are available at costs which already reflect discounts for quantity. Table 10 shows estimated cost comparisons when old round transducers are replaced with new flat transducers. The values have been normalized to the estimated cost of a flat transducer plus a modified and upgraded electronics package produced in the first year in quantities of 2500 . A cost of $\$ 250$ was included for retrofitting existing electronic packages. Profit factors and discount rates are the same as for the data shown in Table 9.

For transducer replacement, estimated savings can be calculated by knowing the transducer cost and quantity under the above stated assumptions and using the values given in Table 10. Again, as in Table 9, the greatest savings are realized after the first production year. Here, however, the quantity of replacement transducers is far less important because it is assumed that at least 2500 flat transducers are already being produced and the quantity discounts apply to replacement transducers.

\subsection{Life Expectancy and Cost}

Ownership costs of MILES transducers can include many factors. By far, the largest single cost factor for short periods of ownership time is the original cost of the transducers and associated electronics. It is estimated that 85 to 90 percent of the first-year cost goes into these two items. Other factors, such as data upgrading, test equipment, modifications and training, account for only about 10 to 15 percent of the overall short-time costs. 
Table 10. Estimated Cost Comparisons for Replacement of Transducers only (See text and footnotes for the assumptions made.)

\begin{tabular}{|c|c|c|c|c|}
\hline \multirow[b]{2}{*}{ Production $\mathrm{Yr}$. } & \multicolumn{2}{|c|}{ Cost Estimate ${ }^{a}$} & \multirow{2}{*}{$\begin{array}{c}\text { Cost Ratio } \\
\text { Flat/ } \\
\text { Round } \\
\end{array}$} & \multirow{2}{*}{$\begin{array}{c}\text { Savings/ } \\
\$ 1000 / \text { System } \\
\end{array}$} \\
\hline & Round $^{\mathrm{b}}$ & Flat ${ }^{c}$ & & \\
\hline First & 1.104 & 1.000 & 0.906 & 94.00 \\
\hline Second & 1.069 & 0.911 & 0.852 & 148.00 \\
\hline Third & 1.050 & 0.881 & 0.839 & 161.00 \\
\hline Fourth & 1.030 & 0.856 & 0.831 & 169.00 \\
\hline
\end{tabular}

Footnotes: a. Cost estimate is given in normalized values using the estimated cost of flat transducer systems in quantities of 2500 .

b. Cost estimate of transducer only.

c. Includes cost of $\$ 250$ per system for modification and upgrading.

d. Dollar amounts based on the cost in thousands of flat replacement transducers. For example, if a new flat transducer cost is $\$ 670$ during the second preduction year, the net savings for 500 transducers can be computed by multiplying the savings/ $\$ 1000 /$ system by the transducer cost by the quantity, or $(148.00)(0.670)(500)=\$ 49,580$. 
For longer periods of time, the ownership costs are largely controlled by the maintenance costs and component replacements. The two most expensive components are the transducer and the eleectronics package. Assuming that maintenance costs are the same for the round transducers as for the flat transducers, then the ownership cost difference between the two reduces to mainly the costs of the replacement transducer and electronics packages.

For the sake of this analysis, the assumption is made that the electronics packages will operate satisfactorily for much longer periods than the transducers. ${ }^{32}$ If an oversimplification of the cost algorithms for the round and the flat transducers is made, comparison of the cost effectiveness of one type of transducer versus the other is possible in rather direct and simple terms using values of initial transducer costs and life expectancies. In a situation where both the round and the flat transducers have finite but different life expectancies, the total long term costs can be derived from the cost of the transducer and the number of times that the transducer must be replaced, as,

$$
C_{f}=T_{f} t_{f} \text { and } C_{r}=T_{r} t_{r}
$$

where $\mathrm{C}_{f}$ and $\mathrm{Cr}$ are the total costs of the transducers for long periods of time, $T_{f}$ and $T_{r}$ are the initial costs of the transducers, and $t_{f}$ and $t$ are the numbers of times the transducers are replaced, an integer, where $e^{r} \geq 1$.

The subscripts $f$ and $r$ denote flat and round, respectively. The number of times the transducers are replaced depends directly upon the life of the transducer; the parameters $t_{f}$ and $t_{r}$ can be derived from

$$
t_{f}=N / n_{f} \text { and } t_{r}=N / n_{r} \text {, }
$$

where $\mathrm{N}$ is the time the transducers are deployed, usually expressed in years, and $n_{f}$ and $n_{r}$ are the life expectancies of the transducers, expressed in the same units of time as $\mathrm{N}$.

If $\mathrm{P}$ is the prorata cost per time interval $\mathrm{N}$, then $\mathrm{P}=\mathrm{C} / \mathrm{N}$ and

$$
P_{f}=T_{f} t_{f} / N \text { and } P_{r}=T_{r} t_{r} / N
$$

32 Life expectancy analysis in this report is limited to consideration of the transducers; electronics package life expectancy was not included within the scope of these project tasks. 
In the limit where $\mathrm{N} \rightarrow \infty$ (or for practical engineering considerations, $\mathrm{N} \gg \mathrm{n}$ ), the long term prorata cost, $\mathrm{P}$, can be shown to be the transducer cost divided by the life expectancy, as

$$
\mathrm{P}_{\mathrm{f}}=\mathrm{T}_{\mathrm{f}} / \mathrm{n}_{\mathrm{f}} \text { and } \mathrm{P}_{\mathrm{r}}=\mathrm{T}_{\mathrm{r}} / \mathrm{n}_{\mathrm{r}} \text {. }
$$

It is interesting to note that these relationships are independent of $\mathrm{N}$, so long as the inequality $\mathrm{N} \gg \mathrm{n}$ is met. From Eqs. (7) and (8) one can derive a measure of cost effectiveness in terms of transducer cost and life expectancy. When the prorata costs are equal, then the two transducer types are equally cost effective. This condition is established when $\mathrm{P}_{\mathrm{f}}=\mathrm{P}_{\mathrm{r}}$, as

$$
\frac{T_{f}}{n_{f}}=\frac{T_{r}}{n_{f}} \quad \text { or } \quad \frac{T_{r}}{T_{f}}=\frac{n_{r}}{n_{f}} \text {. }
$$

A cost effectiveness factor, Q, can be defined as

$$
Q=\frac{P_{r}}{P_{f}} \quad \text { or } \quad Q=\left(\frac{T_{r}}{T_{f}}\right)\left(\frac{n_{f}}{n_{r}}\right) \text {. }
$$

Decisions on cost effectiveness can be based on the foregoing relationships.

1. When $Q=1$, the cost effectiveness of the flat transducer is equal to the round transducer. $\left(\mathrm{T}_{\mathrm{r}} / \mathrm{T}_{\mathrm{f}}=\mathrm{n}_{\mathrm{r}} / \mathrm{n}_{\mathrm{f}}\right.$, as in Eq. (10)).

2. When $Q>1$, the flat transducers are more cost effective $\left(\mathrm{T}_{\mathrm{r}} / \mathrm{T}_{\mathrm{f}}>\mathrm{n}_{\mathrm{r}} / \mathrm{n}_{\mathrm{f}}\right)$.

3. When $Q<1$, the round transducers are more cost effective $\left(\mathrm{T}_{\mathrm{r}} / \mathrm{T}_{\tilde{\mathrm{I}}}<\mathrm{n}_{\mathrm{r}} / \mathrm{n}_{\mathrm{f}}\right)$.

The savings or cost of deploying one type of transducer rather than the other depends on the cost effectiveness and the length of time the transducers are deployed. This can be expressed simply as

$$
\mathrm{S}=\mathrm{C}_{\mathrm{r}}-\mathrm{C}_{\mathrm{f}}
$$

where $\mathrm{C}_{r}$ and $\mathrm{C}_{f}$ are the total costs, respectively. This leads to three economic results:

1. When $S=0$, there is no savings for one type of transducer over the other, 
2. When $S>0$, there is a cost savings by deploying the flat transducers, and

3. When $S<0$, there is a cost loss by deploying the flat transducers.

Equation (13) can also be expressed as

$$
S=T_{r} t_{r}-T_{f} t_{f}
$$

wherein $t_{r}$ and $t_{f}$ are integers and give the savings (or losses) for short periods of time, i.e., when $\mathrm{N}$ is not much larger than ${ }_{n}$ or $\mathrm{n}_{\mathrm{f}}$. The maximum that the savings can approach for long periods of ${ }^{\mathrm{r}}$ time when $\mathrm{N} \gg \mathrm{n}$ can be expressed as

$$
\mathrm{S}^{\prime}=\mathrm{N}\left(\mathrm{T}_{\mathrm{f}} / \mathrm{n}_{\mathrm{f}}\right)(\mathrm{Q}-1)=\mathrm{N}\left(\mathrm{T}_{\mathrm{r}} / \mathrm{n}_{\mathrm{r}}\right)(1-1 / \mathrm{Q}) \text {. }
$$

On a yearly basis, $S$ may be divided by $N$ to obtain the maximum possible savings per year. This is useful for comparison purposes and removes the effect of the fractions left over when $t_{f}$ and $t_{r}$ are made integers.

Several examples are given in Appendix $\mathrm{C}$ which demonstrate the usefulness of the above relationships.

In these examples and the discussions, consideration was not given to the "logistic value" of maintaining intrusion detection, nor to the problems and costs associated with troubleshooting transducers which have failed, especially those which begin by generating intermittent false alarms. The final choice must, of course, consider these and many other factors, thus making the choice between types of transducers much more complex and considerably more than simply a "cost effectiveness" choice.

\section{SUMMARY AND RECOMMENDATIONS}

This section is divided into two portions; the summary, which is organized by order of tasks, and secondly, selected recommendations which are felt would improve the quality and durability of the transducers or would lead to better knowledge regarding their performance and life.

\subsection{Summary}

In the laboratory tests, such as were performed and are reported herein, a finite sample of specimens was selected for testing. A question is always present as to whether the tests represented conditions of "real life" and whether the few specimens tested were truly representative of the large number of transducers which would ultimately be produced and deployed. 
It is known, in some instances, that the test conditions intentionally did not represent "real life" conditions, for purposes of accelerated life testing. Where conditions differed, an attempt to distinguish the important differences was made. As to whether the selected specimens were truly representative of a large population is conjecture, for the most part, and the reader is cautioned to bear this fact in mind.

\subsubsection{Long-Term Resistance to Corrosive Moisture}

Specially fabricated round and flat transducers (seven of each type) were exposed for 120 hours to boiling saline solution mixed to simulate sea water. Two others of each type were used to control specimens. The individual test cycles consisted of six hours of boiling, two hours of $100{ }^{\circ} \mathrm{F}$ drying and baking, and an overnight "rest" in an ambient outdoor environment.

Electrical leakage resistance was measured on each transducer at the beginning of each test cycle. When a transducer's leakage resistance became less than $20 \mathrm{M} \Omega$, it was considered a "failure". After 120 hours of accumulated exposure to the hot saline solution, five of the seven flat transducers had leakage resistances less than 20 $M \Omega$. The other two flat transducers showed signs of imminent "failure" due to moisture penetration. Moisture penetrated in two places, either through small corrosive pits in the weld zones of the jacket's rolled lips, or at the "end plugs" of the transducers. Both sources of leaks allowed significant moisture to enter the flat transducers, rendering them useless.

It is extremely difficult to estimate an equivalent aging factor for the 120 hours of the boiling saline solution test. Using the worst case data available, an equivalent ambient-temperature life could be only 26 days. This is contrasted by best case data where the ambienttemperature life would be in excess of 50 years in a chloride environment. It is doubtful that the transducers would survive 50 years of service but, certainly, 26 days is likewise unrealistic.

These tests did reveal the type and location of expected corrosion. The end-plug leaks are of considerable concern and probably would control the life of the transducer in a large number of instances.

Only one of seven round transducers failed during the 120 hours of test exposure. The steam heating line broke loose during one test cycle, allowing it to flail inside the tank. It apparently slashed one round transducer, cutting through the polyurethane jacket. The remaining six round transducers tested showed signs of decreasing electrical leakage resistance. This was attributed to changes in the dielectric properties of the insulation material within the transducers, and not to moisture penetration. The jacket lost its bright, shiny appearance and decreased in hardness. Also, the jacket had a tendency to become 
loose over the braided shield, indicating a dimensional instability of the urethane. Using test data from other researchers, the equivalent test time would be 25 years, based on the same decrease in Shore A hardness ( 7.8 percent) and an ambient temperature of $50^{\circ} \mathrm{F}$. The transducers probably could be serviceable for longer periods because a larger decrease in hardness certainly could be tolerated. However, hardness alone cannot be used as the sole controlling parameter of jacket durability.

Under the conditions of this test, the round transducers proved to be superior to the flat transducers by a large margin. In a less severe environment (and ignoring the end plug leaks), the margin would not be as great.

\subsubsection{Resistance to Freeze-Thaw Cycling}

Seven round and seven flat 42-in long transducers were subjected to freeze-thaw temperature cycling. The transducers were each buried in a tray of water-saturated sand. Electrical leakage resistance and mechanical strain were measured to determine the effects of this environment. Temperature extremes ranged from $0^{\circ} \mathrm{F}$ to $100^{\circ} \mathrm{F}$. Ten cycles were completed.

None of the round transducers showed any signs of failure. The jackets remained shiny in appearance, the Shore A jacket hardness showed no measureable change, the electrical leakage resistance remained high and, in general, no effects of the freeze-thaw cycling were detectable.

One of seven flat transducers failed early in the cyling sequence. It showed a significant decrease of leakage resistance after only two cycles. Microscopic examination of the transducer after the completion of the ten cycles revealed a small crack at the edge of the weld zone. It is likely that this small region accumulated a residual stress. The additional stress caused by the freeze-thaw cycling ultimately caused a crack in the stainless steel jacket which penetrated its full thickness. Strain measurements on this particular transducer were also higher than on the other transducers by a factor of almost 2:1. The freeze-thaw stresses alone would not be expected to have caused the noted failure except, perhaps, for the residual stresses at the location of the failure. Furthermore, reeling and unreeling of the transducer during and after manufacture could have initiated a small crack and the freeze-thaw cycling could have caused its growth.

Under the test conditions discussed, the round transducers were superior to the flat transducers, notably because of the one failure. Had the one flat transducer not failed, then the results would have not been in favor of the round transducers but, rather, the two transducer types would have appeared equally resistant to freeze-thaw cycling. 


\subsubsection{Resistance to Rock Damage}

Round and flat MILES transducer specimens were tested for rock damage by impressing a known load across them with a $6.4 \mathrm{~mm}(0.25-$ in) diameter round steel rod. For the initial testing, ten round and ten flat specimens, nominally $25.4 \mathrm{~cm}$ (10 in) long, were loaded to failure. For the round transducers the average failure load was $7251 \mathrm{bf}$. For the flat transducers the average failure load was $39701 \mathrm{bf}$.

For the 100 hour test, twelve specimens each of the round and the flat transducers, nominally $20.3 \mathrm{~cm}$ ( 8 in) long, were continuously loaded to nominally one-half the average failure load for a duration of 100 hours. The round transducers had a load of $3801 \mathrm{bf}$ on each specimen while the flat transducers had a load of 2040 lbf on each.

For the round transducers, one of the twelve failed immediately upon the application of the "half load". At the end of 100 hours, two additional failures had occurred. In each of three failures a short between shield and the coil was noted.

For the flat transducers, two failed immediately upon the application of the "half 1oad". At the end of 100 hours, one other failure occurred. In all, three flat transducers failed.

For the ten round transducer specimens tested to "full load" failures, nine of the ten polyurethane jackets crushed to the point where a hole had penetrated completely through the material. For the "half load", 100 hour tests, ten of the twelve jackets were penetrated. Even though only a few had failed electrically, ten would have been rendered unuseable because of a penetrated jacket. Therefore, the true failure of the round transducers was not the electrical opens and shorts but, rather more importantly, the penetrations of the outer polyurethane jacket material. The load at which the jacket was penetrated was not determined, but was less than those loads stated above.

In no case was the stainless steel sheath penetrated. Under the conditions of these tests, the flat stainless steel transducers proved far superior to the round transducers. The flat transducers could sustain a load more than five times that for the round transducers.

\subsubsection{Durability of the Polyurethane Jacketing}

The jacketing material was a modified tetramethylene-ether glycolmethylene bis (4-phenyl diisocyanate) polyurethane elastomer. It seems to have almost every desirable quality for this application except a high resistance to penetration by sharp objects. (It offers no protection against gophers, for example). Its weatherability is only slightly less than some polyethylene materials. The polyurethane has certain advantages where good sealing is important, such as for MILES transducers. 
Its tear resistance is high and it exhibits excellent hydrolytic stability. Tests predict ambient temperature lives ranging from several decades to several centuries.

Several buried transducers, at Griffis Air Force Base Site 2D, were temporarily dug up and examined. Of particular interest was a transducer designed as MILES 96R-1 which had been deployed since June 1972 . Microscopic observations revealed different surface "blemishes" on the polyurethane jacket which can be described as scratches, abrasions, dents, pores, pits and cracks. All were superficially shallow and insignificant except for certain cracks. One crack, in particular, was about $8.6 \mathrm{~mm}$ long, $0.32 \mathrm{~mm}$ wide, and appeared to have a depth of nearly the thickness of the polyurethane jacket. This crack constitutes a "near failure" and would likely control the life expectancy of that transducer.

Even with the weakness of poor rodent resistance, the choice of this polyurethane elastomer material, as compared to all other known rubber or rubber-like materials and other elastomers, was an excellent choice. No better material for this purpose is known to exist.

\subsubsection{Reeling and Unreeling Durability of the Flat Transducers}

To determine the characteristics and strength of the flat transducers, specimens about $107 \mathrm{~cm}$ (42 inches) long were tensile tested in a universal testing machine, and revealed a yield strength of 57,900 psi. This implies a calculated stress of about 13,900 psi. Compared with a yield strength of 57,900 psi, it appears reasonably low and careful reeling and unreeling would not be expected to cause serious problems.

A 30-m length of flat MILES transducer was used to help determine the durability during reeling and unreeling of the transducer in actual use. Four small, foil-type, resistance strain gages were placed on the welded lips of the transducer at $7.5 \mathrm{~m}$, and another four gages at $15 \mathrm{~m}$, from the free end. The transducer was unreeled and reeled a total of seven times to determine the strain differences. The overall average of the absolute strain differences was $463 \times 10^{-6}$ in/in between the reeled and the unreeled conditions.

It was noted that permanent and severe buckling could easily occur in the steel jacket by very slight twisting of the transducer. In fact, in careful laboratory handling it was difficult not to end up with some buckling which caused permanent "wrinkles" in the stainless steel sheath. The end effect or seriousness of such wrinkles was not examined, but it is evident that local stresses occur that exceed the material's yield strength enough to cause permanent deformations. It is not known how, or by what amount, these deformations decrease the durability of the flat transducers. 


\subsubsection{Cost Effectiveness Analysis}

Ownership costs of MILES transducers can include many factors. The largest single cost factor (about 85 to 90 percent) for short periods is the original cost of the transducers and necessary electronics. Other factors are data upgrading, test equipment, modifications and training which account for about 10 to 15 percent of the costs.

This analysis treated original costs of transducers and the related electronic packages in terms of normalized ratios. Data, thus given, largely remove factors of economic inflation while retaining most of the considerations of quantity pricing and production rates. The assumptions made were stated and discussed. Comparisons between the round and the flat transducers show that the flat transducers are less costly, especially after the first-year non-recurring costs have been recovered. Costs and savings can be calculated by using the estimated factors given in Tables 9 and 10.

For long periods of time, the ownership costs are controlled by the maintenance costs and component replacement. Maintenance costs would probably be about the same for the round and the flat transducers. Therefore, the long-term costs reduce to component replacement. Simplified long-term cost algorithms were given. Costs and savings can be calculated using these algorithms for any period, and for the number of times any one type of transducer would be replaced. A cost effectiveness factor, Q, was given in terms of transducer costs and life expectancies. Decisions can be made by evaluating $Q$; when $Q=1$, the two transducers are equally cost effective; when $Q>1$, the flat transducers are more cost effective; when $Q<1$, the round transducers are more cost effective. Examples are given in Appendix $C$ of this report which illustrate typical situations.

\subsubsection{Final Choice; Round or Flat Transducers?}

The final choice of which transducer to deploy rests on two main factors: 1) the cost effectiveness, and 2) the logistic-protection effectiveness. Cost effectiveness can be estimated if costs and life expectancy estimates are known. Unfortunately, there are still little reliable data available with which to predict service life expectancies with great confidence. Exact values are not required to decide cost effectiveness. The advantage of one type of transducer over the other can either be apparent by a wide margin $(|Q|>>1)$ or the margin will likely be small $(Q \simeq 1)$. In the former instance, the decision will be clear cut in favor of the highest cost effectiveness, barring some high over-riding logistic consideration. When $Q$ approaches unity, other factors will control the decision. 
The "logistic value" of maintaining intrusion protection, and combatting intermittent or erratic false alarms, is difficult to assess. Certainly, these annoying incidents have to be considered in the final choice and are outside the realm of cost-effectiveness choices. In the end, the choice between type of transducers will probably be a complex decision of cost effectiveness and logistic protection.

It may, indeed, be found that the best choice is the deployment of both round and flat transducers; for example, round polyurethane-jacketed transducers in sandy beach regions where chlorides are a problem, and stainless steel flat transducers where rocks and rodents are a problem. At this time, neither transducer type answers all of the problems known to exist in the many deployment regions.

With the evidence present at hand, it is felt that the round transducers would be the better choice until such time as the welding quality improves and the end-plug leak problem is solved. Upon making these two improvements, then the stainless steel flat transducers could well be superior to the round transducers.

\subsection{Recommendations}

Based on the results of this work, the following recommendations are offered which are felt would improve transducer durability, increase cost effectiveness, or increase the knowledge regarding both. The recommendations offered should not be interpreted as the only ones needed, but seem to be the more important ones at the moment.

\subsubsection{Flat Transducers}

It was apparent from examining a number of flat transducers that manufacturing improvements are needed in the forming of the stainless steel ribbon into sheath halves, and in the welding process. Inconsistancies in the embossing process which formed the transverse-stiffening corrugations weaken the transducer; the extent was not determined, nor were the consequences.

The crevices which were formed beneath the rolled lips in the welding process created undesirable regions of highly corrosive activity, generally known as crevice corrosion. Elimination or treatment of this region is desirable to decrease corrosive susceptibility.

The brazing process used in securing and sealing the end plugs needs to be improved and a method developed for testing for end-plug leaks. One possibility would be to drill and thread a hole through the end plug and to add a tubing fitting on which a water tight cap can be placed. Satisfactory sealing could easily be achieved with the selection of a suitable fitting This would allow pressure testing of the end-plug braze (as well as the whole transducer) at any time. 
Failures of transducers deployed in the field need to be carefully examined to determine the exact nature of such failures and data need to be collected so that the mean time between failures can be determined. It is felt that this would be the only meaningful method of determining service-life expectancy.

The change of sensitivity of the transducer, that results from . natural aging and as a result of handling, needs to be determined.

\subsubsection{Round Transducers}

The major weakness of the round transducers appears to be their low resistance to penetration from sharp objects or from heavy loads applied to them, such as was done in the rock damage tests. Methods of increasing the resistance to penetration need to be examined. No specific recommendations to this end are offered.

As was recommended for the flat transducers above, the field failures of round transducers need careful examination and data need to be collected. Also, possible changes in sensitivity, with age or environmental conditions, need study.

\section{ACKNOWLEDGEMENTS}

The author expresses thanks and appreciation to the many staff members of the National Bureau of Standards for their efforts in performing the necessary tests, consulting with the author on the many details of the tests and providing the author with data and information. The following deserve special mention: Dr. L. Mordfin for his guidance and advice throughout the project, R. L. Bloss and R. Snyder for their advice and laboratory assistance in making strain measurements, J. Michalak for his help in operating the universal testing machines, and N. Halsey, O. Owens, F. Davis, and O. W. Price for help on several tasks. Special recognition and thanks go to J. D. Pollard for his many hours spent during the corrosion testing and the freeze-thaw cycling tests, many under adverse weather and other undesirable conditions. Dr. W. Gerhold of the Metallurgy Division gave valuable suggestions and references.

Mr. R. Allen and A. Gurdo of the Rome Air Development Center gave valuable guidance, as well as information and data, from first-hand field experience.

And last, thanks are due the typists who had to trudge through the many pages of handwritten draft and the monstrous tables to produce this final version. 


\section{REFERENCES}

1. ASTM B117, Standard Method of Salt Spray (Fog) Testing.

2. MIL-STD-810B, Environmental Test Methods.

3. Uhlig, H. H., The Corrosion Handbook (John Wiley and Sons, New York, 1948).

4. Ailor, W. H., Handbook on Corrosion Testing and Evaluation

(John Wiley and Sons, New York, 1970).

5. LaQue, F. L., Marine Corrosion, Causes and Prevention (John Wiley and Sons, New York, 1975).

6. Romanoff, M., Underground Corrosion, National Bureau of Standards Circular 579, April 1957.

7. Gerhold, W. F. and McCann, J. P., Corrosion Evaluation of Underground Telephone Cable Shielding Materials, paper No. 31, Internationa1 Corrosion Forum, March 22-26, 1976, Houston, Texas.

8. Gahimer, F. H. and Nieske, F. W., Hydrolytic Stability of Urethane and Polyacrylate Elastomers in Humid Environments, J. Electroplastics 1 (Oct. 1969).

9. Millard, E. B., Physical Chemistry for Colleges (McGraw Hill, New York, 1941).

10. Rosato. D. V. and Schwartz, R. T., Environmental Effects on Polymeric Materials 1 (Interscience Publishers, New York, 1968).

11. Allen, K. R., "Polyolefin Thermoplastic Rubber for Electrical/ Electronic Insulation", Proc. International Wire and Cable Symposium, 1973.

12. Blaich, C. F., Toblas, A. R., and Zimmerman, A. R., "Polyurethane Elastomers in Cable Jacketing", Wire Journal, Sept. 1970.

13. Howard, W. E., "Tests of Pocket Gopher Gnawing Electric Cables", Wildlife Management 17, No. 3, July 1953, pp 296-300.

14. Gibbin, J. F., and King, W. T., "The Damage to Lead-Sheathed Cables by Rodents and Insects", Institute of Electrical Engineers, 101, Part 2, No. 129, May 1954, pp 123-1.28.

15. Mailen, T. H. and Stansburg, R. E., "Protection of Geophysical Communications and Power Transmission Cable Against Rodent Species Attack by R-55 Rodent Repellant Treatment", 15th Annual Wire and Cable Symposium, December 7-9, 1966, pp 1-5. 
16. Connally, R. A. and Landstrom, R. E., "Gopher Damage to Buried Cable Materials", ASTM Materials Research and Standards, 1 , No. 12, December 1969.

17. ITT Federal Laboratories, Communications Cable for Tropical Jungle Use, March 1964, AD437910.

18. Murphy, G., Properties of Engineering Materia1s (International Textbook Co., Scranton, Pa. 1957).

19. Lyman, T., editor, Meta1s Handbook, Vo1. 1, 8th Edition (American Society for Metals, Novelty, Ohio 1961).

20. Anon., Aerospace Structura1 Metals Handbook, AFML-TR-68-115, (Air Force Materials Laboratory, Wright Patterson Air Force Base, Ohio, 1970).

21. Anon., Mechanical and Physical Properties of Austenitic ChromiumNicke1 Stainless Steels at Ambient Temperature, Section 1, Bulletin A (International Nickel Co., Inc., New York, N. Y. 1963). 


\section{APPENDIX A}

RELATIVE HUMIDITY AND RAINFALL DATA

The relative humidity and rainfall data cover a period from April 30, 1976 through June 7, 1976. The data were obtained from the National Bureau of Standards Exposure Station, Gaithersburg, Maryland, maintained by the Materials and Composites Section (461.02), of the Structures, Materials, and Safety Division. The Exposure Station site was less than one-half mile from the location where the corrosive moisture tests were performed. The relative humidity values were measured at 8 a.m. daily.

The graphical data show both the relative humidity (in percent, using the left ordinate) and the rainfall (in inches, using the right ordinate). The abscissa gives the same exposure times as in Figures 2 and 3 . 


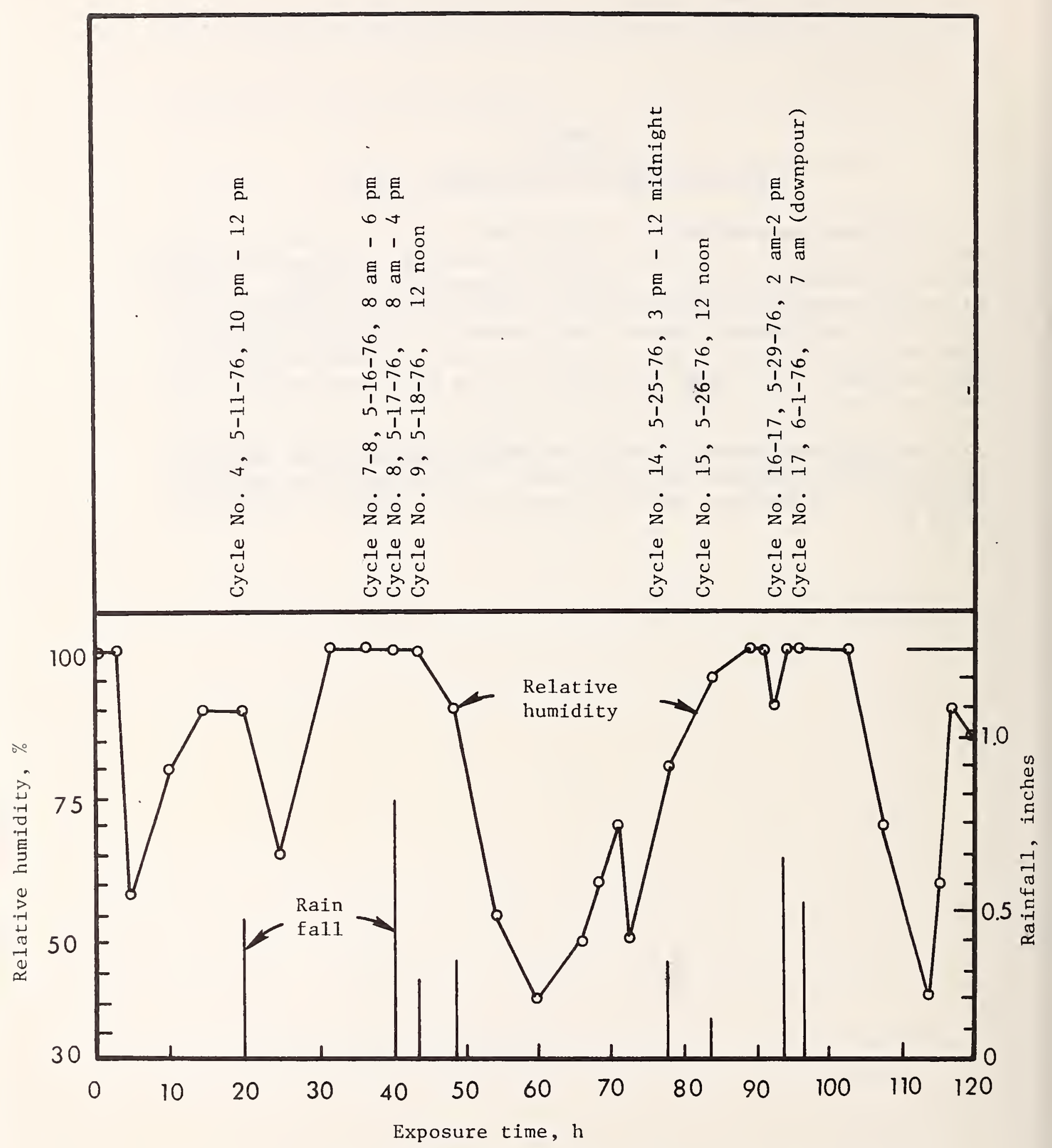

Figure A-1. Relative humidity and rainfall during testing period. 
APPENDIX B

MATERIALS WHICH OFFER GOPHER PROTECTION AND THOSE WHICH ARE VULNERABLE

Listed below are materials which provide gopher protection for wires and cables. See Reference 15 for a discussion. Even though some of these materials offer good rodent protection, corrosion may be a serious problem.

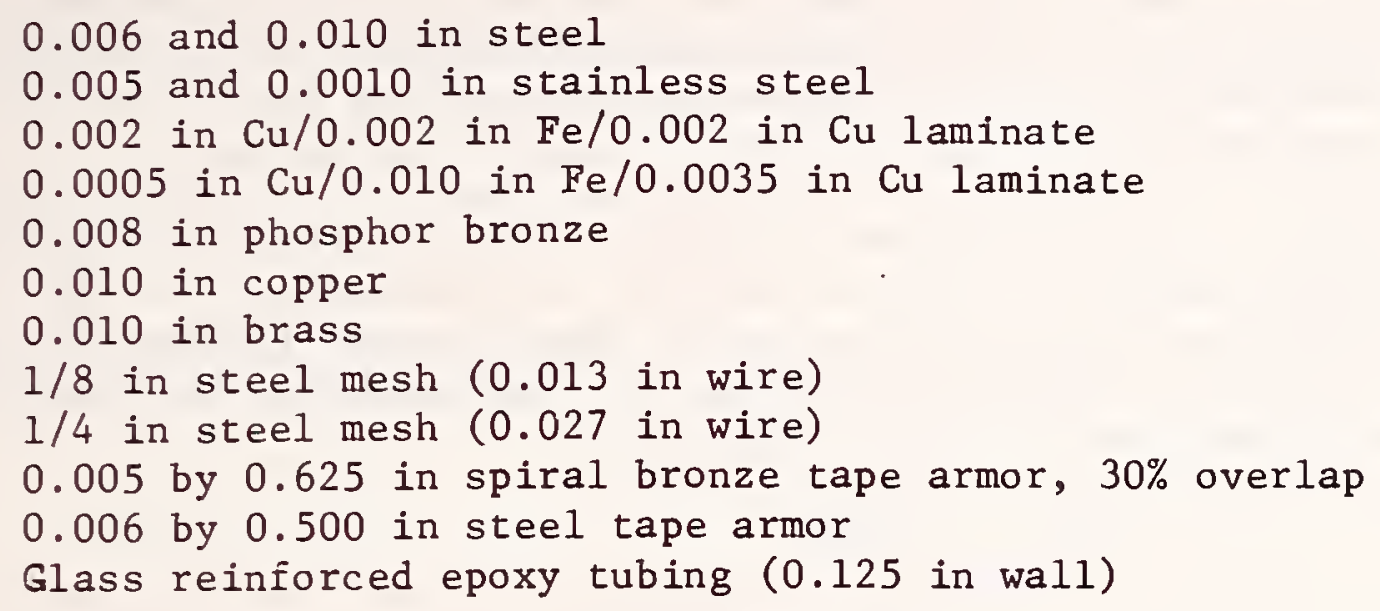

Listed below are materials which are known to be vulnerable to gopher attack and damage. See Reference 15 for a discussion.

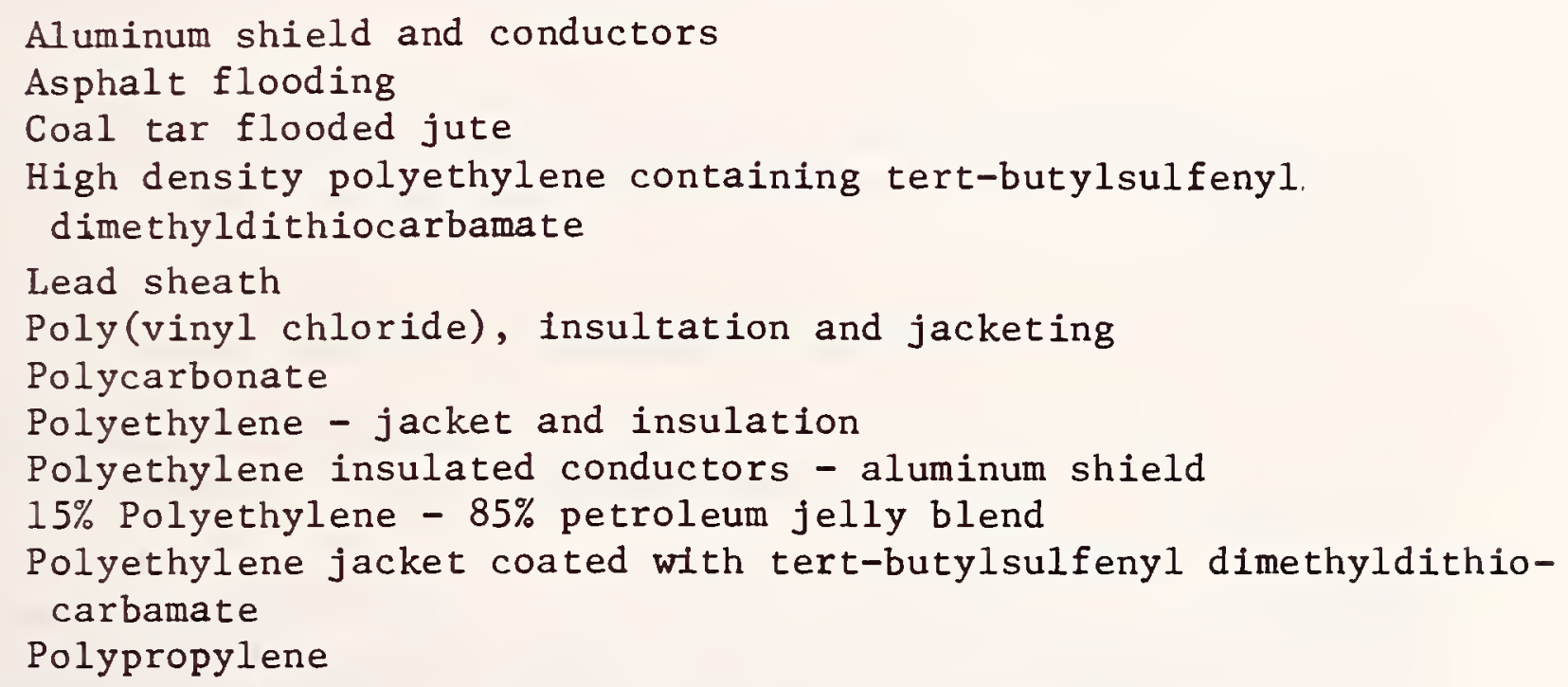

Although polyurethane was not listed, its physical characteristics are sufficiently similar to polyethylene that it falls into the latter category of materials that are vulnerable to gopher attack. 


\section{COST EFFECTIVENESS ANALYSIS EXAMPLES}

Examples given here use the relationships given in Section 7.2. The assumptions made in developing these relationships are stated there. The values used for costs and life expectancies are arbitrary. The costs represent reasonably realistic estimates; however, there is a large margin for speculation regarding the realism of the estimates of life expectancies. The reader is cautioned that the values used in these examples can not be considered continuously realistic nor precisely accurate.

Example I: Given that the cost of the round transducers and their life expectancies are known, and that the estimated cost of the new flat transducers is also known, what minimum life expectancy must the flat transducers achieve in order to have the same cost effectiveness as the round transducer?

$$
\text { Let } \begin{aligned}
\mathrm{T}_{\mathrm{r}} & =\$ 1180 \\
\mathrm{n}_{\mathrm{r}} & =9 \text { years, and } \\
\mathrm{T}_{\mathrm{f}} & =\$ 670 \\
\mathrm{n}_{\mathrm{f}} & =?
\end{aligned}
$$

It is necessary to solve for the value of $n_{f}$ under the conditions that $Q=1$. The relationships are given in Eqs. (9), (10) or (12). From these,

$$
\mathrm{n}_{\mathrm{f}}=\mathrm{n}_{\mathrm{r}}\left(\mathrm{T}_{\mathrm{f}} / \mathrm{T}_{\mathrm{r}}\right)=5.11 \text { years. }
$$

Thus, the round and flat transducers are equally cost effective when the less expensive flat transducer has a life expectancy of 5.11 years.

Example II: Given that the cost of the round transducers and their life expectancies are known and that the life expectancy of the flat transducers is known, what is the maximum cost of the flat transducer in order to have the same cost effectiveness?

$$
\text { Let } \begin{aligned}
\mathrm{T}_{\mathrm{r}} & =\$ 1180 \\
\mathrm{n}_{\mathrm{r}} & =9 \text { years, and } \\
\mathrm{n}_{\mathrm{f}} & =7 \text { years. } \\
\mathrm{T}_{\mathrm{f}} & =?
\end{aligned}
$$


It is necessary to solve for $\mathrm{T}_{\mathrm{f}}$ under the conditions of $\mathrm{Q}=1$. Again, rearranging Eq. (12),

$$
\mathrm{T}_{\mathrm{f}}=\mathrm{T}_{\mathrm{r}}\left(\mathrm{n}_{\mathrm{f}} / \mathrm{n}_{\mathrm{r}}\right)=\$ 918
$$

Thus, the flat transducer would cost $\$ 918$ in order to have the same cost effectiveness as the round transducer under these conditions chosen for this example.

Example III: Given the same conditions as in Example II except that the flat transducer cost, $\mathrm{T}_{\mathrm{f}}$, is $\$ 670$, which transducer is most cost effective, by how much, how many times must each transducer be replaced, and what are the cost savings (or losses) over a period of 25 years?

To determine which transducer is most cost effective, and by how much, solve for Q from Eq. (12).

$$
\mathrm{Q}=\left(\mathrm{T}_{\mathrm{r}} / \mathrm{T}_{\mathrm{f}}\right)\left(\mathrm{n}_{\mathrm{f}} / \mathrm{n}_{\mathrm{r}}\right)=(1.761)(0.778)=1.370
$$

Thus, from the fact that $Q>1$, the flat transducer is more effective than the round transducer by 1.370 times.

To determine how many times each transducer must be replaced, the relationships of Eqs. (3) and (4) are used.

$$
\begin{aligned}
& \mathrm{t}_{\mathrm{r}}=\mathrm{N} / \mathrm{n}_{\mathrm{r}}=25 / 9=2.8, \\
& \mathrm{t}_{\mathrm{f}}=\mathrm{N} / \mathrm{n}_{\mathrm{f}}=25 / 7=3.6 .
\end{aligned}
$$

Thus, the round transducer would have to be replaced twice, and again when $\mathrm{N}=27$ years. The flat transducer would have to be replaced three times, and again when $\mathrm{N}=28$ years.

The cost savings (or losses) can be determined by use of Eq. (14), as

$$
S=(\$ 1180 \cdot 2)-(\$ 670 \cdot 3)=\$ 350 \text {. }
$$

The value of $S$ is, indeed, greater than zero and, thus, it is more cost effective to deploy the flat transducers and there would be a cost savings of $\$ 350$ per transducer over a period of 25 years. The maximum that could be saved, as derived from Eq. (15) and ca1culated on a yearly basis, is $\$ 886 / 25=\$ 35$ per year. This compares with the yearly amount calculated from $\$ 350 / 25=\$ 14$ and indicates that savings would accrue at a greater rate if the transducers were deployed for periods greater than the 25 years selected for this example. 
The above three examples show only a few of the ways in which the relationships can be used to help make an intelligent choice based on cost effectiveness. The reader is cautioned that the true cost algorithms have intentionally been oversimplified, removing inflationary considerations or other factors, such as the cost of labor in replacing transducers or the costs of associated electronics.

\section{APPENDIX D}

SOIL ANALYSIS RESULTS FOR SAMPLES FROM GRIFFIS AIR FORCE BASE SITE 2D, ROME, NEW YORK

Eight soil samples from site 2D, Griffis Air Force Base, Rome, New York, were chemically analyzed for the following substances:

$\begin{array}{ll}\text { calcium } & \text { bicarbonate } \\ \text { magnesium } & \text { sulfate } \\ \text { sodium } & \text { chloride } \\ \text { potassium } & \text { nitrate }\end{array}$

Each of the eight samples contained a slip of paper giving the location from which the sample was obtained. The slips had been placed inside the "zip-lock" plastic bags. Unfortunately, the ink was badly diffused into the paper and the paper was deteriorated from the moisture. As a result, information was lost on some of the locations. The samples were reidentified with an arbitrary NBS sample number; as much of the legible data as was recoverable are given below. 


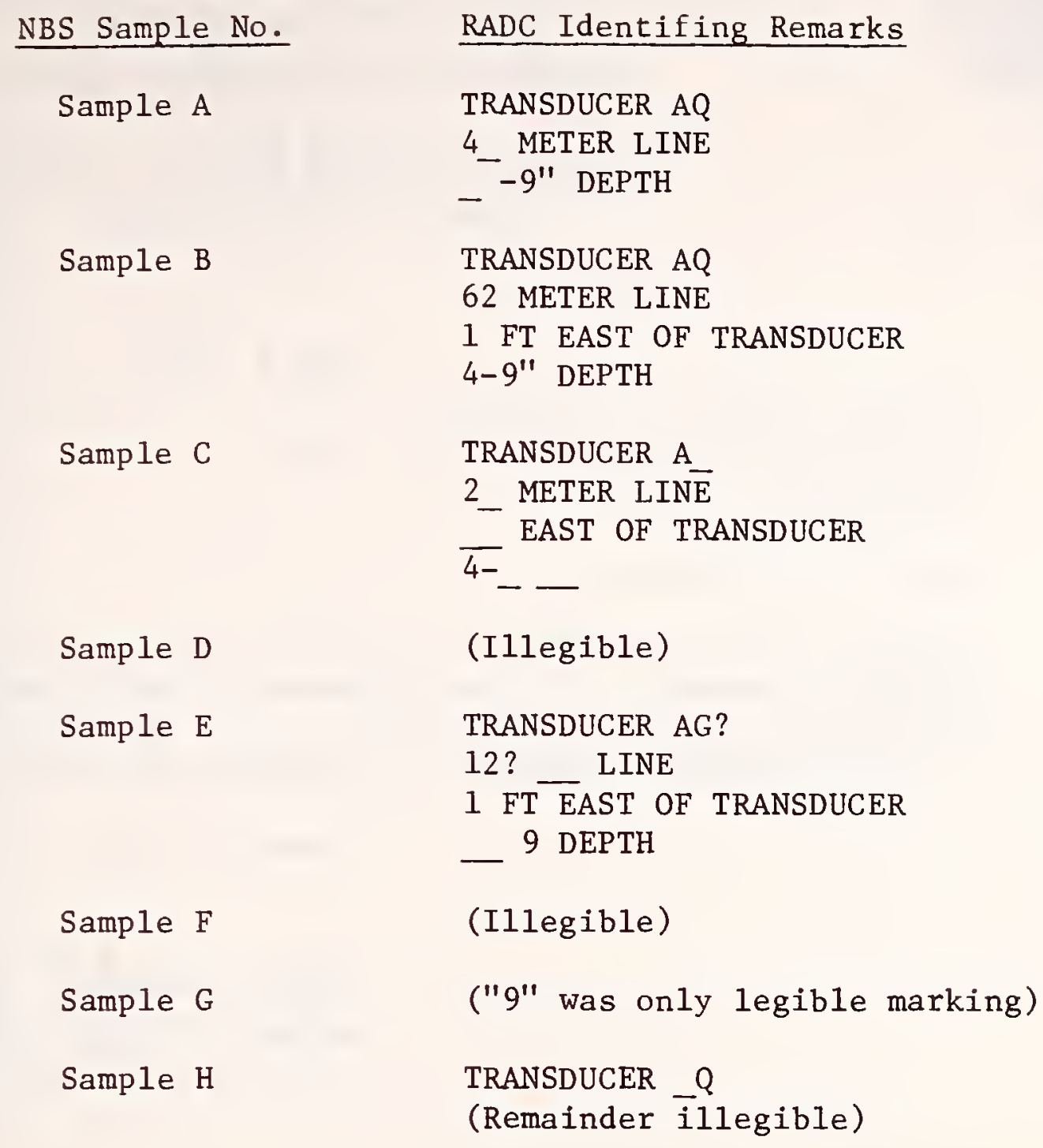

The results of the chemical analysis is shown in the following letter from the Engineering Research Center, Bureau of Reclamation.

Water content, visual clarification, and dry density information. from the same site are given in a Special Report SR 235, "Frost Penetration Measurements at the USAF Intrusion Sensor Site, Rome, New York, 197374" by Tobiasson and Atkins, September 1975, prepared by the U.S. Army Corp of Engineers, Cold Regions Research and Engineering Laboratory, Hanover, New Hampshire. 


\section{United States Department of the Interior}

BUREAU OF RECLAMATION

ENGINEERING AND RESEARCH CENTER

P.O. BOX 25007

IN REPLY

REFER TO: 1523

BUILDING 67, DENVER FEDERAL CENTER

432 .

DENVER, COLORADO 80225

National Bureau of Standards

\section{NOV 81976}

Englneering Mechanics Section - EM219

Wa shington, D.C. 20234

Dear Mr. J. Ramboz:

Enclosed are the results of chemical analysis performed on soll samples as agreed to in your telephone conversation with Mr. Howard Salman on September 16, 1976. The samples will be stored for several months in case additional data is required.

Sincerely yours,

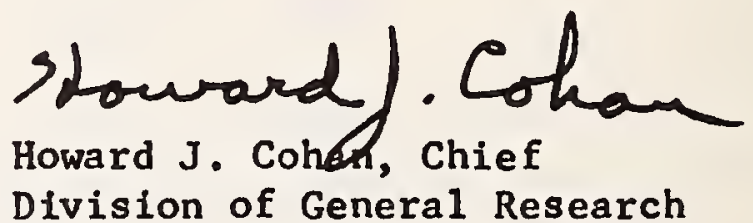

Enclosure

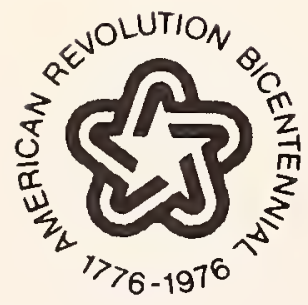




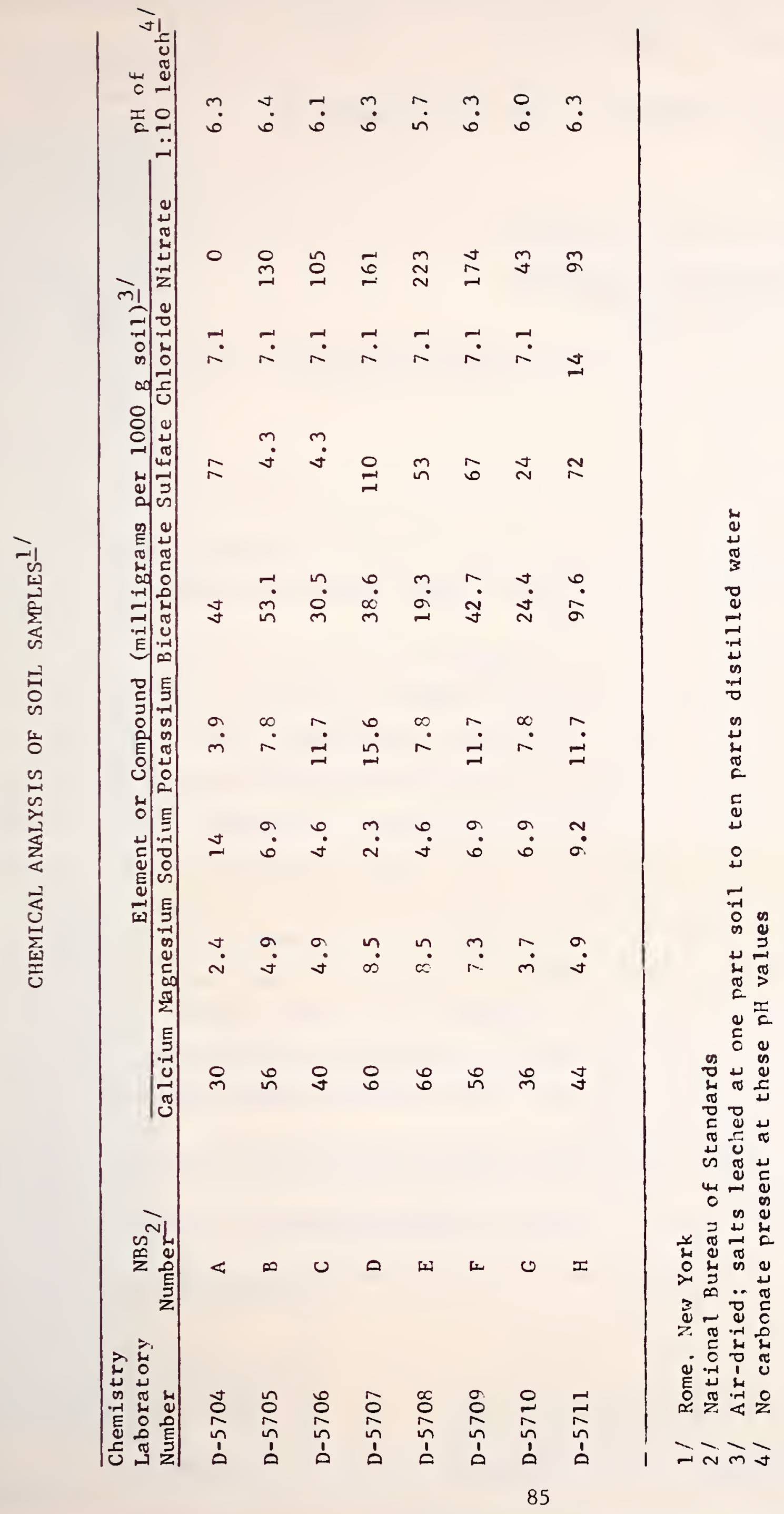


NBS-114A (REV. 7-73)

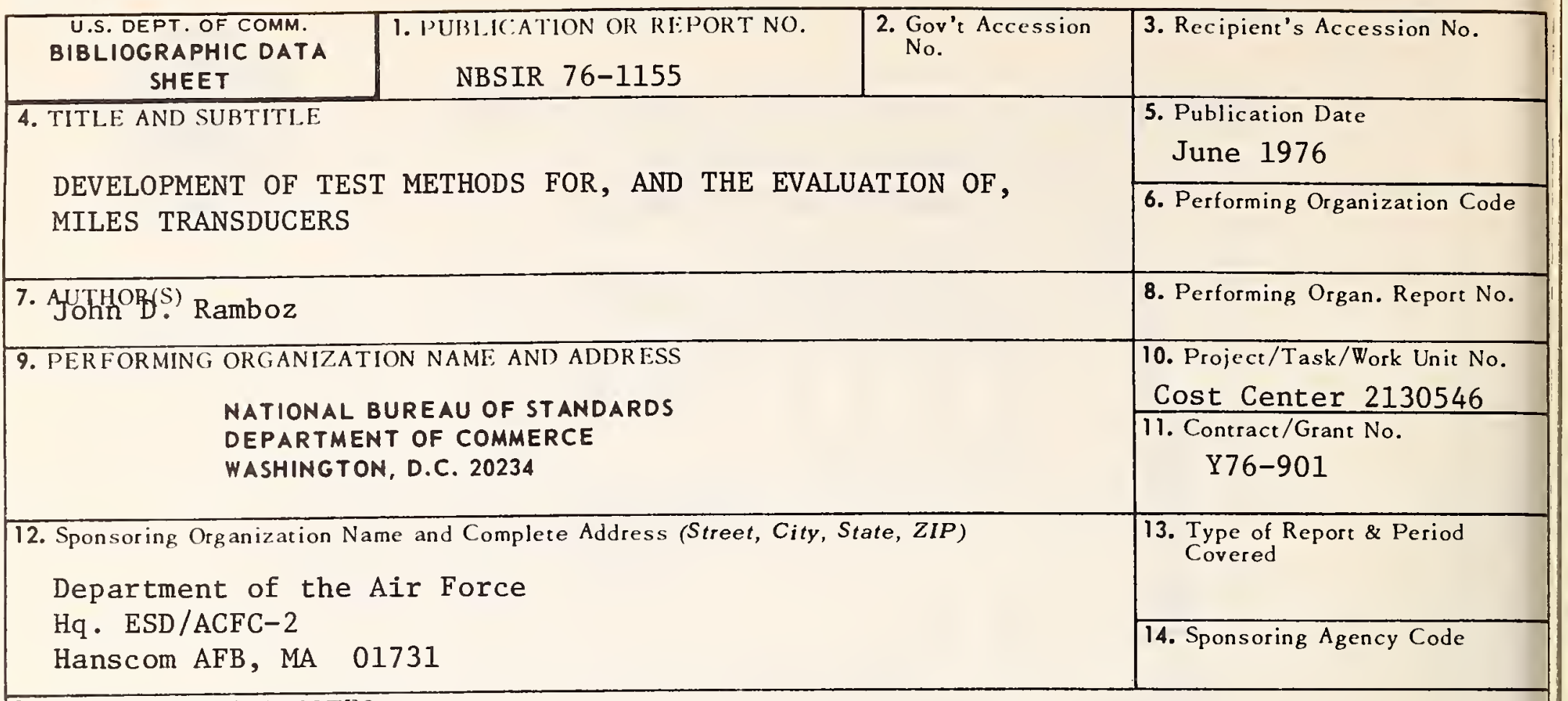

15. SUPPLEMENTARY NOTES

Work performed under the technical direction of Rome Air Development Center, Griffis $\mathrm{AFB}$, Rome, NY

16. ABSTRACT (A 200-word or less factual summary of most significant information. If document includes a significant bibliography or literature survey, mention it here.)

The development of tests is discussed and results are given for two types of Multiphenomenon Intrusion Line Sensors (MILES) transducers. The round type is fabricated as a long coaxial line having a polyurethane outer jacket. The flat type is a coaxial ribbon housing a type 304 stainless steel outer sheath. Five main tasks were completed: long-term resistance to corrosive moisture, resistance to freeze-thaw cycling, resistance to rock damage, durability of the polyurethane jacketing, and reeling and unreeling durability of the flat transducers. Comparative results between the two types of MILES transducers are given and indicate that neither type is ideally suited for all field deployment environments. Chlorides in the soil cause pit corrosion in the crevice region of the $f l a t$ transducer sheaths. Rocks and rodents penetrate the polyurethane of the round transducers. Cost analyses are given with examples illustrating cost effectiveness. Design recommendations are given.

17. KEY WORDS (six to twelve entries; alphabetical order; capitalize only the first letter of the first key word unless a proper name; separated by semicolons)

Evaluation methods; intrusion detestors; MILES transducers; sensors; test methods; testing.

18. AVAILABILITY $\square$ Unlimited

X] For Official Distribution. Do Not Release to NTIS

Order From Sup. of Doc., U.S. Government Printing Office Washington, D.C. 20402, Sl) Cat. No. C13

\begin{tabular}{|l|l|}
\hline $\begin{array}{l}\text { 19. SECURITY CLASS } \\
\text { (THIS REPURT) }\end{array}$ & 21. NO. OF PAGES \\
UNCL ASSIFIED & 22. Price \\
\hline $\begin{array}{l}\text { 20. SECURITY CLASS } \\
\text { (THIS PAGE) }\end{array}$ & \\
UNCLASSIFIED &
\end{tabular}
Springfield, Virginia 22151 